\title{
Direct Ink Writing Technology (3D Printing) of Graphene-Based Ceramic Nanocomposites: A Review
}

\author{
Nestor Washington Solís Pinargote*, Anton Smirnov*, Nikita Peretyagin, Anton Seleznev and \\ Pavel Peretyagin \\ Moscow State University of Technology “STANKIN", Vadkovsky per. 1, Moscow, 127055, Russian \\ Federation; n.peretyagin@stankin.ru (N.P.); a.seleznev@stankin.ru (A.S.); p.peretyagin@stankin.ru (P.P.) \\ * Correspondence: nw.solis@stankin.ru (N.W.S.P.); a.smirnov@stankin.ru (A.S.); Tel.: +7-4999-7323-70 \\ (N.W.S.P.) and (A.S.)
}

\begin{abstract}
In the present work, the state of the art of the most common additive manufacturing (AM) technologies used for the manufacturing of complex shape structures of graphene-based ceramic nanocomposites, ceramic and graphene-based parts is explained. A brief overview of the AM processes for ceramic, which are grouped by the type of feedstock used in each technology, is presented. The main technical factors that affect the quality of the final product were reviewed. The AM processes used for 3D printing of graphene-based materials are described in more detail; moreover, some studies in a wide range of applications related to these AM techniques are cited. Furthermore, different feedstock formulations and their corresponding rheological behaviour were explained. Additionally, the most important works about the fabrication of composites using graphene-based ceramic pastes by Direct Ink Writing (DIW) are disclosed in detail and illustrated with representative examples. Various examples of the most relevant approaches for the manufacturing of graphene-based ceramic nanocomposites by DIW are provided.
\end{abstract}

Keywords: additive manufacturing; graphene oxide; graphene-based paste; direct ink writing; ceramic nanocomposites

\section{Introduction}

A ceramic is a nonmetallic, inorganic solid [1], which has exceptional and diverse physical and chemical properties that characterize it as a multipurpose material. Typical properties that can be found in ceramics materials are ultra-high-temperature ability, excellent wear resistance, great hardness and mechanical strength, high melting points, good thermal stability, and chemical inertness, low density, and low electrical and thermal conductivity. Thanks to these properties, ceramics are used in multifunctional applications such as biomedical engineering, electronics, aerospace, chemical industry, and machinery [2]. Note that the advantage of ceramics over other materials is the ability to obtain predetermined characteristics by changing the raw materials composition and the production technology [3-8]. Commonly, raw materials are composed by mixtures of ceramic powders with or without binders and additives, and these mixtures are used to form green bodies with desired simple shape by different forming methods as dry pressing, slip casting, injection molding, gel casting, tape casting, extrusion and others $[9,10]$. After forming, the green parts are very soft; therefore, it is necessary to apply heat upon them to get a dense product by sintering. Sintering can be defined as a thermal process at higher temperatures with or without pressure for compacting and forming a solid structure via mass transport events that often occur on the diffusional processes [10,11]. Although traditional methods of ceramic forming are well studied and widespread, they have several drawbacks such as high cost, long processing times and the impossibility of producing pieces with interconnected holes or with highly complex shapes. In addition, for obtaining a sintered ceramic part with high surface quality and accuracy, mechanical 
post-processing work is necessary. This post-process work is expensive and time-consuming due to their natural high hardness and brittleness of ceramics materials [2,12].

Over the past 30 years, a new technology for processing materials called additive manufacturing (AM) has been developed rapidly and it is being introduced more and more every day in a wide range of fields. AM, also known as three-dimensional (3D) printing technologies [13], can be described as a technique of blending materials by either fusion, binding, or solidifying materials such as liquid resin and powders of different materials. It builds a part in a layer-by-layer fashion using 3D computer-aided design (CAD) modeling [14].

AM involves a group of advanced manufacturing technologies that allow the flexible production of highly complex and precise structures that are difficult to realize using traditional fabrication methods like casting and machining [15].

In 2015, the International Organization for Standardization Technical Committee (ISO/TC 261) on AM together with the American Society for Testing Materials (ASTM) Committee F42 released a new International Standard ISO/ASTM 52900:2015 in which the terms used in AM are established and defined [16]. In this standard, the AM technologies have been classified into groups taking into consideration the feedstock type, the deposition technique, and the fusing or solidification way of material. Table 1 categorizes the most popular AM technologies in the industry today into the following groups: vat photopolymerization, material jetting, binder jetting, powder bed fusion, direct energy deposition, sheet lamination, and material extrusion.

Table 1. Groups of Additive Manufacturing technologies by ISO/ASTM 52900:2015.

\begin{tabular}{|c|c|c|c|}
\hline Category & $\begin{array}{c}\text { Additive Manufacturing } \\
\text { technology type }\end{array}$ & $\begin{array}{c}\text { Abbreviatio } \\
\mathbf{n}\end{array}$ & Feedstock \\
\hline \multirow{4}{*}{$\begin{array}{l}\text { Vat } \\
\text { photopolymerization }\end{array}$} & \multirow{4}{*}{$\begin{array}{c}\text { Stereolithography } \\
\text { Digital Light Processing } \\
\text { Two-Photon Polymerization } \\
\text { Continuous Liquid Interface } \\
\text { Production } \\
\end{array}$} & SLA & Liquid photopolymers, hybrid \\
\hline & & DLP & polymer-ceramic, hybrid polymer- \\
\hline & & ТРP & graphene. \\
\hline & & CLIP & Liquid photopolymers. \\
\hline \multirow{4}{*}{ Powder bed fusion } & Multi Jet Fusion & MJF & Thermoplastic polymers. \\
\hline & Selective Laser Sintering & SLS & Plastics, composites. \\
\hline & Selective Laser Melting & SLM & Metals. \\
\hline & Electron Beam Melting & EBM & Metals. \\
\hline \multirow{3}{*}{ Material jetting } & Material Jetting & MJ & Photopolymers. \\
\hline & NanoParticle Jetting & NPJ & Metals, ceramics. \\
\hline & Drop On Demand & DOD & Wax, ceramic-, graphene-inks. \\
\hline \multirow[t]{2}{*}{ Material Extrusion } & Fused Deposition Modeling & FDM & $\begin{array}{l}\text { Thermoplastic polymers, metal-, } \\
\text { ceramic-, graphene-reinforced } \\
\text { polymers. }\end{array}$ \\
\hline & Direct Ink Writing & DIW & Ceramics. \\
\hline \multirow{2}{*}{$\begin{array}{l}\text { Direct Energy } \\
\text { Deposition }\end{array}$} & $\begin{array}{l}\text { Electron Beam Additive } \\
\text { Manufacturing }\end{array}$ & EBAM & \multirow{2}{*}{$\begin{array}{l}\text { Metals and alloys in the form of } \\
\text { powder or wire. }\end{array}$} \\
\hline & Laser Engineering Net Shape & LENS & \\
\hline Binder jetting & Binder Jetting & $\mathrm{BJ}$ & Ceramic, metal, gypsum, sand. \\
\hline Sheet Lamination & $\begin{array}{l}\text { Laminated Object } \\
\text { Manufacturing }\end{array}$ & LOM & $\begin{array}{l}\text { Ceramic, metal-filled tapes, paper, } \\
\text { polymer composites. }\end{array}$ \\
\hline
\end{tabular}

The main differences between each of the categories mentioned above can be summarized as follows:

- Vat photopolymerization uses a liquid photopolymer resin from which a 3D object is obtained layer by layer thanks to the curing under the influence of an ultraviolet (UV) light. The local interaction of UV light with the photopolymer produces its polymerization, and the UV light path on the resin surface is coordinated thanks to the help of mirrors controlled by motors. When a resin's layer is cured with the required pattern, its support is immersed in the liquid polymer to form the new layer of the model [17]; 
- Material jetting is a group of technologies that are common compared to the twodimensional (2D) inkjet printing. Material, which mainly contains a photopolymer, is dropped onto a platform, where it hardens thanks to the expose of a UV light; thereby, a part is assembled layer by layer. Material is dropped from a nozzle which moves on the platform surface [17];

- In binder jetting the 3D object is formed layer by layer, when a liquid binder is supplied by drops onto a powder bed. In this way, the binder acts as glue for the powder layers when it is dispersed by a print head that moves on the powder bed surface forming the necessary pattern. When a layer is formed, the powder bed is moving down by an elevator system. After that, a tinny powder layer is spreading over the past layer and the print head dispenses the binder again to form the next layer [17];

- The powder bed fusion technologies utilize an energy source that allows the local sintering or melting between the particles of a material powder. The solid part forming is producing thanks to a layer by layer process. In these technologies, the type of use energy sources can be, for example, lasers or electron beams. Its choice depends on the material powder, for metals is necessary the electron beam and vacuum, while polymers require the use of lasers. Despite this, all the powder bed fusion technologies use a spreading system of the powder material over past layers [17];

- Direct energy deposition involves technologies that form parts directly by the melting of powder material as it is deposited. Despite that, the main idea of this technology must be applied for a wide kind of materials (polymers, ceramics, and metal framework composites) it is predominantly used with wire or metal powders. This fact explains why this technology is often called metal deposition. This technology uses a nozzle that can move freely in any direction of the $\mathrm{x}, \mathrm{y}$ and $\mathrm{z}$ axis to deposit the raw material onto the predetermined surface and where it is automatically melted and solidified [17];

- In sheet lamination, the part is formed from sheets of material that are then bonded. First, a single layer of solid material is put onto the work surface and bonds it to the previous layers. Then a necessary $2 \mathrm{D}$ pattern is cutting into the last bonded layer. After that, a new sheet of material is put onto the preceding layer and all the process is repeated;

- Material extrusion includes different technologies that extrude material through a nozzle onto a platform. Depending on the used material this technology can use a thermal source for polymers melting to get the optimal rheological properties for extruding. In other cases, a paste with a controlled composition of solid and liquid phases is used. The nozzle moves over the platform drawing the necessary pattern for creating a 3D part layer by layer. In the last past years, this technology became popular in the world for its use in the 3D printers [17].

The introduction of AM into the ceramic forming process proposes a powerful way of producing complex 3D parts. However, despite the wide variety of AM technologies, only a few of them can be implemented for printing ceramic parts [13]. Among such technologies, the so-called Direct Ink Writing (DIW) offers greater versatility and particular suitability for the fabrication of ceramic parts [18]. DIW, also referred to as Robocasting [19], is an extrusion-based technique [20,21] used in 3D printing in which new materials can be implemented most economically and flexibly [22]. The main requirement of this technology is the use of pastes with controlled rheological behaviour [23] that allows them to be able to be extruded into filaments capable of maintaining their shape [23] and not collapsing during the 3D object forming process [24]. The required rheological characteristics can be achieved through the correct selection of the number of components, solid phase parameters and the additives used [24].

In the industrial manufacture of ceramic parts, it is very common the use of a slurry that contains various additives, such as plasticizers, dispersants, surfactants, binders, defoamers, lubricants, etc., which in many occasions produce the formation of defects during sintering [25-27]. These defects can be related to the evaporation of the aforementioned additives that leads to volumetric shrinkage and crack formation, which considerably reduce the mechanical properties of the part $[1,28]$.

Some years ago, the use of chemically modified graphene (in other words, graphene oxide (GO)) has been proposed with aim of prepare an aqueous paste without any additive for the 3D printing of graphene-based heaters [29]. Later, García-Tunón et al. [30] formulated free additives pastes of 
diverse materials, based only on the use of GO as a dispersant, rheological modifier, and binder. It was possible, because GO has a great similarity to clay, including its viscoelastic behaviour. Clay has a unique structure and chemistry that allows the formulation of water-based suspensions with ideal viscoelastic behaviour for shaping in a way that cannot be done with any other natural material [31,32]. The special combination of surface chemistry and the structure of GO sheets in contact with water under special conditions allow the preparation of a very stable GO suspension with viscoelastic behaviour comparable to clay [30,33,34]. In addition, GO as an oxide can be homogeneously dispersed in water, and, consequently, mixtures of graphene oxide with any ceramic oxide can be processed following conventional ceramic processing routes [35-39]. Therefore, the implementation of GO to obtain ceramic pastes without additives for their use in AM opens up new possibilities for obtaining complex parts with the help of robocasting technology.

The aim of the present work is to explain the state of the art of the most common AM technologies used for the manufacturing of complex shape structures of both ceramic and graphenebased parts; and, disclose the most important works about the fabrication of composites using graphene-based ceramic pastes by DIW. Where it was necessary, an explanation of important aspects of AM techniques for ceramic or graphene-based materials will be presented. Moreover, overviews of diverse examples of graphene-based pastes for DIW are given. In where it was possible, historical facts of diverse AM techniques were explained.

Our review article is organized as follows: in Section 2 we present a brief overview of the AM processes for ceramic, which are grouped by the type of feedstock used in each technology; besides, we tried to summarize their principles and applications, and to provide their most important historical facts. Section 3 describes in more detail the AM processes used for 3D printing of graphenebased materials and cites some studies in a wide range of applications related to these AM techniques. Different feedstock formulations and their corresponding rheological behaviour were explained. Section 4 is focused on the more actual developments on direct ink writing by the use of graphenebased ceramic pastes. We provide some examples of the most relevant approaches for the manufacturing of graphene-based ceramic composites by DIW. Finally, in Section 5 a summary of this work is described.

\section{Additive Manufacturing processes for ceramic and their principles}

The beginning of AM technologies dates back to July 16, 1984, when André J.C., Le Mehauté A. and De Witte O. filed a patent at Cilas Alcatel [40], in which the stereolithography process was proposed. Three weeks later, on August 8, 1984, Charles W. Hull filed his patent at UVP, Inc. [41] and coined the term "stereolithography" (SLA). After that, the development of AM was followed by technologies as powder bed fusion, fused deposition modelling (FDM), inkjet printing and others [42]. However, it was only in the 1990s when the first reports of 3D printing of ceramic materials appeared [43, 44].

Today there is a wide variety of AM technologies used for different types of materials. Table 1 lists the most popular manufacturing additive technologies in the industry, and the possible types of feedstock that can be used in each technology. From this, it is easy to appreciate that not all AM technologies are suitable for the processing of ceramic materials [13].

In 1991, Professor J.P. Kruth first organized the AM processes according to the form of the used material before printing [45], and his classifications were: powder, solid and liquid-based techniques. Using this principle, it is possible to group the AM technologies for ceramic materials into powderbased, bulk solid-based, and slurry-based [13], as shown in Figure 1.

In addition, it should be noted that the traditional ceramic forming technology such as dry and isostatic pressing, sliding and tape casting, etc. have some limitations. They cannot be used for parts with complex shapes (with inner holes, sharp corners, etc.), and which require high precision. Moreover, these forming methods need the manufacture of molds and post-processing, which is time-consuming and costly [46,47]. Meanwhile, AM technologies such as powder-, slurry - and bulk solid-based techniques are promising methods for producing near net complex shape parts and 
consequently allows for saving time and reducing production costs of required products in comparison with traditional forming methods.

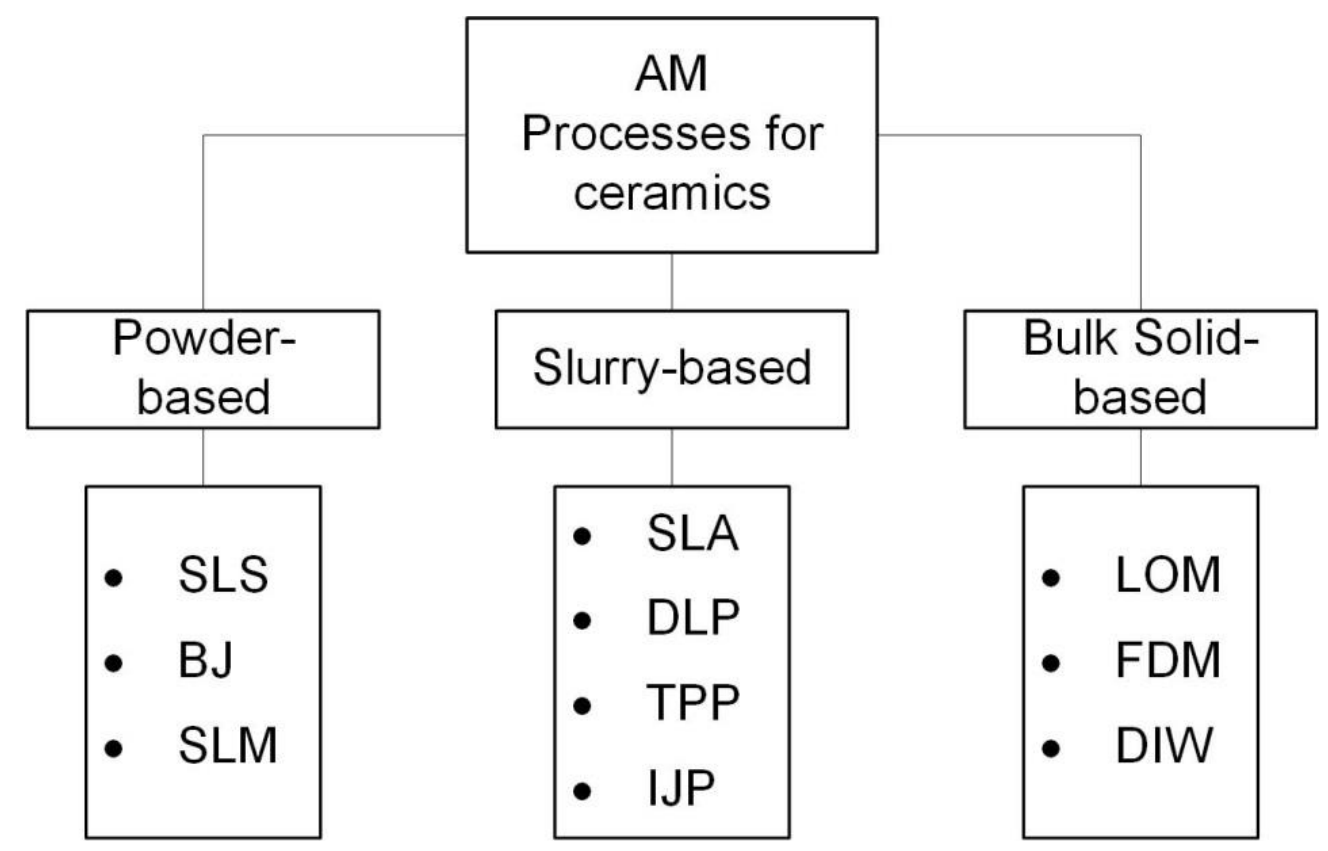

Figure 1. Classification of AM technologies for ceramics by the type of feedstock used: SLS Selective Laser Sintering; BJ - Binder Jetting; SLM - Selective Laser Melting; SLA Stereolithography; DLP - Digital Light Processing; TPP - Two-Photon Polymerization; IJP - Ink Jet printing; LOM - Laminated Object Manufacturing; FDM - Fused Deposition Modeling and DIW Direct Ink Writing.

\subsection{Powder-based technologies}

In this group of AM technologies for ceramic materials, powder beds are used. During the additive process, the ceramic powder can be bonded by melting, sintering, or a binder agent, depending on the type of technology used. Among the AM technologies that utilize powder beds, for ceramic materials three of them are the most important in the industry: selective laser sintering (SLS), selective laser melting (SLM) and binder jetting (BJ).

\subsubsection{Selective laser sintering (SLS)}

This method was first reported by Deckard when he filed a patent in 1986 at the University of Texas [48], and the main goal of this technology was to make wax models for investment casting of metallic prototypes [13]. The SLS process belongs to the category "Powder bed fusion", and it utilizes a high power laser beam as a thermal source for the local sintering of a thin layer in the powder material surface. When the powder is heated enough by a laser beam a diffusion process takes place between particles in the powder, which leads to the densification of the material. The part forming is a layer by layer process. In this way, when a layer is sintered, the powder bed moves down by an elevator system, a new powder layer is distributed onto the previous surface using a spreading system, and then a new cycle of sintering, descent, and spreading is repeated until the final part is formed. Figure 2a shows a schematic diagram of the SLS process. 
a)

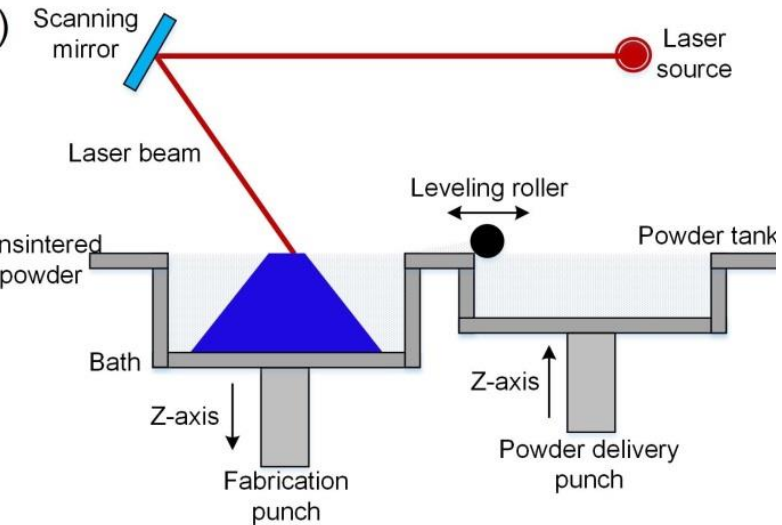

b)

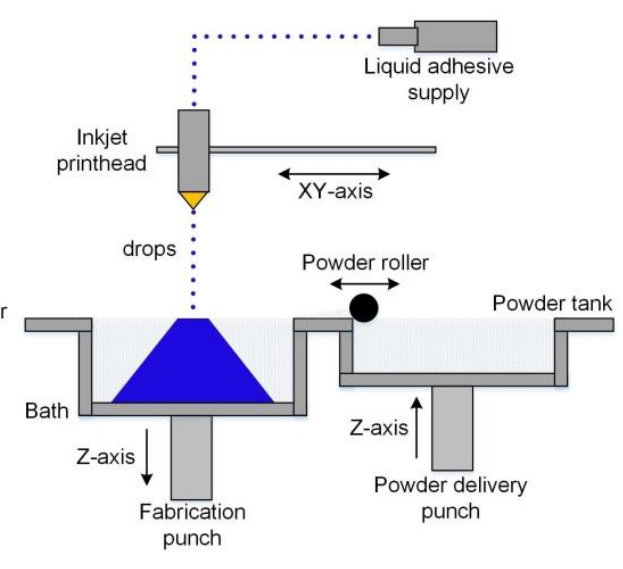

Figure 2. Schematic diagrams of powder-based AM technologies main methods: (a) Selective laser sintering (SLS) and Selective laser melting (SLM); (b) Binder jetting (BJ). Adapted with permission from Ref. [301]. Copyright 2018, Wiley-VCH Verlag GmbH \& Co. KGaA, Weinheim.

The powder bed can be a single material with a low melting point, or a mixture of a high melting point material together with inorganic [49-54] or organic [55-57] binders which may need debinding by high-temperature heat treatment [58] to get the final part. The SLS process must be carried out in vacuum or inert atmospheres such as argon and nitrogen to avoid the oxidation of the binder during sintering. An advantage of this method is that it does not need the creation of additional supports since the low sintering temperatures do not produce internal stresses that can deform the fabricated part.

Although the laser beam can generate a high local temperature, it is not enough for the sintering of the ceramic materials. Thus, it also requires a long dwell time of the laser beam exposition for ceramics. A solution can be to coat or mix the ceramics with materials of lower melting points that will act as binders [13]. This approach was used by Lakshminarayan et al. in 1990, when they reported the first complex shape 3D part obtained by SLS [49, 59].

Moreover, two major problems related to SLS of ceramics are the high shrinkage and the high porosity remaining in the final parts [60]. On the other hand, the benefit of this method is that no extra support structures have to be intentionally prepared for overhanging regions during an SLS process, as they are surrounded by the loose powder in the bed at all times. Thus, the properties of the parts produced by SLS are affected by several factors associated mainly with the feedstock materials and laser-material interactions should be taken into account during the fabrication process.

\subsubsection{Binder jetting (BJ)}

Binder jetting is a process invented 1989 by Sachs et al. when they filed a patent for it at Massachusetts Institute of Technology [61], and thanks to its main characteristics, it belongs to the category "Binder jetting". The principal objective of this technology was to rapidly-produce of parts from a larger variety of materials [13] as plastics [62], metals [63] and ceramics [64]. The BJ process utilizes an organic binder solution that is dropped into a powder bed for the gluing of particles in the surface by a printhead in determinated paths. The scheme of the BJ process is shown in Figure $2 \mathrm{~b}$.

The first report about the application of the BJ process on ceramic materials was made by Sachs et al., in 1992, when they used a matrix of alumina and silicon carbide with a colloidal silica as a binder [64]. Any ceramic powders, which are easier to prepare than wires, sheets, or ceramic slurries, can be used to prepare ceramic preforms, and color printing all of these provide the benefit of BJ with regards to other fabrication methods. However, it must be mentioned that the accuracy and strength of ceramic parts are closely related to powder, binder, printing parameters, equipment, and posttreatment.

In BJ, like SLS, the part forming is a layer by layer process. When a layer is solidified, a new powder layer is distributed onto the previous surface using a spreading system, and then a new cycle 
of gluing and spreading is repeated until the final 3D part is formed. After the part was fabricated, the organic binder must be removed by sintering to obtain the desired mechanical properties. The debinding generally produces shrinkage and porous in the part that depends on the binder percentage in it. The mechanical properties are negatively affected by the amount of porosity in the model. Despite this, BJ is a good method used in biomedical fields for the ceramic scaffold production, thanks to porosities that facilitates the cell cultivation purposes.

In the future, if the problem of accuracy and strength can be solved, binder jetting can become a universal method for preparing ceramic parts, producing a preform of any complicated shape that does not shrink after post-treatment.

\subsubsection{Selective laser melting (SLM)}

The SLM method was first reported in Germany by Wilhelm Meiners et al. when they filed the patent DE 19649865 in 1996 [65]. This process is considered a variant of SLS, but with a thermal source in the form of a laser beam, with much higher energy densities [13] for the local sintering of material. In this way, SLM also belongs to the category "Powder bed fusion". The presence of a more power thermal source allows the sintering process to be carried out in a single step and without the presence of second phases with low melting temperatures as binders.

The conceptual principle of the SLM is the same as SLS, and it means the part forming is a layer by layer procedure (Figure 2a). The thermal source allows the formation of denser parts since the powder particle is completely melted into the liquid phase ensuring rapid densification without the need for debinding. Initially, SLM was designed as a technology to fabricate 3D objects from metal powders [66] and throughout the time, this technique remains very popular among AM technologies for metals thanks to the ability to manufacture parts quickly and efficiently. But, the inclusion of SLM in the ceramic parts manufacturing involves the reaching of complete melt of the ceramic powder by a laser source without the use of binders or secondary processes [13]. This represents a serious technological problem since the melting points of ceramics are very high and this leads to its limited application in the area of ceramic production [13].

Besides, one of the most significant problems arising from the SLM process is the thermal stress induced by extremely short laser-powder interaction times, namely, the drastic heating and cooling rates upon each laser scan [67]. Cracks and distortions, large open pores and rough surface finishes, low dimensional accuracy as well in the SLM-fabricated parts were reported in previous works [6770].

The correct control and management of the energy applied to the powder are of great importance since the application of low energy levels leads to the incomplete melting of the material, and on the other hand, under the action of a high energy level, the powder material is spattered around it [71]. Despite this, SLM is the only perspective method that promises to get ceramic parts with full density directly after its use.

Accordingly, just as in the other methods the overall quality of an SLM-produced ceramic part is influenced by many factors, such as feedstock properties, fabrication parameters, fabrication position and orientation, post-processing and the physical and chemical properties of the interaction in the fabrication process, including the interaction of the energy source and the materials.

\subsection{Slurry-based technologies}

This group of AM technologies for ceramic materials involves the methods that use feedstock, in the form of inks. These inks are liquid systems dispersed with fine ceramic particles. During the additive process, the ceramic parts can be printed by photopolymerization or material jetting, depending on the type of technology used. Among the AM technologies that utilize inks, for ceramic materials four of them are the most important in the industry [13,72]: stereolithography (SLA), digital light processing (DLP), two-photon polymerization (TPP) and inkjet printing (IJP). Note that slurrybased technologies use ceramic/polymer mixtures with low-viscosity inks in th erange of $\mathrm{mPa} \cdot \mathrm{s}$ and with a low ceramic loading (up to $30 \mathrm{vol} \%$ ) [13]. 


\subsubsection{Stereolithography (SLA)}

Stereolithography imposed the start of the additive manufacturing era in the mid-1980s when a patent about this method was filed [41]. The SLA process utilizes a light source for the curing of a liquid photopolymer tiny layer in a vat containing mainly photopolymerizable monomer along with other additives in very small amounts $[73,74]$. For this reason, this process is included in the category "Vat photopolymerization". Commonly, in this method, an ultraviolet (UV) light source is used. This UV light scans the surface of the photopolymer, following a controlled path, thanks to the help of motorized mirrors. A schematic diagram of the SLA is shown in Figure 3a. When a photopolymer interacts with the UV beam, the light activates a series of reactions that are known as polymerization. Polymerization is a process wherein monomers crosslink to form polymers, resulting in a phase change from liquid to solid resin [75]. In SLA the part forming is a layer by layer process. In this way, when a part layer is polymerized its support is lowered a distance equal to the thickness of the new layer by an elevator system. After that, a new cycle of polymerization and lowering is repeated until the final part is formed. The Figure 5 shows a scheme of the SLA process.

The first study of SLA with ceramic particles was reported in 1994 [76]. The authors used slurry with a very high concentration of particles, about 65 vol\%. Commonly, the SLA of ceramics uses fine ceramic particles that are dispersed in the liquid photopolymer [76-81]. In this case, the photopolymer is cured by light irradiation creating a solid resin with an uniform distribution of ceramic particles. After the fabrication of a 3D part, this green body must be processed at high temperatures to eliminate the organic compounds and to rich a higher density.

As a slurry-based AM technology, the feedstock must have certain essential requirements to obtain a good result during the polymerization. First of all, there is the need to be a suspension with a high and homogeneous distribution of the ceramic particles. Also, this suspension must have a good rheological behaviour that includes an optimum viscosity in each case of material and good stability of the suspension over time [17].

The advantages of this method are high resolution, accuracy, smooth surface, accommodate large build areas, and the ability to build intricate geometries [82].

However, this technique is still limited to ceramic materials not absorbing in the UV range and presenting a weak variation of refractive index with the photosensitive organic matrix. Indeed, the introduction of small $(<1 \mu \mathrm{m})$ ceramic particles in a curable monomer increases a level of complexity in comparison to the classical fabrication of pure polymeric materials. The main difficulty is due to the scattering phenomena, which first reduce the cure depth and then increase the processing time and secondly decrease the dimensional resolution.

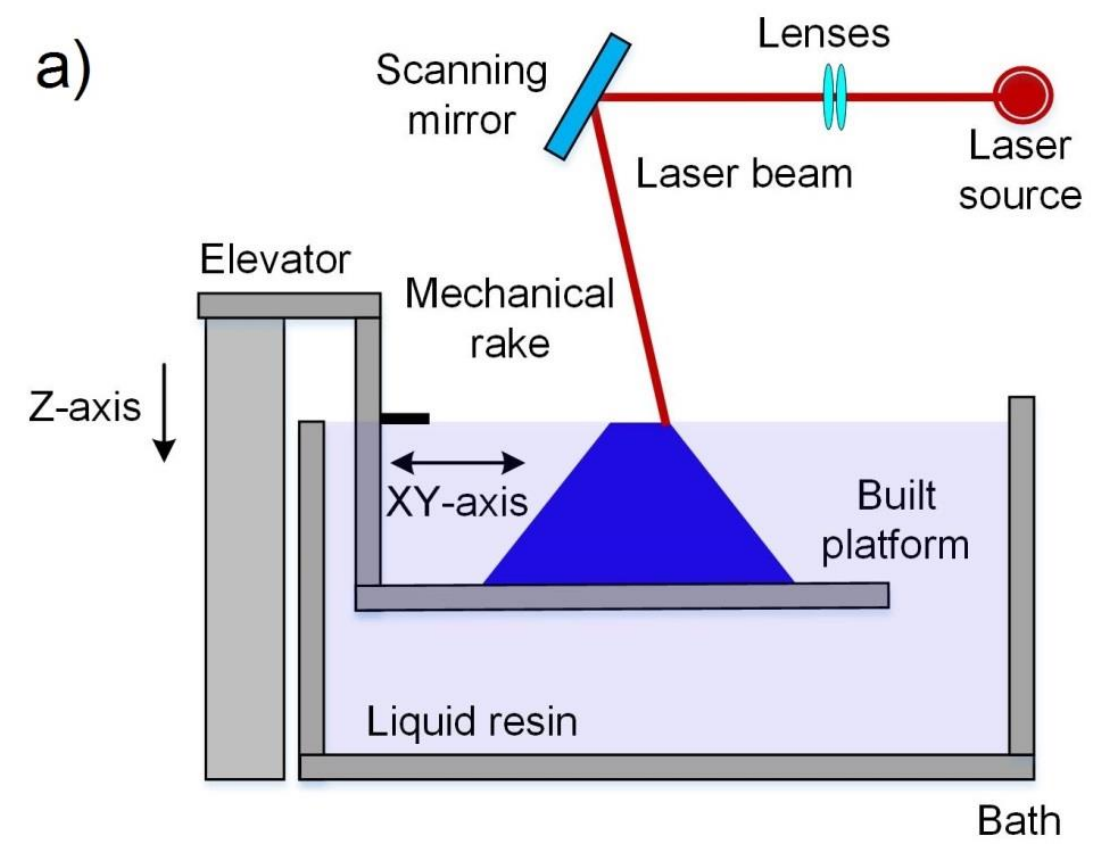



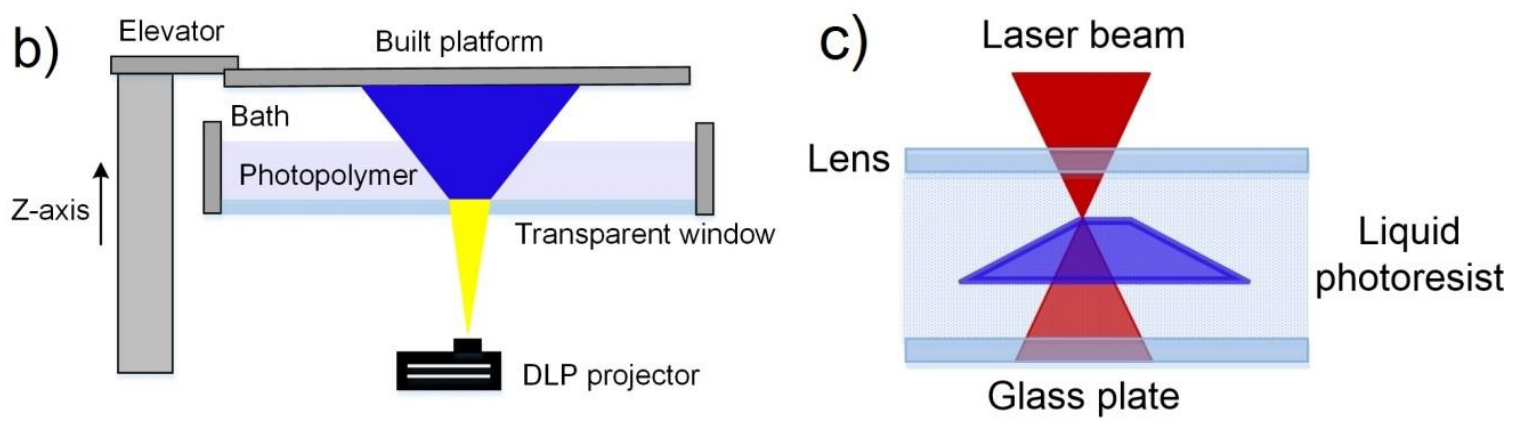

Figure 3. Schematic diagrams of slurry-based AM technologies main methods: (a) Stereolithography (SLA); (b) Digital light processing (DLP); (c) Two-photon polymerization (TPP). Figures 3 ( $a$ and b) adapted with permission from Ref. [301]. Copyright 2018, Wiley-VCH Verlag $\mathrm{GmbH} \& \mathrm{Co}$. KGaA, Weinheim.

\subsubsection{Digital light processing (DLP)}

The DLP process is an improved version of SLA, in which a UV light source is not used for the solidification of the photopolymer. In this process, a white light source is used to project the crosssections of the 3D part, one projection at a time, with the help of a digital mask [74]. The idea of this process was invented by Nakamoto and Yamaguchi in 1996 [83] when they used a physical mask instead of a digital projector. This process, as well as the SLA, also belongs to the category "Vat photopolymerization".

During the DLP process, the liquid photopolymer is exposed to the direct projection of the sectioned figure of the model for its polymerization with the help of the digital mask $[84,85]$. Then, the solid surface changes its vertical position, thanks to the help of an elevation system, changing the planar focus for the projection and formation of the new layers with the required sectioned shape of the 3D model. This process is repeated until the part is completely fabricated. Figure $3 \mathrm{~b}$ shows a scheme of the DLP process.

DLP compared to SLA is a much faster and cheaper process that has a very high resolution [86] thanks to the easy choice of the optimal size of the projected pixel [74]. These advantages make it a very attractive process for the ceramic industry $[87,88]$. The use of this method in the production of ceramic pieces has acquired a great impact, and to this day it is one of the most used techniques thanks to the possibility of obtaining pieces with high densities and hardnesses [89,90] including a high quality of the surface. The DLP technology used exclusively for ceramic materials is generally marketed under the name of lithography-based ceramic manufacturing (LCM) [91]. Generally, this method is used to fabricate heat exchangers [92], metamaterial structures [93] and cellular ceramic structures with very small feature sizes [94].

At the same time, the main disadvantages of this technology compared to SLA are: parts cannot be left out in the sun or they will degrade; parts overall have worse mechanical properties - they break or crack more easily and are at risk of deteriorating over time; resins are expensive, and the regular replacements of resin tanks and occasionally print platforms also adds up.

\subsubsection{Two-photon polymerization (TPP)}

Two-photon polymerization (TPP) is an AM technology related to the "Vat photopolymerization" group in which a multiphoton polymerization-based process is used [74]. The principal purpose of this method is to utilize the nanoscale fabrication of parts for their application in different areas such as nanoelectronics, nanomechanics, and nanobiomedicine [13]. The first workrelated with the TPP field was carried out by Wu et al. in 1992 to get high-aspect-ratio trenches of simple shapes [95]. Later, this process was improved and applied to fabricate complex forms, as was shown in the work of Maruo et al. in 1997 [96]. 
The polymerization process in TPP is based on the interaction of two or more photons from a laser with a specific wavelength [13] when it focuses on a specific point within a liquid photopolymer [96-97]. A schematic diagram of the TPP is shown in Figure 3c. After polymerization of a certain volume of material, the focus point of the laser is moved for the formation of the following layers. The final resolution and the quality of the surface obtained depend directly on the precise positioning and control of the size of the focal point [74].

The advantages of TPP are mainly related to the possibility of polymerizing tiny volumes at high speed within the photopolymer [98] which gives the possibility of manufacturing microstructures with lateral feature sizes in the order of nanometers [99-100]. The use of a technology with this type of characteristics for the ceramic part production with complex shapes opens up new and interesting possibilities for this industry.

The first work on TPP for the obtaining of ceramic parts was published by Pham et al. [101]. In this work, a SiCN woodpile nano- and microceramic microstructures of submicron resolution [13] was created.

This technology has a series of restrictions that limit its use and among these, we can define: very expensive, time-consuming, and challenging for complex structures. [74]. Furthermore, the working principle of TPP allows only the use of transparent polymers; this means that the opaque polymers that were usually used for SLA and DLP processes are not applicable for TPP. It should be noted that this process can produce only very small parts on the order of a few microns and due to the high precision of the process; it also takes a longer amount of time to completely manufacture a part.

\subsubsection{Inkjet printing (IJP)}

Inkjet printing, sometimes known as material jetting, is a non-contact method of AM mainly created to obtain two-dimensional patterns inspired by a technology developed in the 1950s [102]. The IJP process is based on the controllable dispensing of liquid-phase materials by the use of micrometer-sized printhead nozzles [103] that is the reason why this technology is related to the Material jetting category. The liquid-phase material, also known as Ink, is dispensed onto a surface by droplets in a specified pattern in which the ink drying occurs forming a thin layer of the ink residue. After that, new layers can be placed on top of each other to form a multilayer 3D object. The IJP processes can use one of the main two methods of ink dispensing: continuous inkjet (CIJ), or dropon-demand (DOD) printing [104]. Figure 4 shows the printing methods used in IJP.

a)

\section{Substrate}
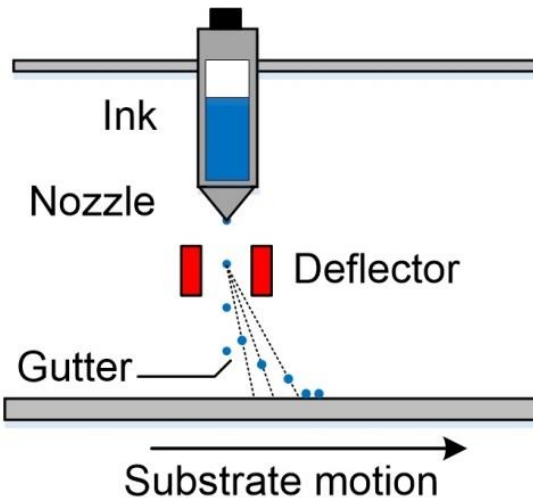

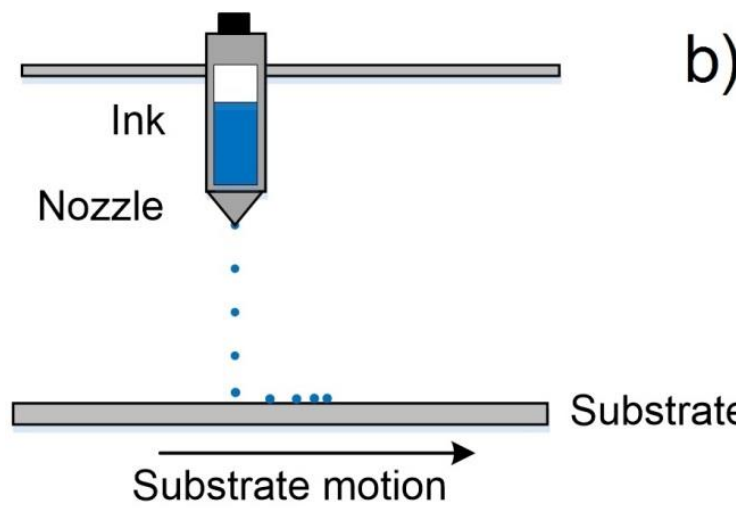

Figure 4. Schematic diagrams of printing methods used in Inkjet printing: (a) continuous inkjet (CIJ); (b) drop-on-demand (DOD).

The CIJ method involves the production of a stream of drops jetting out through a controllable micronozzle [74]. Then, the formed droplets pass through an electrostatic field that influences them and deflects their trajectories to print on a substrate or allows them to follow their movement towards a collector for reuse. In this way, only small quantities of droplets are used for printing, and the largest number of drops is recycled, i.e. CIJ is a non-economical material process. The DOD method 
produces ink droplets when and where it is required, thus this method is more economical than CIJ. Moreover, the small size of droplets and the high positioning accuracy make it more ideal for 3D printing [13]. In DOD the droplets can be formed by piezoelectric effect or thermal excitation in the printing nozzle head [105]. Piezoelectric DOD utilizes a piezoelectric element located in the fluid chamber near the nozzle head for the droplet formation [106]. In this case, the droplet is created and ejected by a generating pressure pulse that forces the ink to leave the nozzle head [105]. The pressure pulse is formed thanks to the piezoelectric element deformation under the application of a voltage. When a droplet is ejected, it falls by the gravity then it impregnated in the subtracted thanks to the momentum obtained during its movement [74]. After that, occurs the solvent evaporation from the impregnated droplet creating a small layer made up of the ink residue. In thermal DOD process, sometimes named as bubble jet printing [74], a thermal excitation for the formation of the droplets and ejecting is used. The thermal excitation is generated when a pulse current crosses through a heating element that is located in the fluid chamber near the nozzle head and direct contact with the ink. When the temperature of the heater element reaches the ink's boiling point rapid ink vaporization is occurred creating a bubble. This bubble formation is followed by a very fast collapse when the pulse current source is "switched off".

Different types of materials as polymers or metals for electronic patterning [107], solder paste for microelectronics soldering [108] and cells for restoration in tissue engineering [109] were used in IJP. However, the IJP method is limited only to the production of miniaturized parts due to the low ink volume used in each droplet [13]. The obtaining of a solid ceramic part after an IJP process involves the drying and sintering post-processing of the printed part.

Thanks to the development of computational technologies, the increase in positioning precision and advances in the 3D printing field, the use of the IJP method has been achieved for ceramic materials dispersed in liquid solvents [13]. The first report of IJP with ceramic materials dates back to 1995 [110] when Blazdell et al. used ceramic inks $\left(\mathrm{ZrO}_{2}\right.$ and $\left.\mathrm{TiO}_{2}\right)$ with a volumetric fraction of $5 \%$. After that, different researches groups improved the IJP and the feedstock preparation for obtaining materials with ceramic loading until $40 \%$ [111-112].

\subsection{Bulk solid-based}

This group of AM technologies for ceramic materials involves the methods that use material sheets, semi-molten [74] or semi-liquid systems [13] in which fine ceramic particles are well dispersed as feedstock. Note that semi-molten and semi-liquid systems, commonly of ceramic/polymer mixtures, have a high-viscosity in the range of some Pa-s like pastes with a greater ceramic loading (up to $60 \mathrm{vol} \%$ ) [13]. In this group, some AM technologies that belong to different categories such as Sheet lamination or Material Extrusion will be considered. Among the AM technologies that utilize solid feedstock for ceramic materials are laminated object manufacturing (LOM), Fused Deposition Modeling (FDM), and direct ink writing (DIW) that are the most important in the industry $[13,72]$.

\subsubsection{Laminated object manufacturing (LOM)}

Laminated object manufacturing is a process related to the Sheet lamination group and it was mainly developed for the fabrication of metal, paper or plastic parts. The first report of this method was in 1984 when Kunieda published his work "Manufacturing of High Cycle and High Precision Injection Molds by Diffusion Bonding of Laminated Thin Metal Sheets" in which molds for injection molding of plastics were obtained by laminating metal sheets cut by laser [113]. As said before, the concept of this method is to utilize, generally obtained by laser cutting, tiny pre-patterned material sheets that are stacked on top of each other and bonded by either using a heat $[114,115]$ source or adhesives $[13,74]$ to form 3D parts. The type of the used joining process is depending on the raw material. For instance, sheets of metal materials are bonding by the use of ultrasonic processes that produce local heating of the sheets creating a very strong bond [116]. For paper sheets, an adhesive material, as glue, is used. In the case of polymer materials, the use of heat and pressure is necessary $[117,118]$. Generally, this method needs a machining post-process to reach the final shape, surface quality and accuracy of the part. Figure 5a depicts the process scheme for LOM. 
Laminated object manufacturing exhibit several advantages such as low process and machine cost, high volumetric build rate, low material requirement, high surface finish and the ability to obtaining parts of combination material and composites [119,74]. However, this technology has some disadvantages such as the necessary use of tiny sheets of material, different bonding processes for different types of materials and a non-high resolution of complex parts.

Only after 10 years that Kunieda published his work, the first report about LOM with ceramic materials appeared $[120,121]$. The authors of this work, Griffin et al., used sheets of alumina and zirconia for the manufacturing of solid parts with a high density after removing the binder and sintering at high temperatures.

After Griffin's investigation, a large number of materials such as $\mathrm{Al}_{2} \mathrm{O}_{3}$ and $\mathrm{SiC}$ [122-125], binary composites like $\mathrm{ZrO}_{2} / \mathrm{Al}_{2} \mathrm{O}_{3}$, $\mathrm{Si} / \mathrm{SiC}$, TiC/Ni [126-128], or more complex systems, for example, $\mathrm{LiO}_{2}-$ $\mathrm{ZrO}_{2}-\mathrm{SiO}_{2}-\mathrm{Al}_{2} \mathrm{O}_{3}$ (LZSA) glass-ceramic composite [129] have been investigated for they use in LOM.

Despite the great effort made in the study of ceramics for LOM, in recent years no progress has been observed in this field. Thus, the application of this technique is restricted only for the manufacture of ceramic parts with simple geometry, and large sizes, which create a problem for its application in the production of advanced ceramic components that, are generally characterized by their complex geometry and much times for its miniature sizes.
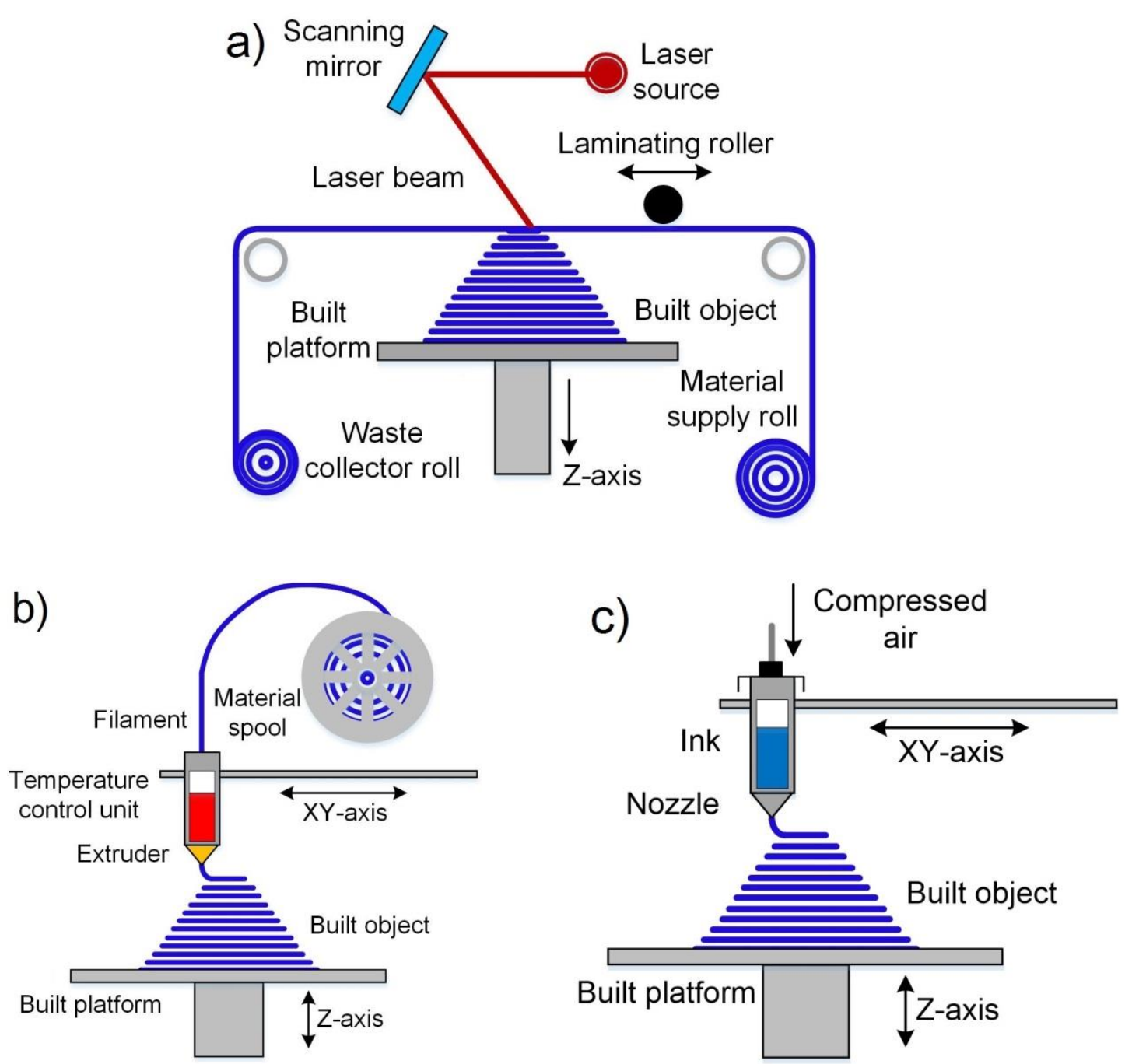

Figure 5. Schematic diagrams of bulk solid-based AM technologies main methods: (a) Laminated object manufacturing (LOM); (b) Fused Deposition Modeling (FDM); (c) Direct ink writing (DIW). Figures 5 ( $a$ and b) adapted with permission from Ref. [301]. Copyright 2018, Wiley-VCH Verlag $\mathrm{GmbH} \& \mathrm{Co}$. KGaA, Weinheim. 


\subsubsection{Fused Deposition Modeling (FDM)}

FDM, also named fused deposition of ceramics (FDC), was first reported by Crump when he filed his own patent US 5121329 "Apparatus and method for creating three-dimensional objects" in 1989 [130]. Nowadays, this process is considered as the most usual AM technology in the world thanks to its accessibility, easy in use and low cost [131,132]. Different types of materials can be utilized in FDM process, such as polymers, metals, and ceramic-or metal-filled polymers [29]. The main concept of the FDM process is to create a part layer by layer [133] by supplying a filament of semi-molten materials. The feedstock is a thermoplastic polymer filament such as acrylonitrile butadiene styrene copolymers (ABS), polycarbonate (PC), Polyamide (PA) and polylactic acid (PLA) [134] that is permanently providing to a nozzle which is heated at a temperature just above the filament melting point [13]. The semi-molted material is extruded through the moving controlled nozzle to form the desired pattern [72]. After the extrusion, the filament adheres to previously deposited layers and immediately cools allowing its solidification. When a layer is solidified with the desired pattern the part support is lowered a distance equal to the thickness of the new layer by an elevator system and a new cycle of extrusion and lowering is repeated until the final part is formed [17]. The schematic diagram of the FDM process is shown in Figure 5b. Generally, FDM technology is widely used to manufacture parts with poor surface finish, low resolution, and mechanical properties. These low characteristics are commonly related to the influence of many factors such as material properties, air gap, printing orientation, raster angle, layer thickness, and raster width $[74,135]$. For this reason, the polymer parts obtained by FDM are often used as conceptual prototypes [135].

For the application of FDM in ceramic production, it is necessary to prepare filaments composed of binder thermoplastic polymers and tiny ceramic particles with a loading of about $60 \mathrm{vol} \%$. The ceramic particles should be well dispersed in the filaments so that a constant and stable flow can be attained [17], moreover the viscosities of the fused filaments should generally range from 10 to 100 $\mathrm{Pa} \cdot \mathrm{s}$ [13]. Once the green body is obtained by FDM, the elimination of the binder polymer and the sintering are necessary to get the ceramic part. As Danforth reported in the first work about ceramic part fabrication by FDM in 1995 [136], the debinding step leads to the formation of pores that directly influence on the formation of defects and obtaining low densities. Despite this, thanks to the successful development of this technology and material science, the mechanical properties of parts obtained by FDM are now comparable with other processing routes [137]. This is why the application of FDM for ceramic production is successfully expanding into various fields as electronic components [138], biological parts [139], sensors [140], bioceramic scaffolds [141-145], and others [146,147].

\subsubsection{Direct ink writing (DIW)}

Direct ink writing is a process related to the material extrusion group and it is also known as Robocasting [148], Direct Write Fabrication [149] or Robot-Assisted Shape Deposition [150]. DIW was first reported by Cesarano and Calvert when they filed a patent at Sandia National Laboratories on October 28, 1997 [151,152]. DIW is a simple, flexible, and inexpensive approach, suitable for many kinds of materials, such as ceramics, metal alloys, polymers, and even edible materials [153], this is the most versatile method to fabricate 3D prototypes [154], which its main goal is to make parts by extrusion of concentrated suspensions formulated of main material together with additives to get appropriate viscoelastic behaviour [13,72]. The concept of this technique is very close to de FDM with the difference that the DIW process depends on the feedstock rheology behaviour to maintain the shape of the printed part in the time [148]. The high viscosity (103-106 mPa s) and shear thinning behaviour (a decrease of viscosity with an increase of shear forces inside the nozzle) of the feedstock are indispensable for this technique [20,154,155]. In this way, the pseudo-plastic feedstock is extruded by compressed air through a moving controlled nozzle to form a desired two-dimensional pattern [72]. In DIW the possibility of nozzle clogging is much lower than IJP [156]. When a layer was printed the part support is lowered a distance equal to the thickness of the new layer. After that, a new layer is deposited on top of previously deposited forming a part thanks to a layer by layer procedure. As other technologies of ceramic production debinding and sintering post-processes are necessary to 
obtain a ceramic part without organics. Figure $5 c$ demonstrates a schematic diagram of the DIW process.

This technology for ceramic materials, compared to SLA, is much faster and cheaper. The exclusive use of ceramic pastes with required viscoelastic behaviour allows printing figures that can maintain their original form regardless of the loads generated by the newly deposited layers on them. Generally, the used pastes have a high loading of ceramic particles and optimal content of additives. Thanks to this, it is possible to build parts with different configurations from complex porous scaffolds [21], to composite materials [157] and solid monolithic parts [158]. Moreover, some researchers could prepare and use for printing filaments with different cross-sectional forms [159, 160].

Thanks to the flexibility and simplicity of DIW, other scientists have been able to implement this technology for the fabrication of parts with periodic structures [26,161], for electrodes for lithium-ion (Li-ion) batteries [162, 163] and, in recent years, the manufacture of bioceramic implants $[19,164,165]$. The last is the prominent application thanks to/as a result of the porosities that appear in the part after sintering. These porous structures are preferred in the manufacture of ceramic implants because they promote the growth of human body tissue in them [167-169]. Thus, DIW is well suited to the fabrication of tailored porous ceramic structures possessing periodic features, with little or no surface resolution needed [13].

The aforementioned results show that DIW is a prominent technique for obtaining ceramic pieces with complex geometry, but with the great disadvantage that it is not possible to obtain highly dense pieces, which limits their application in the industry.

\section{Additive Manufacturing for graphene-based materials}

As previously stated, in the last few years AM technologies have become so popular throughout the world that they have come to be applied in different fields of science and industry using different types of materials such as polymers, metals, ceramics, and composites. At the same time, in the last 20 years the development of materials science, specifically in the area of nanotechnology, has allowed the appearance, study, and development of interesting and perspective new materials, which are known as nanomaterials, for their application in the industry $[36,170]$. Micro- and nanomaterials of the same compound differ in that the latter can have exceptional and never-before-seen optical, electronic, and mechanical properties in comparison with the first. The great interest in nanomaterials is also because the properties of macro materials drastically change when nanomaterials are added to their structure [171,172]. Thanks to this, many ceramic-based composites that have a certain percentage of nanomaterials are converted into materials with improved mechanical properties. One of these promising nanomaterials is graphene $[173,174]$. Graphene is a revolutionary material that opens wide perspectives with its use, as an example, for increasing the flexural strength and fracture toughness of ceramic materials $[175,176]$. In the following sections, the characteristics and possible applications of graphene-based material, as well as the most popular additive technologies for them, will be explained in more detail.

\subsection{Graphene and its derivatives materials}

Graphene is a two-dimensional carbon allotropic form consisting of a single layer of sp2 hybridized atoms that are organized in a honeycomb lattice structure [177]. Graphene was discovered in 2004 by Andre Geim and Konstantin Novoselov, who worked at the University of Manchester. This material demonstrates unique properties such as very high thermal conductivity (above $5000 \mathrm{~W}$ $\left.\mathrm{mK}^{-1}\right)[178,179]$, high modulus of elasticity $(1 \mathrm{TPa})$ [180], large surface area $\left(2630 \mathrm{~m}^{2} / \mathrm{g}\right)$ [181], high electron mobility in room temperature $\left(250.000 \mathrm{~cm}^{2} / \mathrm{V} \mathrm{s}\right)$ [182] and high tensile strength of $130 \mathrm{GPa}$ [180]. Moreover, graphene shows high light transmittance [183], very high electrical conductivity [184], and complete impermeability to any gases [185] that make it a very promising material for a large number of multifunctional applications such as medicine [186], composite materials [187,188], electronics [189], light processing [190], supercapacitors [191], energy [192], strain sensors [13] and others $[193,194]$. 
Different methods of obtaining graphene have been investigated, but the most used are chemical vapor deposition [195], epitaxial growth [196], the mechanical, oxidation-reduction method [197], and liquid phase and electrochemical exfoliation [198]. It should be noted that the widespread use of pristine graphene is limited mainly because it is hydrophobic [199]. The solution to this problem is the surface functionalization of graphene that is carried out by chemical modification [200,201]. Generally, chemical modification of graphene can be done in two ways: covalent [202], or noncovalent functionalization [203]. Functionalization via non-covalent interactions creates a weak interaction of a $\pi-\pi$, van der Waals or electrostatic type between graphene and the target matter [201], while the covalent modification use the covalent bonding of oxygen-containing functional groups on the surface of graphene, forming carboxylic acid groups at the edges and epoxy and hydroxyl groups at the basal plane [200]. Usually, researchers around the world use processes based on the Hummers method, which are known as the modified Hummers method [204], for the covalent modification. The main idea of the Hummers method is the use of very strong oxidizing agents, such as concentrated sulfuric acid, nitric acid, and potassium permanganate, for the formation of oxygenated functional groups on the graphite [205], which is then mechanically exfoliated to obtain fine sheets of graphene with also functional groups on its surface [206]. This material is called Graphene Oxide (GO) and it is hydrophilic that disperses easily in water [206].

The oxidation of graphene creates a large number of defects in its lattice structure that degrade the material properties, moreover, the functional groups in the GO surface make it electrically insulating [197,206]. Fortunately, a partial restore of graphene properties is possible thanks to a reduction process of GO that can be carried out mainly by chemical or thermal ways, although other less popular routes have also been used [197,206,207]. The idea of the reduction process is to remove the functional groups from the GO surface to obtain reduced graphene oxide (rGO) by the application of reducing agents [208] in the chemical reduction, or by a heat treatment in the thermal [153, 29].

Graphene and rGO differ from each other primarily by the presence of defects and some functional groups that remained in their structure after the reduction process. This fact turns rGO into a material with properties close to graphene and, at the same time, soluble in different media that allows it to be used in industry [209]. For instance, a large number of graphene-based composites have been created to improve the mechanical [210], thermal [211] and electrical [212] properties of polymer matrices used with applications in aerospace, electronics, and energy storage [206,213,214]. Furthermore, graphene-based composites with inorganic matrices, such as metals, ceramics, and composites have been developed [206,215-218].

\subsection{Additive technologies for graphene-based materials}

Like ceramic materials, graphene and its derivatives materials are also being studied to define their role and use in AM [219]. Since graphene oxide is hydrophilic, it is the most suitable material to be used as a precursor of graphene in additive technologies since this material can be easily dispersed in different solvents, and especially in water. Thus, the appropriate AM techniques to be used with graphene-based materials should belong to the categories vat photopolymerization, material jetting and material extrusion. In this review, only the AM techniques that are more typical for the production of graphene-based composites, in particular SLA, IJP, FDM, and DIW, will be analyzed. Some of these methods are based on the use of polymers; and the introduction of graphene-based material into them allows the obtaining of polymer nanocomposites with improved properties, for example, barrier properties [185,220,221], optical properties [222,223], thermal properties [224-226], electrical properties [227-229] and mechanical properties [224,230-232].

The final properties of polymer nanocomposites crucially depend on the effectiveness of the nanoparticle dispersion process [233]. Thus, a good nanofillers dispersion in the polymer will produce a maximum increase in the properties of the composite [234-237]. In many studies, the process of preparing composites has been taken into account to obtain a high homogeneity and dispersion of graphene-based materials within a polymer matrix [238]. The tactics implemented in different works can be summarized in three strategies [233]: 1- In situ intercalative polymerization. In this method, graphene or GO is first swollen in the liquid monomer, then a suitable initiator is 
diffused and polymerization reaction proceeds by heat or radiation; 2 - Solution intercalation. Three steps are involved in this method: dispersion of graphene or GO in a suitable solvent, the addition of polymer and removal of the solvent. Graphene or GO can be dispersed in various solvents by sonication. Then, the graphene-based-solution is mixed with the polymer matrix, which is adsorbed onto the carbon sheets. Next, the carbon sheets sandwich the polymer to form a nanocomposite by removing the solvent, which is crucial for the properties of nanocomposites. The main advantage of this method is introducing low or even no polarity during the synthesis process; 3 - Melt intercalation. Graphene or GO is mechanically mixed with thermoplastic polymer at elevated temperatures by extrusion or injection molding. This method is solvent-free.

Of these three strategies the last two are the most widely used, while, as far as is known, the literature on preparation of graphene-based polymer composites by in situ polymerization before being extruded into filaments for FDM printing is still limited [29].

\subsubsection{Stereolithography (SLA)}

In section 2.2.1, the history facts, basic principles, advantages and disadvantages of this technique were considered. In summary, SLA uses a liquid photopolymer that polymerizes under the action of a UV light source to fabricate a part with a high resolution [239]. It is necessary to consider two essential issues for SLA-based composites: (1) Rapid solidification of by light initiated polymerization, which requests a fast light-responsive composite resin system; (2) Sufficient low viscosity to allow for the dipping of the resin layer, which determines a low graphene content and homogeneous filler distribution [240].

Over time, the SLA evolved and improved versions of this technique such as DLP, continuous liquid interface production (CLIP), projection microstereolithography (P $\mu S L)$ and TPP [82,241-243] appeared. These modifications allow manufacturing parts with a higher resolution, shorter manufacturing time and low post-process requirements [244].

In 2015, Lin et al. [233] reported the first manufacturing of GO reinforced complex architectures by mask projection-based Stereolithography (MPSL), also called digital light processing (DLP), with a good combination of strength and ductility. First of all, the expected weight amount of GO nanosheets was sonicated in acetone and then they were dispersed in the polymer resin. This research demonstrated that tensile strength and elongation of printed composite parts with only $0.2 \mathrm{wt} \%$ GO increased by $62.2 \%$ and $12.8 \%$, respectively. Moreover, this research group noticed a novel fracture phenomenon of 3D printed truss architecture under the compression test. Later, in 2017 an experiment was carried out by Manapat et al. [245] on the manufacture of high-strength nanocomposites by a typical SLA process. In this work, the authors used the GO metastable structure to improve the thermo-mechanical properties of a printed part that was then annealed at low temperature. For this, composites with different GO contents (between 0 and $1 \mathrm{wt} \%$ ) were prepared by dispersing the GO in acetone and then mixing the as prepared dispersion with a resin. The viscosities of the prepared GO resin varied between 0.6 and 1.6 Pa.s depending on the concentration of GO. Before, the as-obtained GO resins were used to manufacture the 3D parts with an axial resolution of 50 microns, which were then annealed at low temperatures $\left(50{ }^{\circ} \mathrm{C}\right.$ and $100{ }^{\circ} \mathrm{C}$ for 12 hours). The best results were obtained after annealing at $100^{\circ} \mathrm{C}$ for the $1 \mathrm{wt} \% \mathrm{GO}$ nanocomposite that showed a very high increase of $673.6 \%$ on tensile strength compared with the casted material (Figure 6) [245]. 


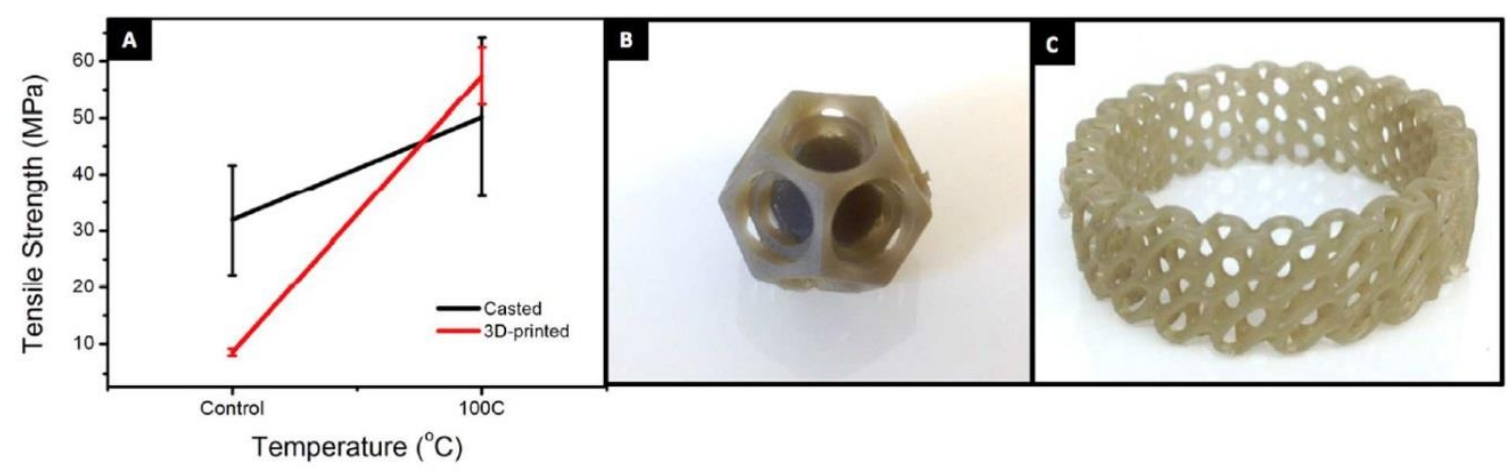

Figure 6. a) Tensile strength comparison of casted and 3D-printed parts; SLA-printed complexshaped GO nanocomposites: (b) nested dodecahedron and (c) diagrid ring. Reprinted with permission from [245]. Copyright (2017) American Chemical Society.

The previous work result shows that SLA is a good candidate to be used in the rapid manufacturing of parts based on graphene reinforced composites that can be used in different applications, such as in the biomedicine field. For example, in the work [246] published in 2018, a graphene-reinforced composite for bone structure scaffolds was reported. Here, Feng et al. invented a biodegradable UV-cured resin by SLA to create the personalized complex structure for bone tissue scaffolds, which have been reinforced by the filling of graphene layers. The formulation consists of a commercial polyurethane resin as an oligomer, trimethylolpropane trimethacrylate (TEGDMA) as a reactive diluent and phenylbis (2, 4, 6-trimethylbenzoyl)-phosphine oxide (Irgacure 819) as a photoinitiator. The obtained resin had suitable viscosities for SLA in the order of 847 Pa.s $\left(\right.$ at $\left.25^{\circ} \mathrm{C}\right)$ and 500 Pa.s (at $30^{\circ} \mathrm{C}$ ). Thanks to the inclusion and the good dispersion of graphene fillers, the manufactured parts by SLA had improved their mechanical properties when they are compared with the conventional direct casting method. Thus, the tensile strength of the printed part rose to $68 \mathrm{MPa}$ from $42 \mathrm{MPa}$ that is the value for the same material but produced by direct casting. Other improvements are also been registered in the flexural strength (115 MPa) and flexural modulus (5.8 $\mathrm{GPa}$ ). Consequently, these results show that this graphene-reinforced resin has a great ability for the production of biological tissue engineering compared to the traditional mold-based multistep methods that have a considerably low cost. Figure 7 [246] shows the images of jawbones, and gyroid scaffolds of pure UV-cured resin and graphene-reinforced nanocomposite manufactured in this work.
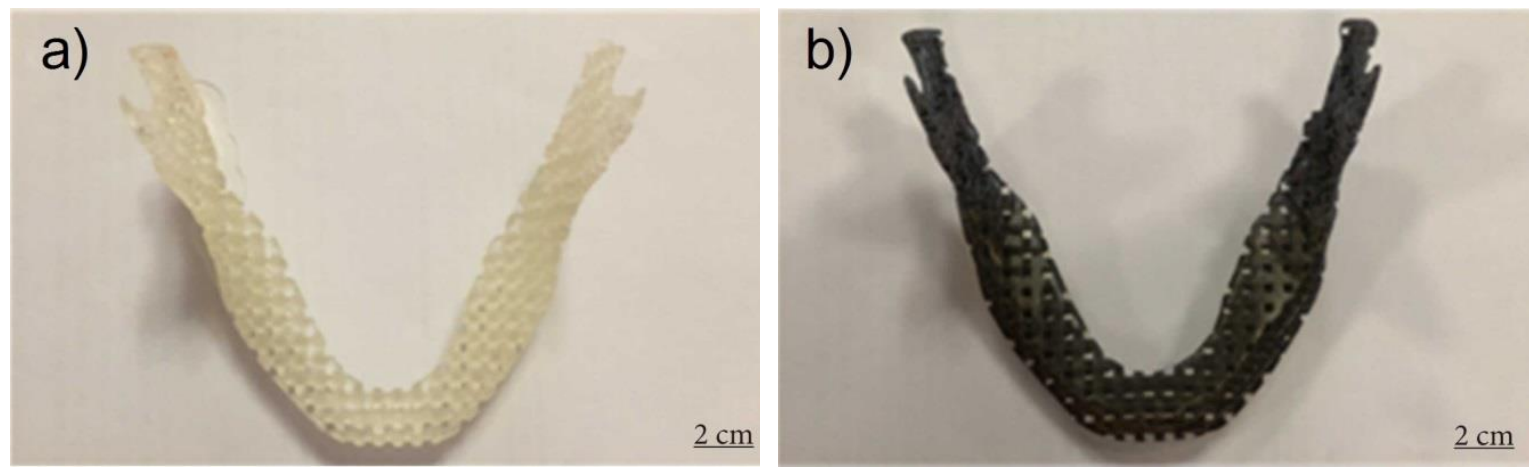

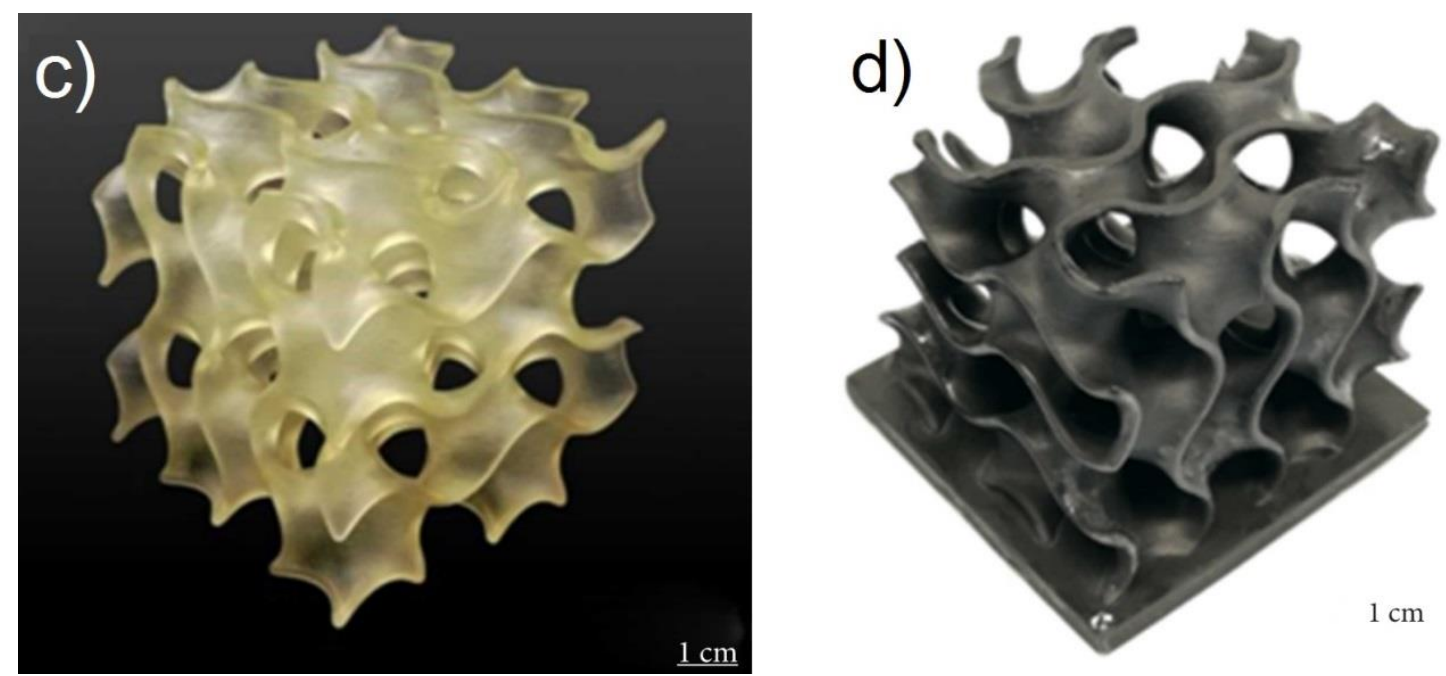

Figure 7. Images of (a) pure UV-cured resin and (b) graphene-reinforced nanocomposite jawbone with a square architecture. Images of (c) pure UV-cured resin and (d) graphene-reinforced nanocomposite gyroid scaffold for bone tissue engineering. Reproduced with permission from Ref. [246]. Copyright (C) 2019 Zuying Feng et al.

A short time ago, Hensleigh et al. [247] investigated the manufacturing of complex microarchitected graphene aerogels by using an "XGO" resin. In this study was demonstrated that graphene containing resin could be precisely patterned by light into any desirable shape with 3D spatial features sizes of $\sim 10$ microns (Figure $8 \mathrm{~g}$, [247]), that is a much higher resolution compared with other works where the obtained feature sizes were on the order of $100 \mu \mathrm{m}$. 


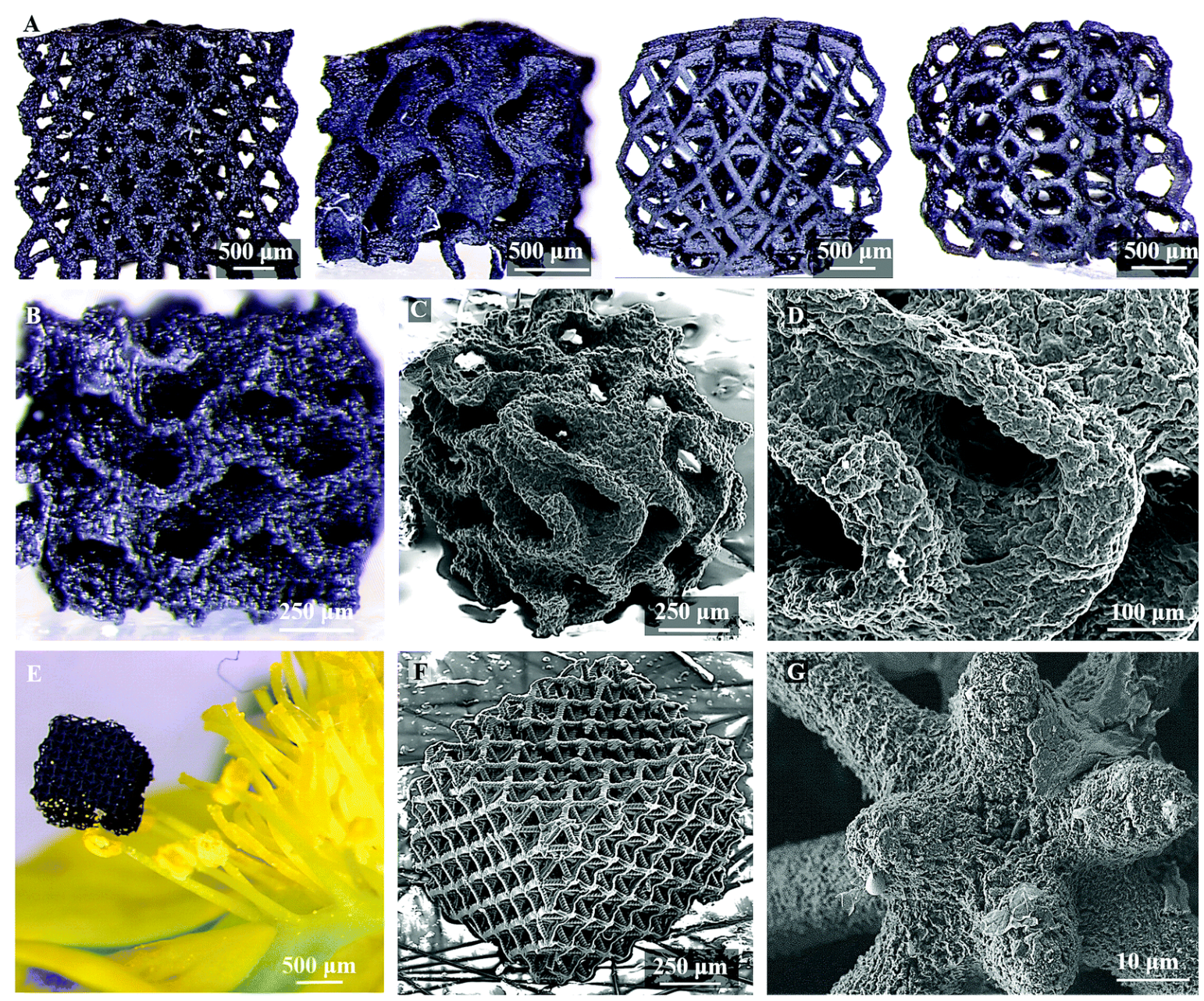

Figure 8. (a) Four "Green" MAG parts of differing unit-cell structures before pyrolysis from left to right octet-truss, gyroid, cubo-octahedron, and Kelvin foam; (b) optical image of pyrolyzed gyroid; (c) SEM image of pyrolyzed gyroid with intricate overhang structures (d) zoomed image of pyrolyzed gyroid in " $\mathrm{c}$ "; (e) optical image of pyrolyzed MAG octet-truss, of a different design than shown in "a" supported by a single strawberry blossom filament; (f) SEM image of pyrolyzed octettruss MAG in " $\mathrm{e}$ "; $(\mathrm{g})$ zoomed image of octet-truss in " $\mathrm{e}$ " showing the very high 10 micron resolution achievable in our process. Reproduced from Ref. [247] with permission from the Royal Society of Chemistry.

In the current state of the art, other graphene-based 3D parts obtained by SLA improved versions as DLP [248,249], TPP [250] and others [244] can be found.

\subsubsection{Inkjet printing (IJP)}

This technology was widely considered in point 2.2.4 of this paper. It is necessary to remember that in this technique the feedstock should be a low viscosity homogeneous or colloid ink to be able to form spherical droplets for accurate fabrication [154]. Note that nozzle diameter $\alpha(\mu \mathrm{m})$ and density $\mathrm{Q}\left(\mathrm{g} / \mathrm{cm}^{3}\right)$, surface tension $\gamma(\mathrm{mN} / \mathrm{m})$, viscosity $\eta(\mathrm{mPa} s)$ of the ink directly influence on the drop formation [29]; and these ink characteristics must be taken into account during the preparation of the graphene-based feedstock [251-256]. One of the methods for ink preparation is the liquid phase exfoliation [257], in which graphite is first dispersed in a solvent and then exfoliated by sonication. Unfortunately, solvents that could give a better exfoliation result, such as $\mathrm{N}$-methyl pyrrolidone (NMP) and dimethylformamide (DMF), are extremely toxic. For this reason, studies are constantly carried out to find a replacement for these toxic materials [257-259]. Despite the efforts that were made to obtain such materials, the dispersity of graphene suspensions remained poor. A very 
practical way to stabilize the inks is to use GO or rGO together with surfactants that improve the dispersity of sheets $[257,260,261,262]$, thereby it reduces the probability of agglomerate formation in graphene-based inks [257].

Different studies on IJP with graphene-based inks have been carried out, mainly for applications in electronic, bioelectronic, and energy storage [263-268]. For example, in $2017 \mathrm{Li}$ et al. [258] reported a simple full-inkjet-printing technique for the scalable fabrication of graphene-based microsupercapacitors (MSCs) on various substrates. The authors prepared an ink based on highperformance graphene with dimethylformamide (DMF) that had a concentration of $2.3 \mathrm{mg} / \mathrm{mL}$ of graphene sheets and a stable period of more than half a year. This suspension was used for the fabrication of tiny films (with thickness up to $\sim 0.7 \mu \mathrm{m}$ ) that served as both the electrodes and current collectors. The fully printed graphene-based MSCs demonstrated an extremely high capacitance of about $0.7 \mathrm{mF} / \mathrm{cm}^{2}$, which considerably exceeds the maximum value reached $\left(\sim 0.1 \mathrm{mF} / \mathrm{cm}^{2}\right)$ in printed graphene-based MSCs [269,270] before this study. Moreover, the authors demonstrated that this approach enabled the scalable fabrication of MSCs and effective connection in parallel and/or in series at different scales [29], for instance, more than 100 devices have been connected to form large-scale MSC arrays as power banks on both silicon wafers and Kapton. Without any extra protection or encapsulation, the MSC arrays can be reliably charged up to $12 \mathrm{~V}$ and retain the performance even 8 months after fabrication.

Karim et al. [271] first reported an organic nanoparticle-based inkjet printable textile surface pretreatment which enables all inkjet-printed graphene-based wearable e-textiles. In this study, a way to print a continuous conductive path on a rough and porous textile surface, which is the main problem related to inkjet printing of conductive inks on textiles, was found. Figure 9 displays a schematic diagram of the inkjet-printed graphene e-textile manufacturing process. The textile surfaces were pre-treated with hydroxyl functionalized cross-linked styrene/divinylbenzene nanoparticles (NP1); on the other hand, the rGO water-based ink was prepared using a green nontoxic reducing agent, L-ascorbic acid in the presence of polyvinyl alcohol (PVA). Later, a continuous conductive electrical path of water-based rGO inks onto the pre-treated coating was printed by inkjet printing. The results of this study show that this approach reduces the sheet resistance of graphenebased printed e-textiles by three orders of magnitude from $1.09 \times 106 \Omega / \mathrm{sq}$ to $2.14 \times 103 \Omega / \mathrm{sq}$ compared with untreated textiles. Here, the pre-treatment acts as a receptor layer for water-based rGO inks, which can subsequently be dried at low temperature $\left(100^{\circ} \mathrm{C}\right)$; thus reducing the chance of damaging heat-sensitive fabrics. In this way, inkjet printing of water-based and bio-compatible graphene inks could potentially open up opportunities to manufacture environmentally-friendly next-generation e-textiles for sports, healthcare and military applications. In figure 10 are shown the different conductive patterns that were inkjet-printed onto the NP1 printed area and the untreated area of the fabric.

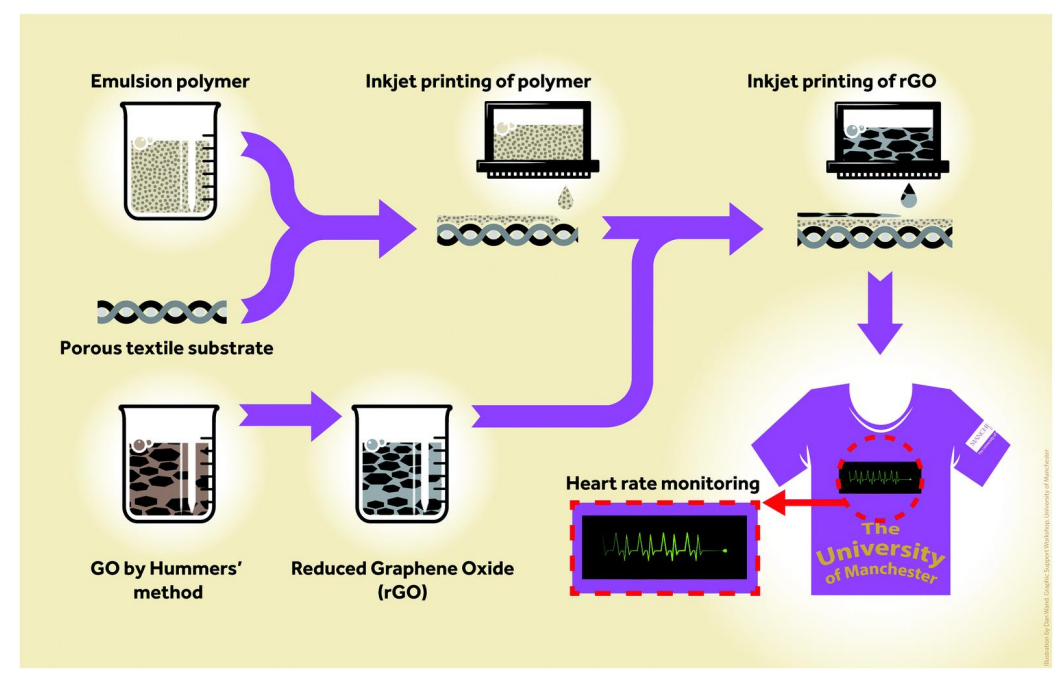


Figure 9. Schematic diagram of the inkjet-printed graphene e-textile manufacturing process. Reproduced from Ref. [271] with permission from the Royal Society of Chemistry.

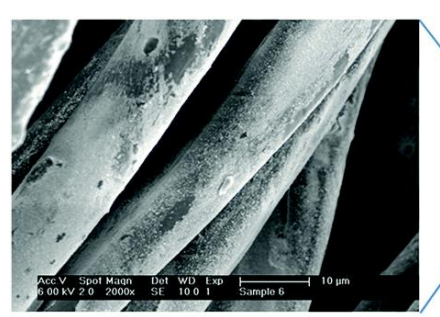

a)

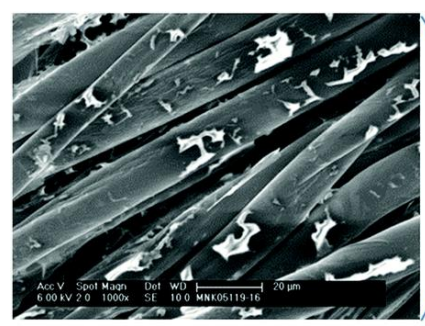

d)

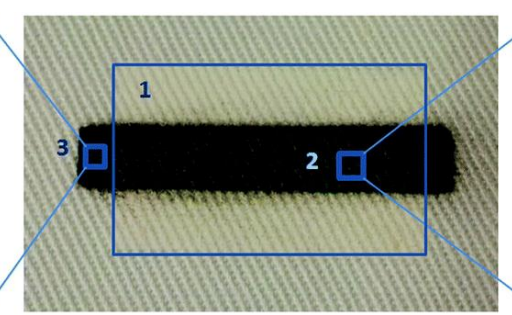

b)

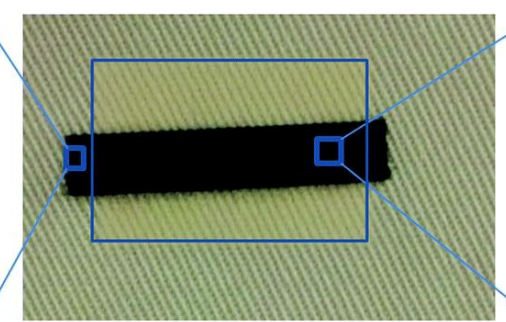

e)

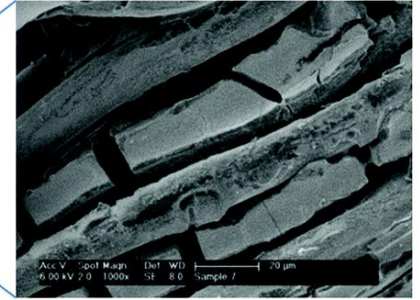

c)

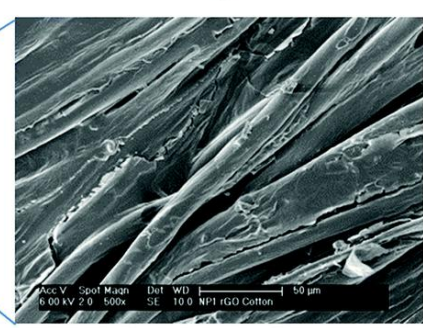

f)

Figure 10. (a) SEM images of the inkjet printed silver ink (6 layers) onto untreated cotton $(\times 2000)$; (b): (1) NP1 (12 layers) printed area; (2) inkjet-printed conductive pattern onto NP1 printed area with silver ink (6 layers) and (3) inkjet-printed silver ink onto untreated area (6 layers); (c) SEM images of the inkjet printed silver ink (6 layers) onto NP1 (12 layers) printed cotton fabrics ( $\times 1000)$; (d) SEM images of the inkjet printed rGO ink (6 layers) onto untreated cotton ( $\times 1000)$; (e) inkjetprinted conductive pattern with rGO onto NP1 printed and untreated area of cotton; (f) SEM images of the inkjet printed rGO ink (6 layers) onto NP1 (12 layers) printed cotton fabrics $(\times 500)$. Reproduced from Ref. [271] with permission from the Royal Society of Chemistry.

Recently, Asli et al. [265] proposed a method for high-yield production of aqueous graphene for electrohydrodynamic drop-on-demand printing of biocompatible conductive patterns. Here, a facile, scalable and aqueous phase exfoliation of graphite to high yield and quality of few-layer graphene (FLG) using Bovine Serum Albomine (BSA) and wet ball milling was suggested for the first time. The principle of this method is based on the combination of BSA as an exfoliating/stabling agent, with the sheer force of continuous low-speed wet ball milling, for achieving the exfoliation of graphite particles to 2-3 layers graphene sheets on average. The as-obtained graphene suspensions possessed a concentration of $5.1 \mathrm{mg} / \mathrm{mL}$ and it remained stable for weeks. This stable graphene dispersion is advantageous during the printing process, as it dramatically lessens the likelihood of clogging issues. Then, the prepared ink was printed on a flexible substrate (Polyimide) with the controlled resolution by the use of an electrostatic field in the drop-on-demand printer. After printing, thermal annealing is essential for the improvement of the conductivity of the printed FLG. On one hand, it leads to the release of possible oxide compounds; and on the other hand, results in the BSA burn-off, which is essential for maintaining the stability of the patterns when in touch with water; moreover, thermal annealing reduces flake-to-flake and flake-to-substrate defects while improving the order of the surface morphology. Thus, the post-processing was carried out in different durations (from 10 to 120 min), and temperatures (from $50{ }^{\circ} \mathrm{C}$ to $280^{\circ} \mathrm{C}$ ). The results demonstrated that no-annealed layer had a sheet resistance of $133 \Omega / \mathrm{sq}$, while annealed samples reduced the sheet resistance to $36.75 \Omega / \mathrm{sq}$ in an in a standard oven at $280^{\circ} \mathrm{C}$ with a duration of $30 \mathrm{~min}$. After annealing, the conductive layers lines did not lose their adhesion to PI when in touch with water, which is desirable as cell media are typically water-based. This approach has big potential for applications in biosensors, as well as other 
applications in flexible and printable electronics. Figure 11 displays SEM and optical analysis of printed patterns.
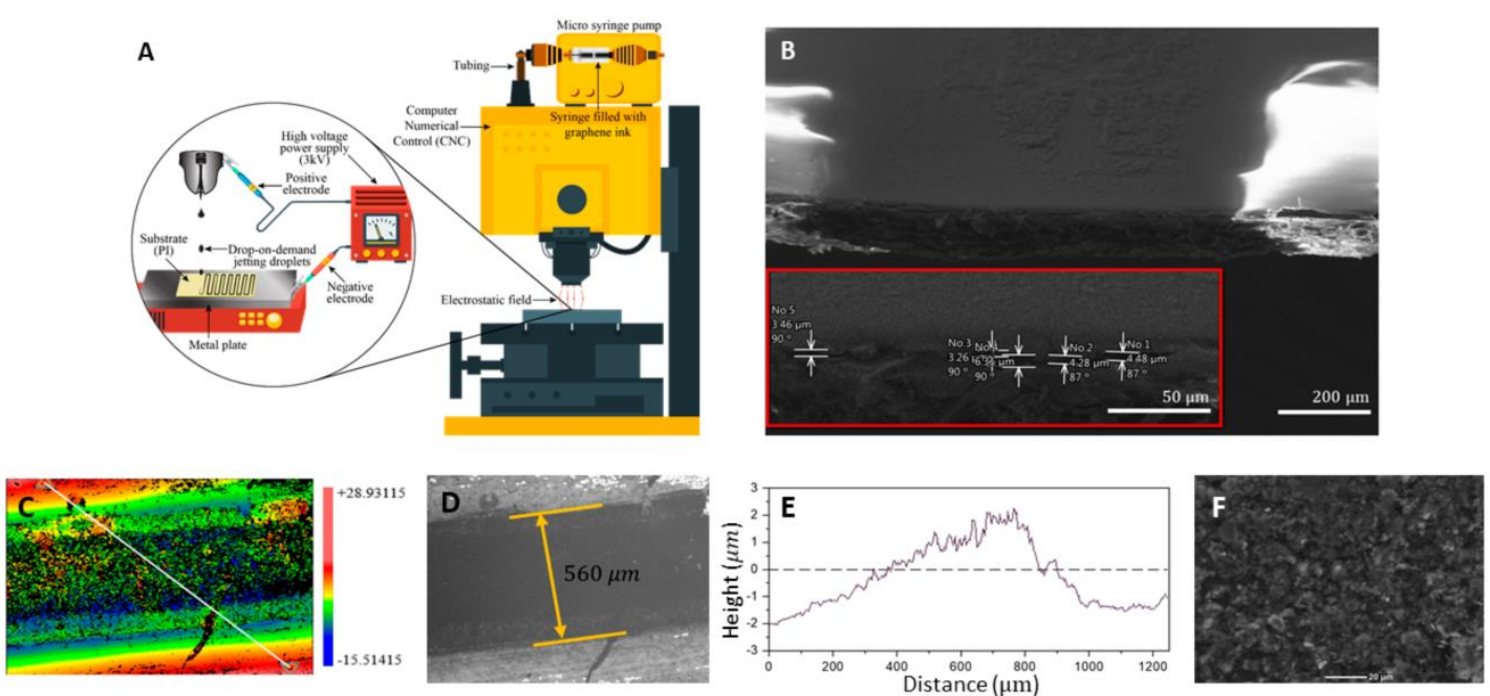

Figure 11. (a) Drop-on-demand printer setup for the inkjet printing of graphene; (b) SEM for crosssectional view of printed patterns with magnifications which show a normal height of $\approx 4 \mu \mathrm{m}$; (c) height contour of full printed graphene and sample line through which an average height is reported. (d) The 20x magnified section of the sample print. (e) In distance 0 and 1200 on the sample line (c), the height is measured over the substrate. The maximum measured height is the peak of the printed material. The dierence between these two indicates the height of the print $(\approx 4 \mu \mathrm{m})$ at maximum which is compatible with SEM imaging. (f) SEM for THE top view of printed graphene after annealing at $280 \mathrm{C}$ for $30 \mathrm{~min}$; scale bar: $20 \mu \mathrm{m}$. Reproduced with permission from Ref. [265].

\subsubsection{Fused Deposition Modeling (FDM)}

As we said in part 2.3.2, FDM is a very frequent AM technology that melts and extrudes thermoplastic filaments to form the final 3D part [272]. Thanks to the facility to add different phases in the thermoplastic matrix, this technology can be used for the production of parts with a wide type of composite materials [273]. As an example, the inclusion of electrically conductive carbon allotropic forms like graphene, graphite, carbon nanotubes, and carbon black into the filament of the printed parts can demonstrate an improvement in electrical properties and, as in the case of graphene and CNT, in mechanical properties [219,274-276].

The first study about the possibility of using graphene-based compounds in FDM to manufacture parts was reported by Wei et al. [277]. In this work, the solution intercalation strategy was used. The authors utilized N-Methylpyrolidone (NMP) as a solvent, to get good dispersion of ABS and GO. After the GO was reduced some quantities of rGO/ABS powder formed and precipitated from solution. Next, this powder was used for the preparation by extrusion of a filament that would later be used for the manufacture of parts by FDM. The maximum content of graphene in the manufactured filaments was $7.4 \mathrm{wt} \%$.

In recent years, different studies have been carried out on the application of graphene-based composites in FDM to be applied in different areas, as well as biomaterial scaffolds [278], electrochemical energy storage architectures [279,280], and flexible circuits [281].

For example, in 2017 Chen et al. [278] fabricated scaffolds for tissue engineering by application of thermoplastic polyurethane (TPU)/PLA/GO nanocomposites and explored their biocompatibility. These nanocomposites were obtained by a solution intercalation strategy and then the abtained mixtures were precipitated in alcohol to obtain the precipitates. Next, the precipitates were dried and extruded for the fabrication of nanocomposite filament. Diverse amounts of $\mathrm{GO}(0.5,2$, and $5 \mathrm{wt} \%)$ were mixed with polymer with a fixed ratio of TPU/PLA equal to 7:3. Thereby, a monolayer of the 
as-prepared composite was printed on a glass substrate; then the live/dead viability/cytotoxicity assay using NIH3T3 mouse embryonic fibroblast cells was carry on. The experiments demonstrated that all scaffolds provided cell growth because they detected only live cells and not any dead cells in scaffolds. The maximum density of cells was reached in the scaffold with $0.5 \mathrm{wt} \% \mathrm{GO}$, Figure $11 \mathrm{~b}$ [278].
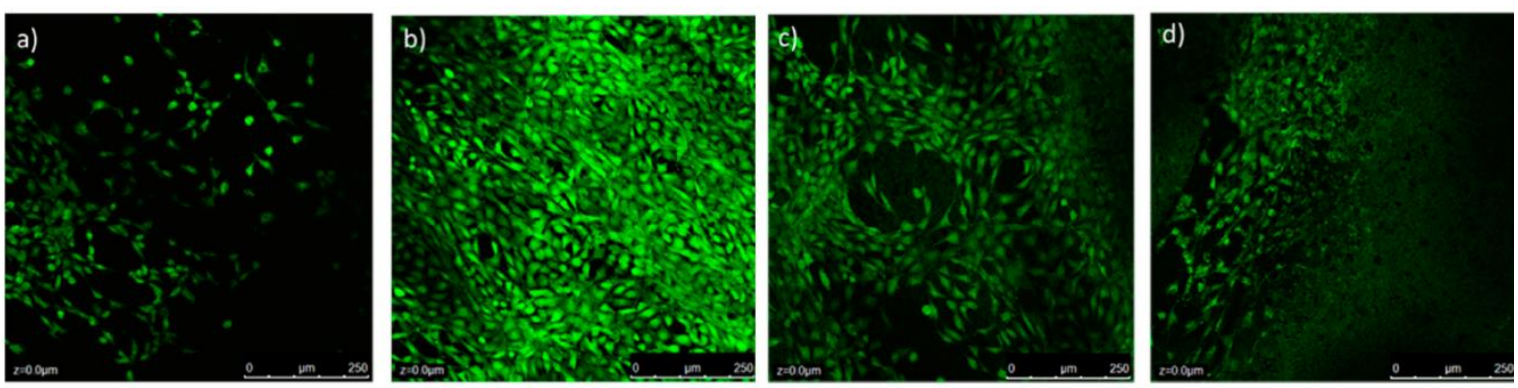

Figure 12. $96 \mathrm{~h}$ cell culture results of NIH3T3 cells on 3D printed TPU/PLA with different GO loadings: (a) $0 \mathrm{wt} \% \mathrm{GO}$, (b) $0.5 \mathrm{wt} \% \mathrm{GO}$, (c) $2 \mathrm{wt} \% \mathrm{GO}$, (d) $5 \mathrm{wt} \%$ GO. Green color indicates live cells, whereas red color indicates dead cell. Adapted with permission from [278]. Copyright (2017) American Chemical Society.

Foo et al. [282] developed a method for producing 3D printed electrode (3DEs) and its novel applications in electronic devices. Here, the 3Des were created by employing a commercial graphenebased conductive filament that was purchased from Black Magic. Besides, a layer of gold was sputtered on the surface of the 3DEs for the complete fabrication of the electrode, which was named 3DE/Au, Figure 13 [282]. The 3DE/Au was used as the current collector and working electrode for a solid-state supercapacitor with a multilayered structure. Before the assembly of the supercapacitor, a layer of polypyrrole/reduced graphene oxide (Ppy/rGO) nanocomposites were deposited on the 3DE/Au surface via an in-situ electrochemical polymerization method. The assembled supercapacitor exhibited a good capacitance performance with a specific capacitance of $98.37 \mathrm{~F} / \mathrm{g}$. Also, these 3DEs were fabricated into a photoelectrochemical sensing platform that had a photocurrent response at $\sim 724.1 \mu \mathrm{A}$ and a lower detection limit $(0.05 \mu \mathrm{M})$ compared with indium-doped tin oxide (ITO) or fluorine-doped tin oxide (FTO) glass electrode. Zhang et al. [281] manufacture by FDM highly conductive graphene flexible circuits. In this study, the authors used the modified two-step in-situ reduced method to synthesize the high conductive graphene, whose conductivity can reach to 600 $\mathrm{S} / \mathrm{cm}$. The first step was chemical reduction by 4 -iodoaniline, while a thermal reduction at $1050{ }^{\circ} \mathrm{C}$ for $1 \mathrm{~h}$ under the argon atmosphere for the second step. After mixing rGO (6 wt $\%)$ and PLA homogeneously by melt intercalation, filaments of PLA-rGO composite were finally prepared and the conductivity was $4.76 \mathrm{~S} / \mathrm{cm}$. SEM images showed that graphene was well dispersed in the PLA substrate. The authors demonstrated that the orientation of $\mathrm{r}-\mathrm{GO}$ fillers takes place during the extrusion process, and this effect contributes to the increase in the conductivity of the filaments. In addition, the 3D flexible circuits exhibit good bonding force between layers, indicating that the 3D structure can maintain the same good mechanical property in both the axial direction and transverse direction. Besides, the manufactured 2D flexible circuits on paper and polyimide (PI) substrates showed a great bonding force between the composite circuits and both substrates, Figure 14 [281].

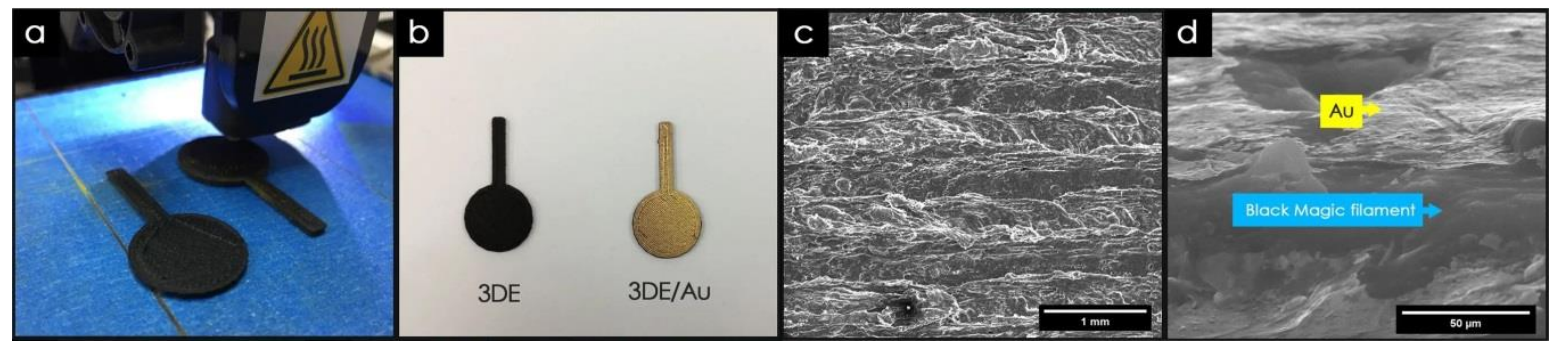


Figure 13. Physiochemical characterization. (a) Optical image of 3D printing process, (b) 3D printed electrode used throughout study. (c) FESEM image of 3DE/Au electrode, and (d) corresponding magnified crosssectional area. Reproduced with permission from Ref. [282].

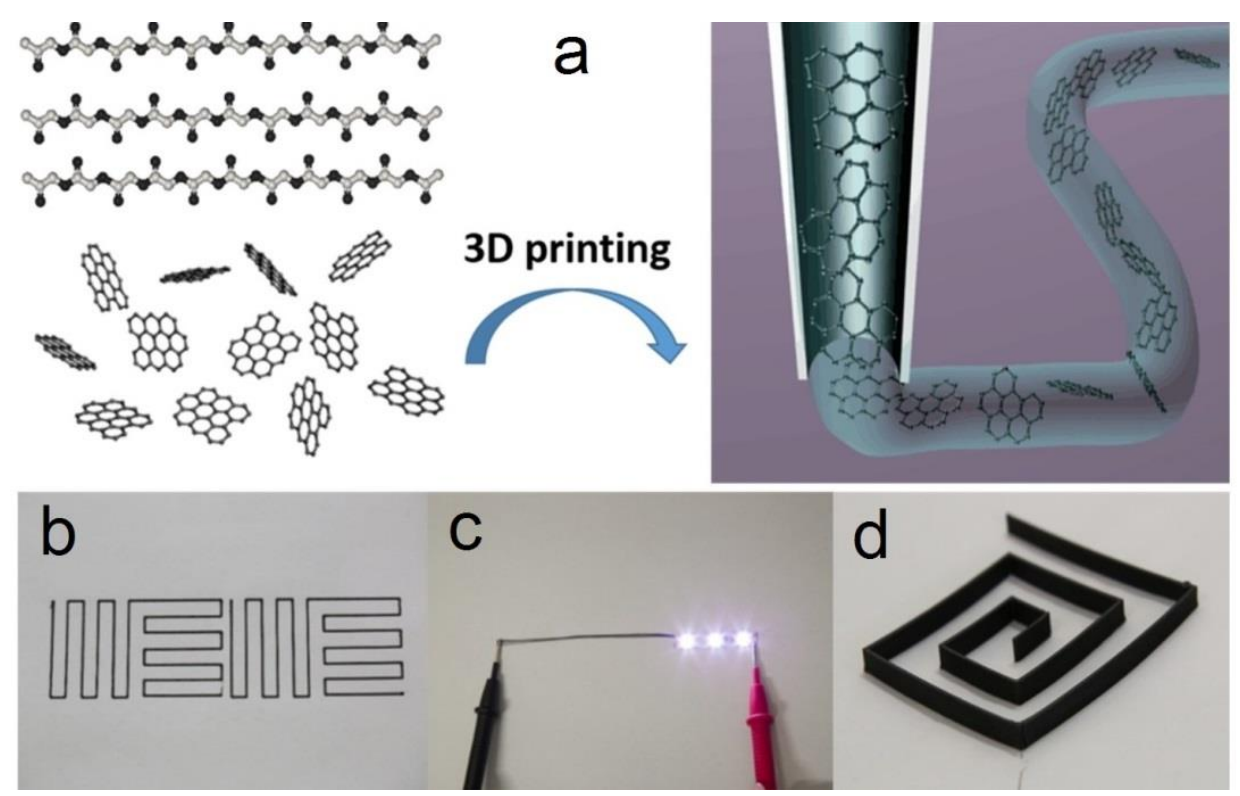

Figure 14. (a) Simplified schematics depicting the process of graphene-based 3D printing by FDM; (b) two units of 3D printed paper-based flexible circuits pattern; (c) LED circuit with a bunch of 3D printed filaments; (d) 3D printed flexible circuits. Reprinted from Publication [281], Copyright (2016), with permission from Elsevier.

\subsubsection{Direct ink writing (DIW)}

Direct ink writing is an AM technique based on the extrusion and deposition of a pseudo-plastic material (paste), which can maintain the shape of the extruded filament and the printed part in the time after extrusion. Previously, we had already considered this technique at the point 2.3.3 of the present work. The paste feedstock must have a high viscosity $\left(10^{3}-10^{6} \mathrm{mPa}\right.$ s, depending on the shear rate) and shear thinning behaviour (a decrease of viscosity with an increase of shear forces inside the nozzle) is essential for this technique $[20,154,155]$.

Among the all AM technologies, direct ink writing is one of the most broadly used for the manufacturing of 3D parts from a graphene-based feedstock [283] tanks to the combination of the great possibilities of DIW with the unique properties of graphene that has shown noteworthy printing capabilities and unique viscoelastic properties [29,155,281,283-285].

Naficy et al. [286] reported that graphene-based pastes with concentration up to $13.3 \mathrm{mg} / \mathrm{mL}$ are suitable for DIW. In figure 15 [286] the storage and loss moduli of GO suspensions and the schematic illustrations of the proposed model for the evolution of liquid crystal (LC) phases in GO dispersions upon increasing concentration are showed. In this work, the storage modulus $\left(G^{\prime}\right)$ of $G O$ at 13.3 $\mathrm{mg} / \mathrm{mL}$ was measured and its value was found to be in the range of 350 to $490 \mathrm{~Pa}$. These values considerably exceed the calculated elastic modulus value ( $\sim 0 \mathrm{~Pa})$ of a single-wall nanotube (SWNT) suspension with the same concentration. The rheological behaviour of LC GO dispersions are is shown in Figure 16 [286]. 

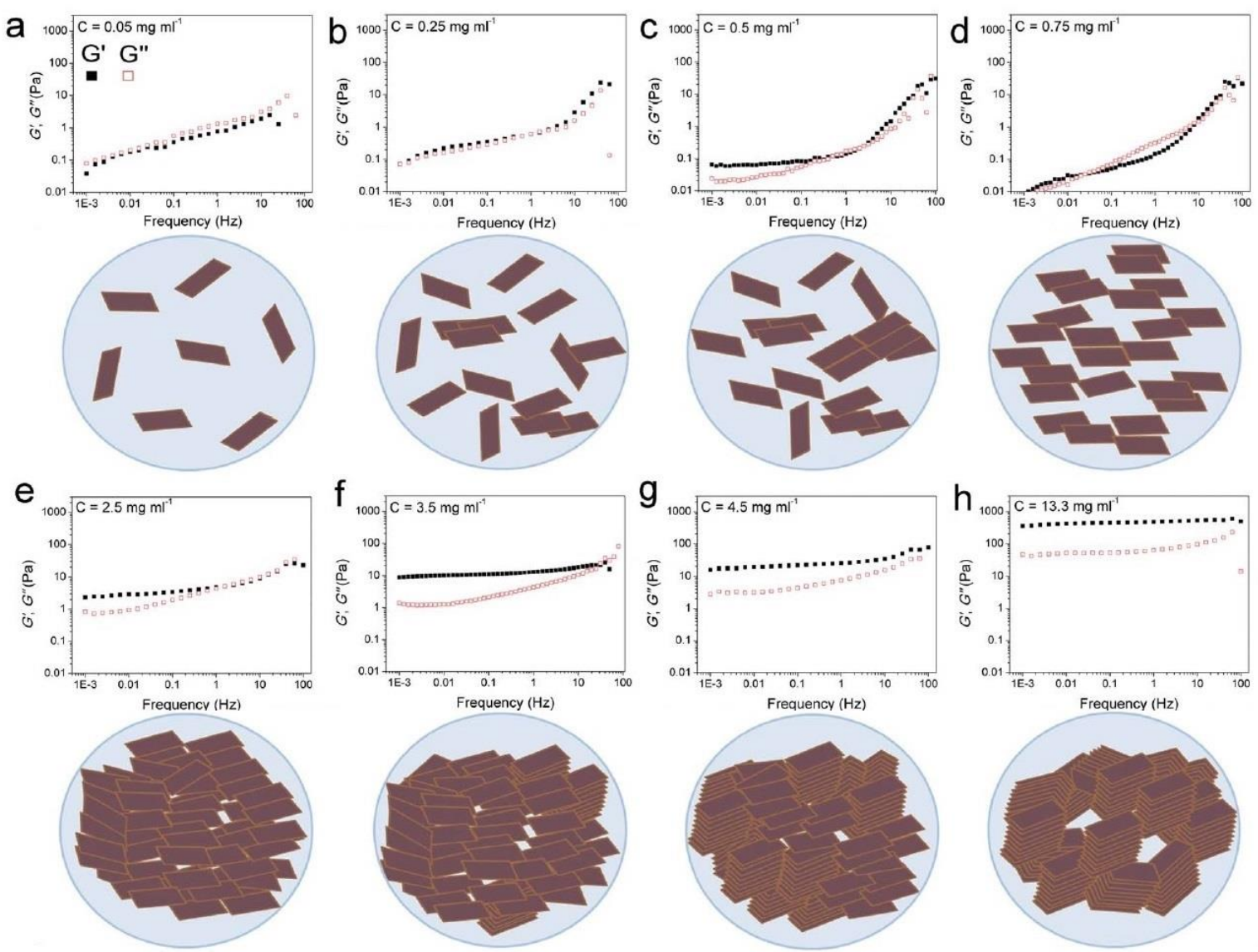

Figure 15. Storage and loss moduli (filled squares and open squares, respectively) of GO suspensions and the schematic illustrations of the proposed model for the evolution of LC phases in GO dispersions upon increasing concentration. (a) At this extremely low concentration. (b and c) Upon increasing the concentration to $0.25 \mathrm{mg} / \mathrm{ml}$ some nematic ordering starts to appear. (d) The dispersion forms a single phase nematic liquid crystal. (e) Further increase in concentration results in higher packing of the nematic phase. (f) In addition to long-range orientation in the nematic phase, some parts in GO exhibit long-range positional order. ( $g$ and $h$ ) Smaller monodomains are formed associated with exceptional increase in elastic modulus. Adapted from Ref. [286] with permission from The Royal Society of Chemistry.
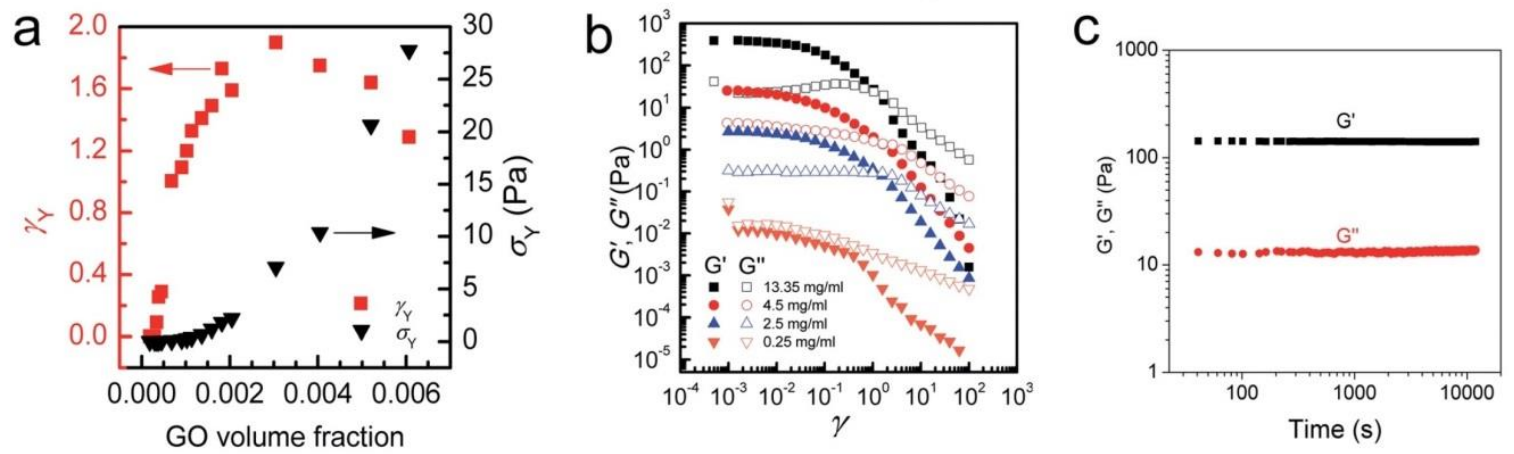

Figure 16. Interpretation of rheological behaviour of LC GO dispersions. (a) Yield strain $(\gamma \mathrm{Y})$ and yield stress $(\sigma \mathrm{Y})$ of various GO suspensions with different GO concentration. (b) Storage and loss moduli of GO suspensions at the frequency of $0.01 \mathrm{~Hz}$ at different strains. (c) no aging after shear 
rejuvenation/fluidization can be observed. Adapted from Ref. [286] with permission from The Royal Society of Chemistry.

In other work, Yao et al. [287] fabricated by DIW high-temperature and high rate heaters by using an aqueous paste with a high concentration of $\mathrm{GO}(80 \mathrm{mg} / \mathrm{mL})$. The apparent viscosity of the paste falls in a range of 102 and $103 \mathrm{~Pa} \cdot \mathrm{s}$ (at a shear rate of $1 \mathrm{~s}^{-1}$ ), while the storage modulus $\left(\mathrm{G}^{\prime}\right)$ shows a plateau at $10^{4} \mathrm{~Pa}$ with shear stress in a range of $10^{-1} \mathrm{~Pa}$ and $10^{2} \mathrm{~Pa}$. these values are essential for the layer-by-layer stacked architectures to have good shape retention. In the experiments, the prepared heaters generated high temperatures up to $3000 \mathrm{~K}$ in a controlled manner, while the temperature ramping response was fast and the heating rate was up to $\sim 20,000 \mathrm{~K} / \mathrm{s}$. Moreover, $3 \mathrm{D}$ heaters also demonstrated excellent stability at high temperature and stable temperature switching between room temperature and $2000 \mathrm{~K}$ for more than 2000 cycles. Figure 17 shows schematic illustrations and pictures of the 3D printable heater.
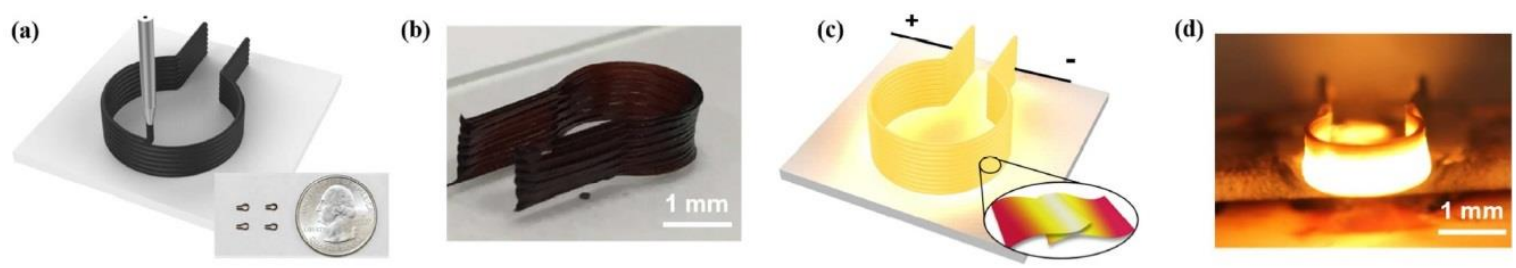

Figure 17. Schematic demonstration of 3D printable heater. (a) 3D printing of RGO heater. Heaters with chamber size $1.5 \mathrm{~mm}$ are shown in the inset. (b) Photo image of as-printed horseshoe-like 3D heater. (c) The action of RGO heater at high temperatures is achieved by applying a driving current. (d) Photo image of 3D printed heater under high temperature operation. Adapted with permission from Ref. [287]. Copyright (2016) American Chemical Society.

In 2014, were first reported 3D-printed nanostructures composed entirely of graphene by Kim et al. [288]. In this work, a meniscus-guided growth method was adopted to write free-standing reduced graphene oxide ( $\mathrm{rGO}$ ) nanowires without any supporting materials by a micropipette. Due to the very small open diameter $(1-2 \mu \mathrm{m})$ of the micropipette, the water would evaporate very fast which led to the solidifying of the GO suspension by pulling the micropipette. Thanks to the high control of moving various freestanding graphene structures could be printed with $100 \mathrm{~nm}$ resolution, ranging from straight wires, bridges, suspended junctions to woven structures [240].

Diverse studies about DIW of graphene-based materials with diverse applications, like as scaffold [283], Li-ion battery [153], and supercapacitor [155, 289] had been reported too. For example, Jakus et al. [290] fabricated multifunctional microsystems by 3D printable graphene (3DG) composite for electronic and biomedical applications. In this study, graphene powder and polylactide-coglycolide (PLG) were mixed in dichloromethane (DCM). During extrusion, rapid evaporation of DCM ensured a self-supporting filament that would not deform after deposition. The composites had a maximum graphene loading of $60 \mathrm{vol} \%$. Additionally, the authors demonstrated that during the extrusion a flakes orientation occurs along with the filament microstructure. Graphene flakes aligned in the exterior of the filament but stacked within the filament.

Fu et al. [153] produced $\mathrm{Li}_{4} \mathrm{Ti}_{5} \mathrm{O}_{12}$ (LTO)/GO and $\mathrm{LiFePO}_{4}(\mathrm{LFP}) / \mathrm{GO}$ composites for the AM of Li-ion battery by DIW. The composites showed a high electrical conductivity after the thermal annealing of GO. Composite pastes were obtained by the addition of LFP or LTO to GO suspension $(80 \mathrm{mg} / \mathrm{mL})$ with a mass ratio of 7:3, in which only water was de solvent. The storage modulus $\left(\mathrm{G}^{\prime}\right)$ of both pastes was in the region of 104 to $105 \mathrm{~Pa}$ during the plateau region, which indicated a stiffer ink with a solid-like response. On the other hand, yield stress values for the two composite pastes were $103 \mathrm{~Pa}$. These two high values are necessary for the paste application in DIW. After the obtaining of electrodes were freeze-dried and then thermally annealed in $\mathrm{Ar} / \mathrm{H}_{2}$ gas. The initial charge and discharge capacities of LFP/rGO electrode, at a specific current of $10 \mathrm{~mA} / \mathrm{g}$, were 168 and $164 \mathrm{mAh} / \mathrm{g}$, respectively, that are very close values to the theoretical capacity of LFP $(170 \mathrm{mAh} / \mathrm{g})$; while LTO/rGO electrode showed values of 184 and $185 \mathrm{mAh} / \mathrm{g}$, respectively, that are higher than the theoretical 
capacity of LTO (175 mAh/g). On the other hand, the fabricated battery demonstrated initial charge and discharge capacities of 117 and $91 \mathrm{mAh} / \mathrm{g}$ at a specific current of $50 \mathrm{~mA} / \mathrm{g}$.

Liu et al. [289] studied the preparation of graphene oxide/polyaniline (PANi) feedstock for flexible micro-supercapacitors (fMSCs). The authors made composite formulations by growing vertically aligned pseudo-capacitive PANi nanorods on both sides of the GO surface. For this, the first vertically attached PANi nanorods on the GO sheets using an interfacial polymerization approach; and then, a GO/PANi composite with a well-defined nanostructure was obtained. Next, the conductive poly(3,4-ethylenedioxythiophene): poly(styrenesulfonate) (PEDOT:PSS) was utilized as a dispersing agent to achieve highly dispersed water-based GO/PANi-PEDOT:PSS (GO/PA-PE) feedstock with suitable rheological properties for extrusion printing. Here, PANi nanorods were wrapped by PEDOT:PSS changing their morphology from vertically aligned sharp protrusions to a much smoother surface. The use of PEDOT:PSS not only improved the printability of the active materials but also endowed the composition with high electrical conductivity and enabled the full utilization of inner surface capacitance. The printed GO/PA-PE-based symmetric fMSCs exhibited high areal capacitance $\left(153.6 \mathrm{mF} / \mathrm{cm}^{2}\right.$ at $\left.5 \mathrm{mV} / \mathrm{s}\right)$ and volumetric capacitance $\left(19.2 \mathrm{~F} / \mathrm{cm}^{3}\right.$ at $\left.5 \mathrm{mV} / \mathrm{s}\right)$ which were higher or comparable to the literature values. Moreover, the authors demonstrated that by fabricating asymmetric fMSCs using the GO/PANi as the positive electrode and a graphene-based negative electrode, the voltage window can be widened from 0.8 to $1.2 \mathrm{~V}$ and improvements can be achieved in energy density (from 3.36 to $4.83 \mathrm{mWh} / \mathrm{cm}^{3}$ ), power density (from 9.82 to $25.3 \mathrm{~W} / \mathrm{cm}^{3}$ ), and cycling stability (from $75 \%$ to $100 \%$ capacitance retention over 5000 cycles) compared with the symmetric counterpart.

\section{Direct ink writing technology of graphene-based ceramic pastes}

As previously seen at the points 2.3.3 and 3.2.4 of this paper, direct ink writing holds great promise for the production of parts based on both ceramic and graphene-based materials, mainly due to versatility of DIW for the selection of materials and low-cost operation $[20,26]$. It was also indicated that in the ceramic production the parts obtained by DIW can have low mechanical characteristics due to the formed porous that appear during the elimination of additives and binders that were used. As a possible solution to this problem, graphene-based materials were proposed to be used as filler reinforce agents that, thanks to the unique properties of graphene, could improve the mechanical, electrical and thermal properties of the ceramic composite [35].

DIW is one of the most widely applied AM technologies for the fabrication of 3D parts from a graphene-based paste [29]. For obtaining a part with good properties by DIW a high graphene content paste and with a suitable raw material is necessary [29,283-285]. Besides, a high colloid volume fraction in the paste will minimize the drying-induced shrinkage after printing [29]. Very often, the use of additives (binders, viscosifiers, among others) is needed to provide a good dispersion of the graphene-based materials and obtain a paste with appropriate viscoelastic properties. In DIW the paste viscosity for printing, which is related to the loss (i.e., viscous) modulus ( $\left.G^{\prime \prime}\right)$, should be in the order of $10^{3}-10^{6} \mathrm{mPas}$, which are very high values. On the other hand, the storage (i.e., elastic) modulus $\left(G^{\prime}\right)$ is associated with the paste elastic property thus, high values of $G^{\prime}$ are required, because the higher $G^{\prime}$ the stiffer is the paste with a solid-like response [29]. When the ink exits the nozzle, it will recover its yield stress and shear elastic modulus $G^{\prime}$, thus maintaining its shape and dimension [29].

In the state of the art of graphene-based/ceramic 3D printed composites by DIW, diverse works with different applications as conductive ceramic nanocomposites [285,291], energy storage/conversion systems, high-temperature filters, and others, can be found.

Roman-Manso et al. [291] first reported the study of 3D architected graphene/ceramic composites obtained by DIW. These composites are applied in energy storage/conversion systems, high-temperature filters or as catalyst supports, gas sensors, and acoustic metamaterials. These 3D objects were printed starting from a paste containing homogeneous mixtures of $\mathrm{SiC}$ ceramic powders and up to $20 \mathrm{vol} \%$ of graphene nanoplatelets (GNPs), and then, these objects were consolidated by Spark Plasma Sintering (SPS). The paste was prepared as follows: three powder compositions were 
formulated with diverse GNPs contents (5, 10 and $20 \mathrm{vol} \%$ ). The ceramic powder was mainly composed of $\mathrm{b}-\mathrm{SiC}$ and using $\mathrm{Al}_{2} \mathrm{O}_{3}$ and add $\mathrm{Y}_{2} \mathrm{O}_{3}$ as sintering aids, and holding the $\mathrm{SiC}: \mathrm{Al}_{2} \mathrm{O}_{3}: \mathrm{Y}_{2} \mathrm{O}_{3}$ formulation constant at a 93:2:5 ( $\mathrm{wt} \%)$ ratio for all the compositions. To obtain a homogeneous powder composition, the aforementioned components were mixed in an attrition mill with alumina balls in an isopropyl alcohol media. At the same time, a stable dispersion of GNPs in isopropanol was prepared by sonication. Next, the ceramic combination and the nanoplatelets dispersion were mixed and, then, stirred and sonicated. Subsequently, the solvent was removed in a rotary evaporator, and the mixture was dried at $120^{\circ} \mathrm{C}$ and sieved through a $63 \mu \mathrm{m}$ mesh. With aim of preparing the pastes, well-dispersed suspensions of the as-obtained dried blend in an aqueous polymer solution of polyethylenimine (PEI), methylcellulose (MC) and ammonium polyacrylate (APA) were obtained in a planetary centrifugal mixer. In these suspensions, PEI, MC, and APA acted as a dispersant, viscosifying agent and flocculant, respectively. The aqueous polymer composition for pastes with contents up to $10 \mathrm{vol} \%$. of GNPs was (4 wt $\%$ of PEI, $5 \mathrm{wt} \%$ of MC and $0.3 \mathrm{wt} \%$ of APA); while the paste with $20 \mathrm{vol} \%$. needed a slight increase of the PEI content (5 $\mathrm{wt} \%$ ) to achieve the required pseudoplastic behavior. Note that in all cases, the solids content in the pastes was within the range of $69-71 \mathrm{wt} \%$ (42-44 vol\%). Next, 3D architected composites were manufactured using a DIW printer. After printing, the parts were heated up to $415{ }^{\circ} \mathrm{C}$ to burn out the organics and, then, the as-printed parts were sintered in an SPS furnace at $1800{ }^{\circ} \mathrm{C}$ and an Argon atmosphere. Sintered composites showed very-low-density values, ranging from 1.6 to $0.9 \mathrm{~g} / \mathrm{cm}^{3}$ for corresponding GNPs contents of 0 to $20 \mathrm{vol} \%$, as compared with theoretical values of the bulk compositions $3.28 \mathrm{~g} / \mathrm{cm}^{3}$ for the monolithic $\mathrm{SiC}$ and $3.03 \mathrm{~g} / \mathrm{cm}^{3}$ for the $20 \mathrm{vol} \%$ GNPs composites. Besides, the electrical conductivity of the scaffolds shows certain anisotropy with the structure orientation and increases with the GNPs volume fraction. In this way, values of up to $611 \mathrm{~S} / \mathrm{m}$ for the longitudinal and $273 \mathrm{~S} / \mathrm{m}$ for the transverse orientations of the structures relative to the extruded rods are achieved. This anisotropy was determined by the design of the structure and also by the strong preferential orientation of the GNP within the rod during the printing process.

\section{a)}

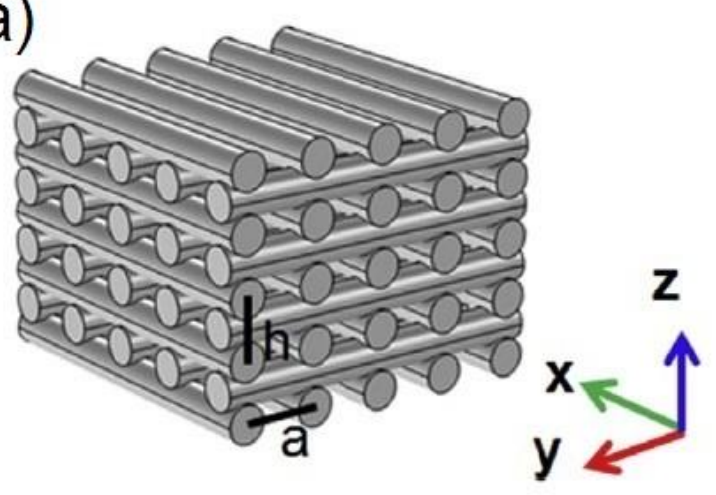

c)

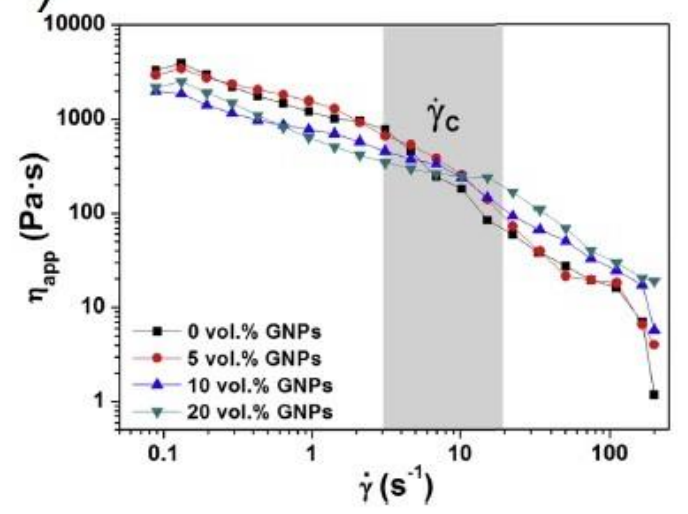

b)

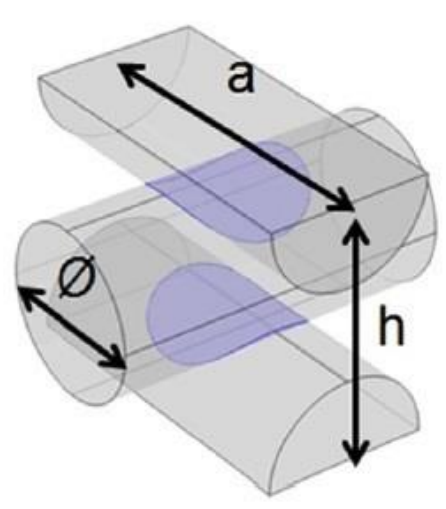

d)

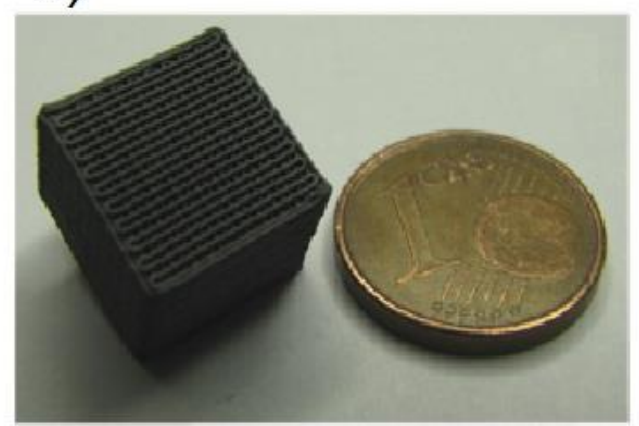


Figure 18. (a) Patterned structure used for scaffolds designing and (b) scheme of the contact area between two orthogonal rods, where $h, a$, and $\varnothing$ correspond to the distance between two equivalent layers in the $\mathrm{z}$ direction, the distance between two adjacent rods, and the rod diameter, respectively. (c) Apparent viscosity as a function of the shear rate for the GNPs/SiC pastes formulated with 0, 5, 10 and 20 vol\% GNPs in the powder compositions. d) View of a 10 vol\% GNPs/SiC sintered scaffold. Reprinted from Publication [291], Copyright (2016), with permission from Elsevier.

Tubio et al. [292] proposed a scalable fabrication of $\mathrm{rGO} / \mathrm{Al}_{2} \mathrm{O}_{3}$ composites with complex mesoscale architecture by DIW for their use in diverse applications. The paste production involved three basic steps: dispersion, mixing, and gelation. In the first step, an aqueous $\mathrm{Al}_{2} \mathrm{O}_{3}$ colloidal suspension with different $\mathrm{GO}$ contents $\left(0.5,1\right.$ and $5 \mathrm{wt} \%$, based on $\mathrm{Al}_{2} \mathrm{O}_{3}$ weight) was prepared in a planetary mixer. Then, the concentration of the as as-prepared suspension was increased by water evaporation at room temperature and mixed again several times. Subsequently, hydroxypropyl methylcellulose (HPMC) was added to increase the viscosity followed by other mixed steps. Next, polyethylenimine (PEI) was added to facilitate the gelation followed by other mixed steps. The rheological tests under steady and dynamic shear conditions were carried out to investigate the printability of as-prepared pastes. The data results showed two important effects: all pastes have shear-thinning (i.e., pseudoplastic) behaviour, and the GO content affects viscosity data in the whole shear-rate range. Moreover, the results showed that the paste with $5 \mathrm{wt} \% \mathrm{GO}$ content had the highest apparent viscosity and storage modulus $\left(\mathrm{G}^{\prime}\right) \sim 1 \times 10^{6} \mathrm{~Pa}$, while the shear yield stress raised to $220 \mathrm{~Pa}$ from 20 Pa for paste with 0 w.t\% GO. Therefore, paste with $5 \mathrm{wt} \%$ GO content was used for the fabrication of $\mathrm{GO} / \mathrm{Al}_{2} \mathrm{O}_{3}$ composites with complex mesoscale architecture by DIW. The obtained parts were sintered at $1600{ }^{\circ} \mathrm{C}$ in the $\mathrm{N}_{2}$ atmosphere to form $\mathrm{rGO}-\mathrm{Al}_{2} \mathrm{O}_{3}$ composites.

In another work, Moyano et al. [293] proposed a new formulation of graphene-based pastes for producing self-supported 3D architectures by DIW. Here, the authors showed that is possible to use just a single surfactant for graphene-based pastes to achieve a suitable shear-thinning behavior and a high elastic modulus at rest. At the same time, the whole paste produce process is simple and scalable. Three aqueous graphene-based pastes were created by mixing GO, GNP and their mixture (GNP (92.7 wt \%) and GO (7.3 wt \%)) with an aqueous solution (30 wt \% concentration) of Poloxamer 407, a triblock copolymer that contains $70 \mathrm{wt} \%$ of PEO units. Pastes with $30 \mathrm{wt} \%$ solution of Poloxamer 407 display shear thinning characteristics. The $\mathrm{G}^{\prime}$ values of the three inks were $8 \times 105 \mathrm{~Pa}$, $4 \times 10^{5} \mathrm{~Pa}$ and $3 \times 10^{5} \mathrm{~Pa}$ for GNP, GO and their mix, respectively. These $\mathrm{G}^{\prime}$ values are comparatively larger than those previously reported for similar GO and GNP aqueous inks but prepared using different polyelectrolytes (anionic and cationic) [294]. The yield stress, which indicates the transition to a semi-liquid state in the inks, stays between 1 and $4 \mathrm{kPa}$. Subsequently, the as-prepared pastes were used for the printing of 3D structures. Next, structures were thermally treated at $1200{ }^{\circ} \mathrm{C}$ to reach an extraordinary compressive strength (above $2 \mathrm{MPa}$ ) for the light GO material $\left(0.12 \mathrm{~g} / \mathrm{cm}^{3}\right)$ and very high electrical conductivity (above $4 \times 10^{3} \mathrm{~S} / \mathrm{m}$ ) for the mix GO-GNP composition. 

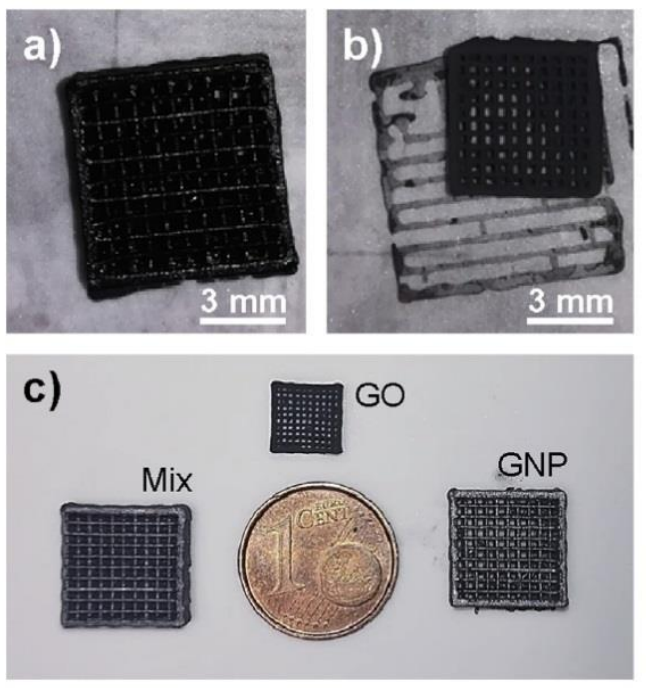

d)

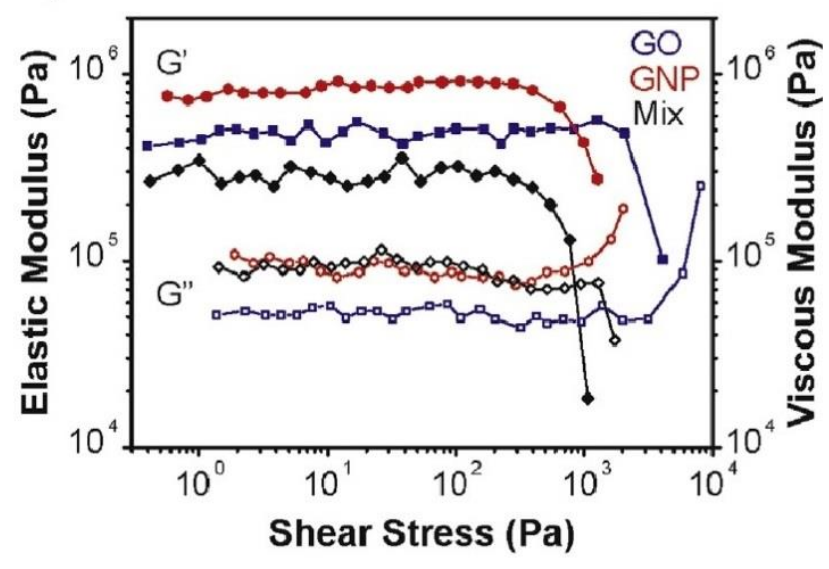

Figure 19. (a) 3D printed GO structure, (b) "a" dried $24 \mathrm{~h}$ in air; (c) image comparing the structures of GO, GNP and mix compositions after treatment at $1200{ }^{\circ} \mathrm{C}$; (d) Elastic $\left(\mathrm{G}^{\prime}\right)$ and viscous $\left(\mathrm{G}^{\prime \prime}\right)$ moduli as a function of shear stress for the three inks: GO, GNP and mix. Reprinted from Publication [293], Copyright (2019), with permission from Elsevier.

The previous examples showed that the classic production of graphene-based ceramic pastes involves the use of various polymers, which are later removed to get a composite of both ceramic and graphene-based materials. Different works have been carried out to develop new formulations and methods of paste preparation to reduce the number of additives in them.

One solution can be to modify the paste rheological behavior to reach suitable viscoelastic characteristics by adding some amount of silica. For example, Zhu et al. [155] investigated the method for manufacturing 3D graphene composite aerogel with periodic macropores for supercapacitor by DIW. Here, to prepare a suitable paste for DIW the GO suspension $(40 \mathrm{mg} / \mathrm{mL})$ was mixed with hydrophilic fumed silica. Silica acted as a viscosifier that imparted both shear-thinning behaviour and a shear yield stress to the GO suspension to enhance the printability of the GO-based paste. Besides, the authors added several graphene nanoplatelets (GNPs) along with a reactant (resorcinolformaldehyde (R-F) solution) to induce gelation post-printing via organic sol-gel chemistry. GNPs and $\mathrm{SiO}_{2}$ concentrations ranged from 0 to $16.7 \mathrm{wt} \%$ for both materials. The results demonstrated that the apparent viscosity of as-prepared composite paste (GO-GNP) shows orders of magnitude higher than that of the GO suspension; moreover, both of them were shear-thinning non-Newtonian fluids. Also, both the storage modulus and yield stress of pure GO ink increase by over one order of magnitude by the addition of the GNP and silica fillers [29]. The magnitudes of these key rheological parameters are in good agreement with those reported for other colloidal inks designed for DIW. After printing, the structure was then processed by gelation, freeze-drying or supercritical-drying, and etching of the silica with hydrofluoric acid, and the 3D graphene aerogel (GA) was finally fabricated [29]. Although in this work efforts were made to avoid the addition of polymer additives, the inclusion of silica did not completely solve this problem, since a reactant was still used for gelation of the paste. 

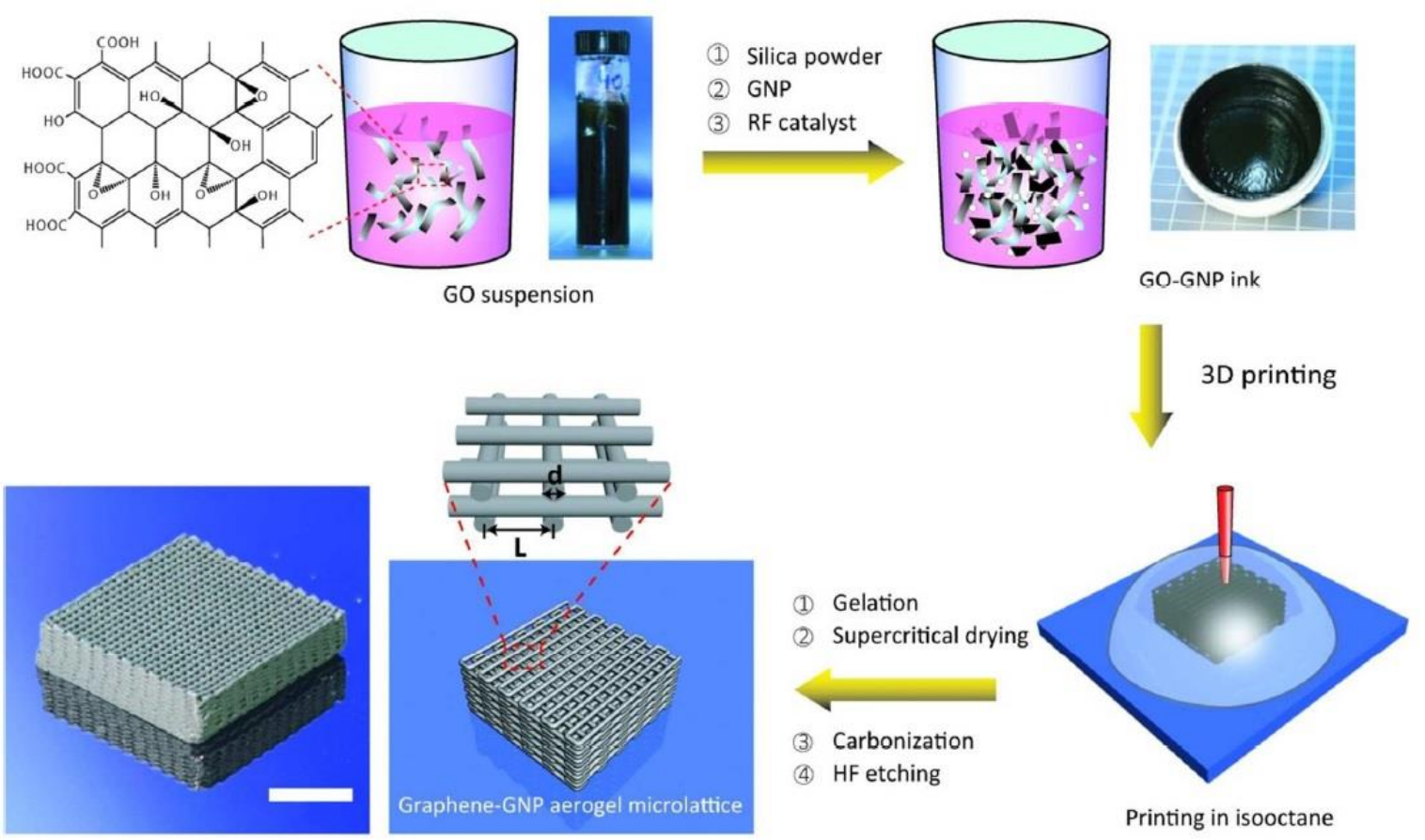

Figure 20. Schematic diagram part fabrication process: Mixing of $\mathrm{SiO}_{2}$, GNPs and R-F with the aqueous GO suspension. Then, the as-prepared GO paste was extruded in an isooctane bath, and the as-obtained part was gelled at $85^{\circ} \mathrm{C}$, then dried using supercritical carbon dioxide. Finally, the silica fillers were etched using diluted hydrofluoric acid. Scale bar is $10 \mathrm{~mm}$. Reprinted with permission from [155]. Copyright (2016) American Chemical Society.

Another approach to preparing pastes with appropriate rheological properties for ceramic/graphene composites manufacturing by DIW could be the use of preceramic polymers (PCP) [295]. Preceramic polymers are polymeric compositions, especially in the form of organo-silicon compounds (e.g., polymers based on a backbone of $\mathrm{Si}$ atoms containing also C, O, N, B and H atoms), which by heat treatment (pyrolysis) above $\sim 800{ }^{\circ} \mathrm{C}$ and under non-oxidative atmosphere (nitrogen or argon) are transformed into ceramic materials, also referred to as polymer derived ceramics (PDCs) [296]. The addition of PCPs into the graphene-based feedstock can modify the composition/phase, structures and properties of the final product after heat treatment [13].

Pierin et al. [297] reported a method for the manufacturing of micro-sized SiOC ceramic components by DIW using a preceramic polymer. The suitable rheological behavior of pastes was obtained by mixing cross-linked preceramic particles with a siloxane resin dissolved in a solvent. Moreover, the addition of a low amount $(0.025-0.1 \mathrm{wt} \%)$ of GO to the paste formulation improves the structural stability during pyrolysis reducing the shrinkage of the preceramic polymer. The resulting parts after pyrolysis at $1000{ }^{\circ} \mathrm{C}$ showed good compression strength, of $\sim 2.5 \mathrm{MPa}$ for a total porosity of $\sim 64 \mathrm{vol} \%$ ( $\sim 3.1 \mathrm{MPa}$ after the addition of $0.1 \mathrm{wt} \%$ graphene oxide).

Zhong et al. first developed GO/geopolymer (GOGP) nanocomposite structures fabricated by DIW, figure 21 [285]. The authors noted that the addition of GO in the geo-polymeric aqueous mixture (aluminosilicate and alkaline-source particles) intensely changes its rheology properties, and enable the DIW that cannot be realized solely by geo-polymer. Paste preparation involves the obtaining of geo-polymeric suspension by mixing of alkaline-source particles and aluminosilicates particles (ASOPs) in water. After stirring for $20 \mathrm{~min}$, suspensions with diverse amounts of GO $(4,5,10$, and 20 $\mathrm{wt} \%$ ) were added into the as-prepared geo-polymeric suspension at a temperature below $5{ }^{\circ} \mathrm{C}$. This low. temperature avoids the geo-polymerization and the GO reduction that could happen at relatively elevated temperatures and would cause the agglomeration of nanoparticles. When GO is added into geo-polymeric suspension, the rheological behaviors of the mixture change dramatically. 
For the GOGP with $4 \mathrm{wt} \%$ of GO the storage ( $\left.\mathrm{G}^{\prime}\right)$ and loss modulus ( $\left.\mathrm{G}^{\prime \prime}\right)$ increased to $\sim 1 \times 10^{5} \mathrm{~Pa}$ and $\sim 1.5 \times 10^{4} \mathrm{~Pa}$ (at the stress of $50 \mathrm{~Pa}$, that is typically used in DIW), which are more than one and two orders of magnitude higher than the corresponding values of pure geopolymer, respectively. Moreover, the shear yield stress is as high as $2000 \mathrm{~Pa}$. Upon increasing the GO load to $5 \mathrm{wt} \%$ of GO, storage modulus increased further, while the shear yield stress decrease to 1000 Pa. However, for the nanocomposites with even higher GO loading (10, and $20 \mathrm{wt} \%)$, the modulus decreases, which is probably related to the lubrication effects of GO. The characterization of cured parts showed that GO nanosheets anchored themselves in geo-polymer and encapsulated individual geo-polymer grains, Figure 22 [285], to resist being pullout and at the same time, form a continuous 3D network throughout the whole nanocomposites. The as-obtained cured parts showed high mechanical properties (compressive strength $>30 \mathrm{MPa}$ ), while after sintering at $1000{ }^{\circ} \mathrm{C}$ the parts achieved a conductivity of $10^{2} \mathrm{~S} / \mathrm{m}$.

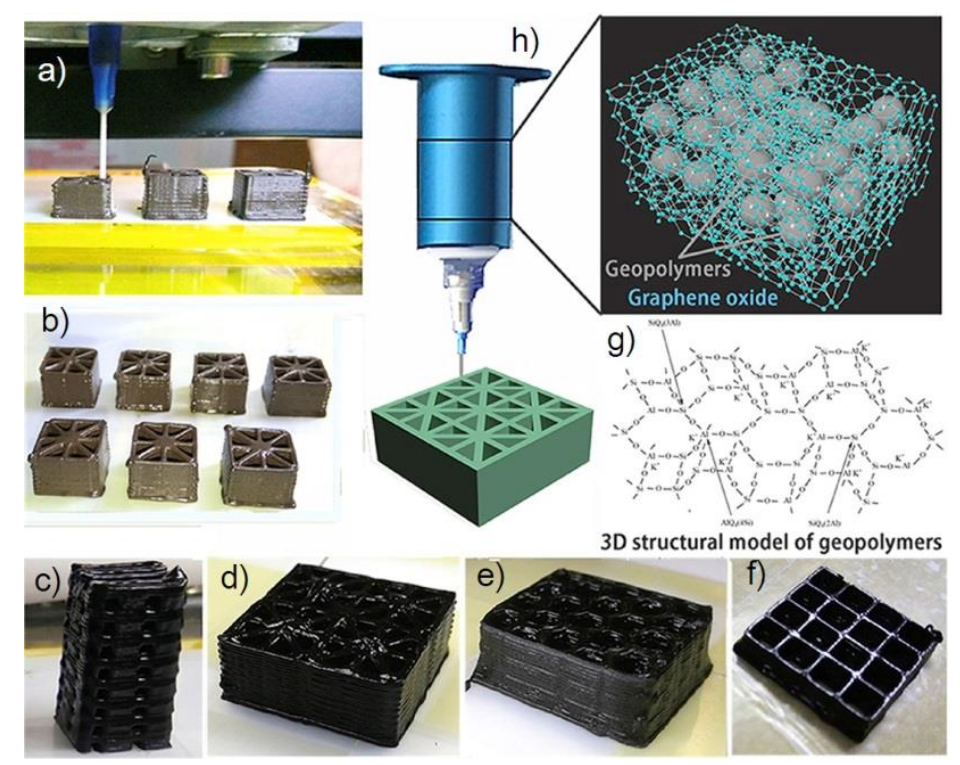

Figure 21. (a-f) 3D printing process and some 3D printed structures. (b-f) The colors of the printed samples turn from brownish to blackish when the GO loading increased. $(\mathrm{g})$ The chemical structure of geopolymer, and $(\mathrm{h})$ shematic diagrams of the ptinting process and the composite structure are also showed. Reprinted from Publication [285], Copyright (2017), with permission from Elsevier. 


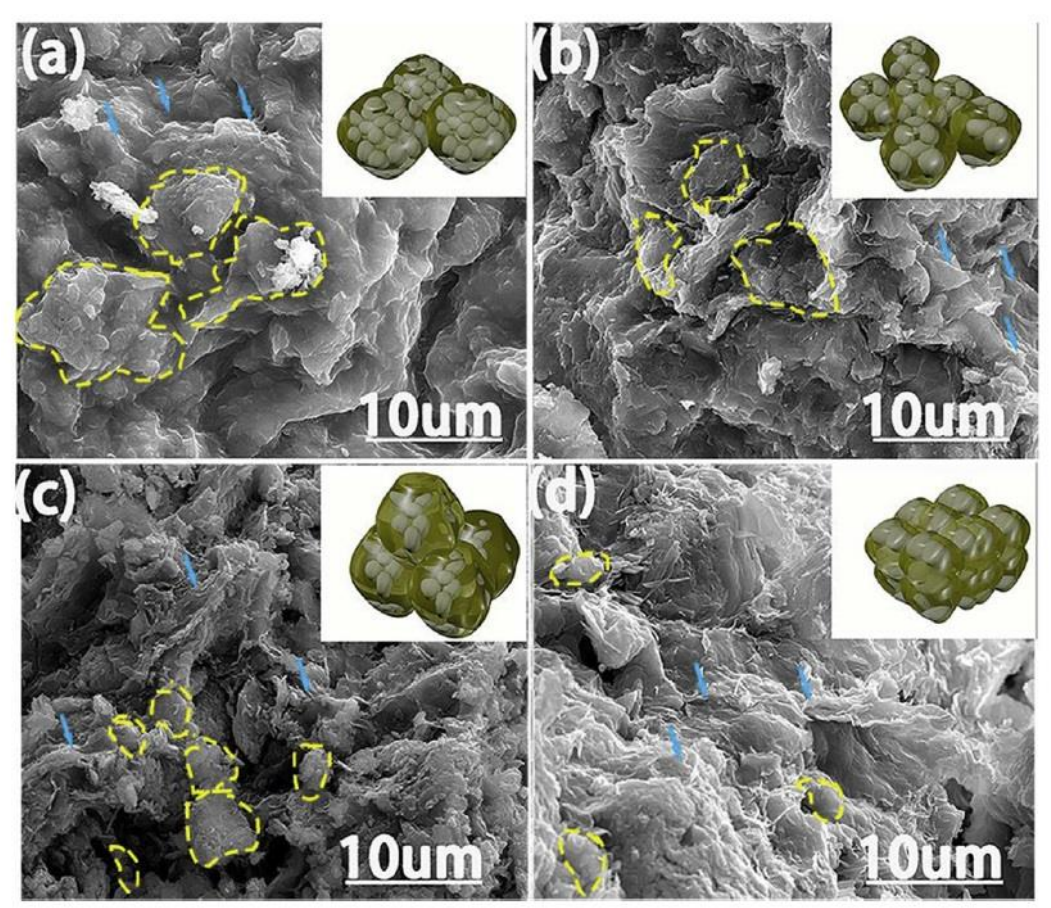

Figure 22. SEM images (a-d) and the corresponding models for the illustration of hydrated geopolymer particles encapsulation by GO layers. As the loading of GO in nanocomposite increased from $4 \mathrm{wt} \%$ to $20 \mathrm{wt} \%$, the size of the particle agglomerate (marked by dotted-line circles) that encapsulated within GO films decrease. Reprinted from Publication [285], Copyright (2017), with permission from Elsevier.

In the state of the art of graphene-based ceramic 3D printed composites using preceramic polymers, interesting methods, which differ from the above examples in the way that ceramic phase is introduced in the 3D part, can be found. Commonly in these solutions, a 3D graphene-based part is first manufactured by DIW; then, it is heated for polymer removal followed by an infiltration step of a ceramic precursor [298-300].

Román-Manso et al. [298] developed an approach to manufacture PDC/GO composites. In this low-temperature method, the first 3D structures were fabricated by DIW using an aqueous GO paste with polymeric additives. After printing, the GO periodic structures were oven-dried at $\sim 80^{\circ} \mathrm{C}$ and immediately afterward frozen in a refrigerator at $-20{ }^{\circ} \mathrm{C}$. This partial drying step helps eliminate water that would cause a network of evenly spaced cracks in the structures during freezing. Subsequently, the as-prepared GO structures were lyophilized to sublimate the ice. Finally, highly porous 3D structures were impregnated by immersion in a liquid organic-polysilazane (a compound of $\mathrm{Si}, \mathrm{C}, \mathrm{H}, \mathrm{N}$ ) during several hours to assure the penetration of the liquid within the structure rods. The impregnated scaffolds were held onto a Pt foil in alumina crucibles and treated in a tubular electric furnace at $200{ }^{\circ} \mathrm{C}$ for crosslinking and, afterward, pyrolysis at $800-1000{ }^{\circ} \mathrm{C}$ under a continuous $\mathrm{N}_{2}$ flow during the whole cycle. Figure 23a displays an image of the as printed GO structure and the composite structure after the pyrolysis treatment $\left(800^{\circ} \mathrm{C}\right)$ evidencing the shape retention and the strong shrinkage experienced by the self-supported structure.

Figure $23 \mathrm{~b}$ and c display top views of a lyophilized GO lattice at different magnifications. The quick-drying treatment, previous to the lyophilization, produced a linear shrinkage of the structures. Figure $23 \mathrm{~d}-\mathrm{f}$ show printed GO structures after the complete infiltration. No substantial cracking (Figure $23 \mathrm{~d}$ and e) is detected in the infiltrated structures after pyrolysis $\left(800-1000{ }^{\circ} \mathrm{C}\right)$. These PDC/GO composites imitate the patterned GO skeleton and, whereas the graphene network provides the conductive path for the composite (electrical conductivity in the range $0.2-4 \mathrm{~S} / \mathrm{cm}$ ). The ceramic coating serves as a protective barrier for the graphene network against the atmosphere, temperature (up to $900{ }^{\circ} \mathrm{C}$ in the air) and even direct flame. 
Similar work was carried out by Moyano et al. [299], in which they studied the electrical, mechanical and capacitive responses of a strong and light 3D ceramic/graphene structure obtained through a controllable and fast infiltration method using a preceramic polymer.
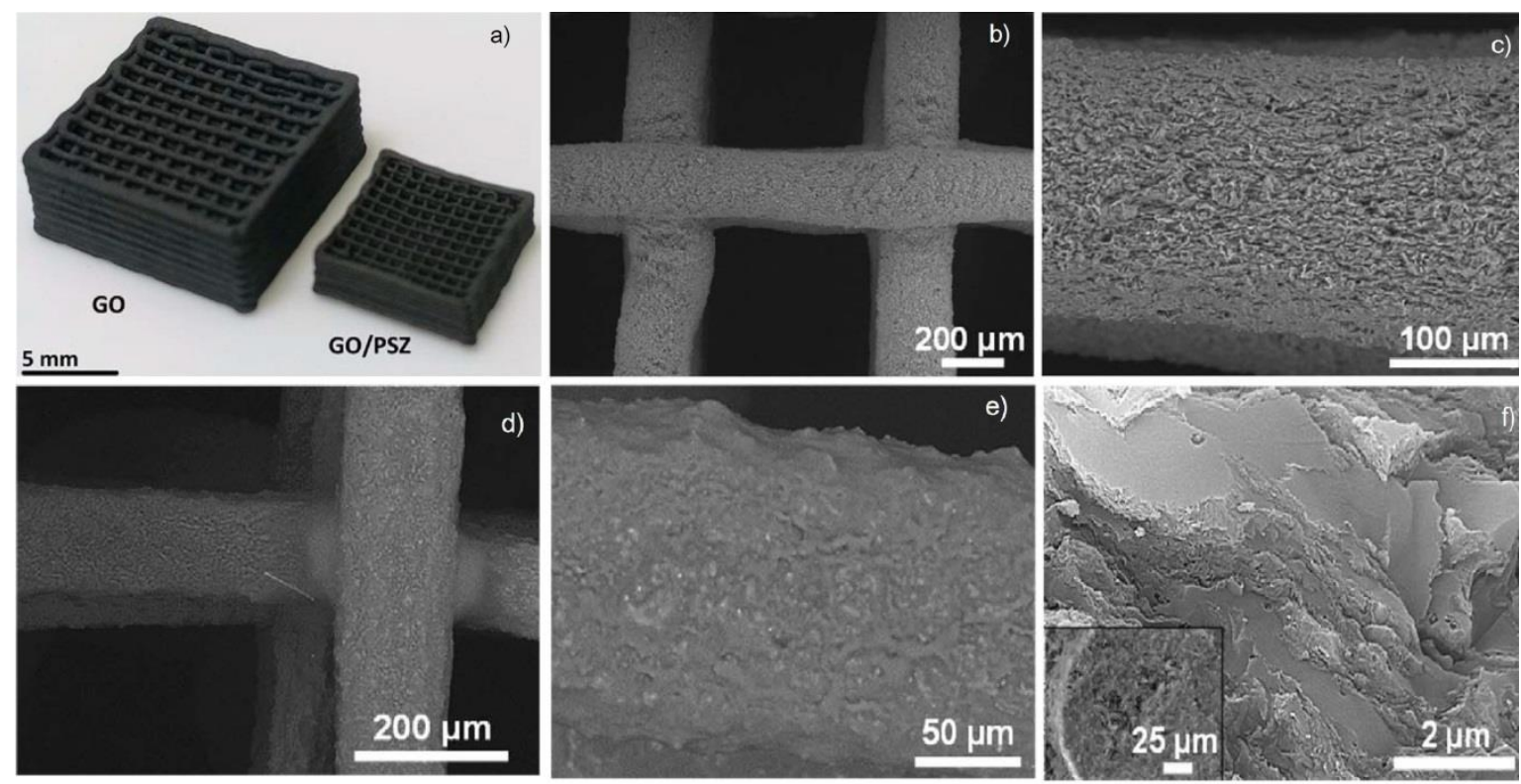

Figure 23. (a) 3D printed scaffolds of GO (as-printed) and the composite structure GO/PSZ pyrolyzed at $800{ }^{\circ} \mathrm{C}$. SEM micrographs of a GO lattice after dying/lyophilization steps showing a top view (b) and the surface of an extruded filament (c). Analogous SEM images of a PSZ infiltrated GO lattice pyrolyzed at $800{ }^{\circ} \mathrm{C}$ in $\mathrm{N}_{2}$, (d) top view, (e) filament and (i) cross section at different magnifications. Reprinted from Publication [298], Copyright (2018), with permission from Elsevier.

Another interesting approach was reported by You et al. [300]. In this work, the authors proposed a method for the in-situ growth of $\mathrm{SiC}$ in 3D printed graphene scaffolds by chemical vapor infiltration (CVI). The scaffolds were fabricated using a well-dispersed graphene-based suspension, which was prepared by adding graphene to ethylene glycol butylether (EGB) in ethanol, followed by sonication and addition of dibutyl phthalate (DBP) and polyvinyl butyral (PVB). Next, the ethanol was evaporated in a water bath at $80^{\circ} \mathrm{C}$ with continuous stirring. The as-prepared suspension had a graphene concentration of $200 \mathrm{mg} / \mathrm{mL}$. After, the graphene scaffolds were printed using the asprepared paste. Subsequently, the printed objects were placed in a carbon tube furnace under the Ar atmosphere and heated to $1100{ }^{\circ} \mathrm{C}$ for thermal decomposition of organic-polymer. The polymer decomposition allows a large specific surface area of the scaffold that is beneficial for promoting the in-situ growth and densification of the $\mathrm{SiC}$. Thus, the $\mathrm{SiC}$ matrix was introduced into the pores of the 3D graphene scaffold by cracking methyltrichlorosilane (MTS) in the CVI process. The content and morphology of the $\mathrm{SiC}$ in the composite were controlled by adjusting the holding time and gas pressure, which are the main CVI parameters. Finally, the 3D graphene/SiC composites exhibit outstanding mechanical performance, delivering a maximum compressive strength of $193 \pm 15.7 \mathrm{MPa}$, which is $394 \%$ higher than that of the directly mixed product. Besides, the combination of the 3D graphene scaffold and $\mathrm{SiC}$ matrix generates a larger number of conductive channels and provides a material that outperforms traditional ceramic materials in terms of electrical conductivity.

Unfortunately, in these last three examples, it is not possible to directly obtain a 3D printed part from which a graphene-based/ceramic composite is obtained after sintering. In these examples, an additional step of ceramic material infiltration into the graphene skeleton is necessary.

As we have seen in this section, each of the discussed methods includes a preparing step of the graphene-based paste that requires at least the presence of an additive, which is mainly utilized to guarantee a homogeneous dispersion and to achieve the suitable viscoelastic properties. In the majority of cases, the additives are eliminated either by a chemical etching or a thermal process at 
high temperatures, which causes the appearance of pores in its structure that can negatively influence in the composite mechanical properties.

In recent years, attempts have been made to find new methods to minimize the presence of additives in graphene-based paste formulations for DIW. For example, García-Tuñón et al. [30] developed a clean, flexible and robust approach to formulating pastes used in DIW that can be adapted to a wide range of materials. Thus, they prepared free additive pastes of diverse materials (polymer, ceramic and metal), based only on the use of GO as the dispersant, rheological modifier, and binder. This procedure was possible to realize thanks to the great similarities between GO and clay. Both exhibit a flake-like shape with different functionalities on their edges and faces that result in the formation of particle networks connected by electrostatic interactions for clay and noncovalent interactions for GO. The unique structure and chemistry of clay permit the formulation of waterbased suspensions with ideal viscoelastic behaviour for shaping. For this reason, clay is used as an additive in suspensions of other materials to provide the right viscoelastic behavior for processing. On the other hand, as for clay, the especial combination of GO sheets surface chemistry and structure in contact with water under special conditions allow the preparation of a very stable GO paste with proper viscoelastic behaviour for a wide range of materials with different chemistries, particle morphologies (from particles, platelets, and fibers to microspheres), and sizes (from nanometers to tens of micrometers). In this research, various kinds of graphene-based paste with ceramic $\left(\mathrm{Al}_{2} \mathrm{O}_{3}\right.$ powders and platelets, $\mathrm{SiC}$ powders) were prepared and, then, used for the printing of ceramic parts. The increases of the paste concentration were reached by two different approaches: 1 - redispersing freeze-dried GO powders and 2 - by water evaporation in an oil bath at $70{ }^{\circ} \mathrm{C}$. In both cases, concentrated GO pastes with good behavior for printing without the need of any other additive were obtained. Moreover, to tune viscoelasticity and flow, the additional freeze-dried powder was in some cases added to achieve the desired rheological behavior. In detail, the ceramic pastes reported in this work had the following concentrations: 1) $28.4 \mathrm{vol} \% \mathrm{SiC}$ with $0.4 \mathrm{vol} \% \mathrm{GO}(10 \mathrm{mg} / \mathrm{mL}), 2) 23 \mathrm{vol} \%$ $\mathrm{Al}_{2} \mathrm{O}_{3}$ platelets $(0.8 \mathrm{vol} \% \mathrm{GO}(23 \mathrm{mg} / \mathrm{mL}))$ and 3) $27 \mathrm{vol} \% \mathrm{Al}_{2} \mathrm{O}_{3}$ platelets $(1.1 \mathrm{vol} \% \mathrm{GO}(33 \mathrm{mg} / \mathrm{mL})$.

The authors found that GO suspensions with a concentration above $\sim 2 \mathrm{vol} \%$ lead to a rapid rise of the solid-like component ( $G^{\prime}$, Figures $24 a$ and $b$, [30]) due to the formation of a well-established and organized structure (Figure 24d, [30]). As the slurry becomes more concentrated, GO flakes arrange, forming a network, similar to a liquid crystal. The increase in concentration results in a considerable increase of the elastic response with storage modulus $\left(\mathrm{G}^{\prime}\right)$ values up to $100 \mathrm{kPa}$ (for 3.5 vol \% GO, Figure 24b, [30]) as well as an exponential increase of the yield stress up to $2300 \mathrm{~Pa}$ (Figure 24c, [30]). Besides, GO additive-free pastes with concentrations between $\sim 2.5$ and $3.5 \mathrm{vol} \%$ (prepared either by redispersing freeze-dried GO powders or by evaporation) displayed the rheological properties and structure needed for robocasting. 
a)

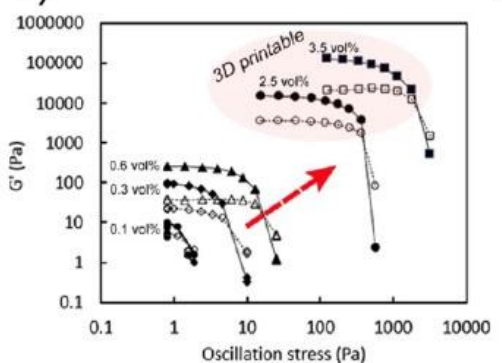

b)

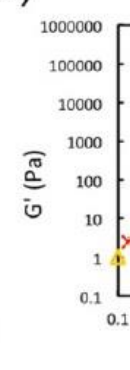

c)

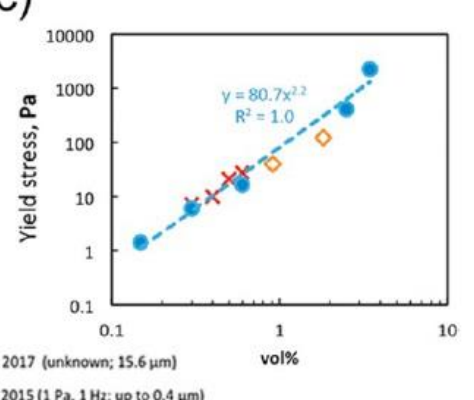

d)
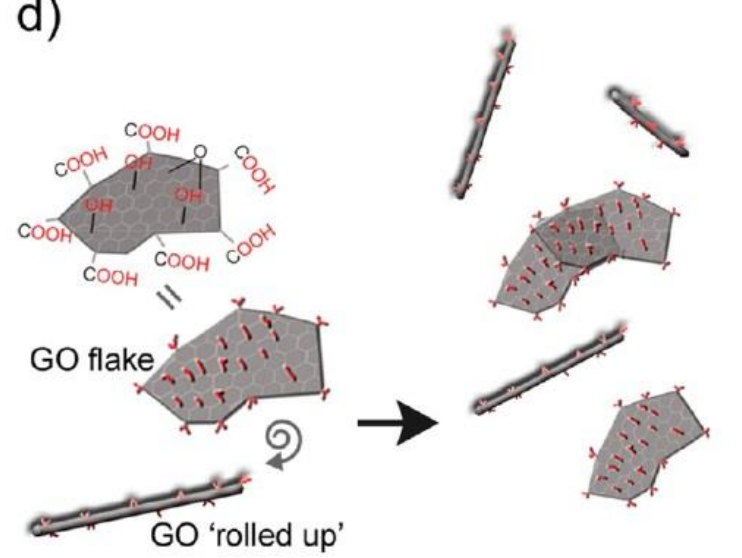

$\begin{array}{ll}\text { vol \% } & \square \text { Wenbo ti et al } 2017 \text { (unknown; } 15.6 \mu \mathrm{m}) \\ & \triangle \text { Cheng zu et al } 2015 \text { (1 Pa, } 1 \mathrm{~Hz} ; \text { up to } 0.4 \mathrm{\mu m}) \\ & \Delta \text { c Valles et al } 2014(0.1 \%, 0.16 \mathrm{~Hz} ; 0.6 \mathrm{~mm})\end{array}$
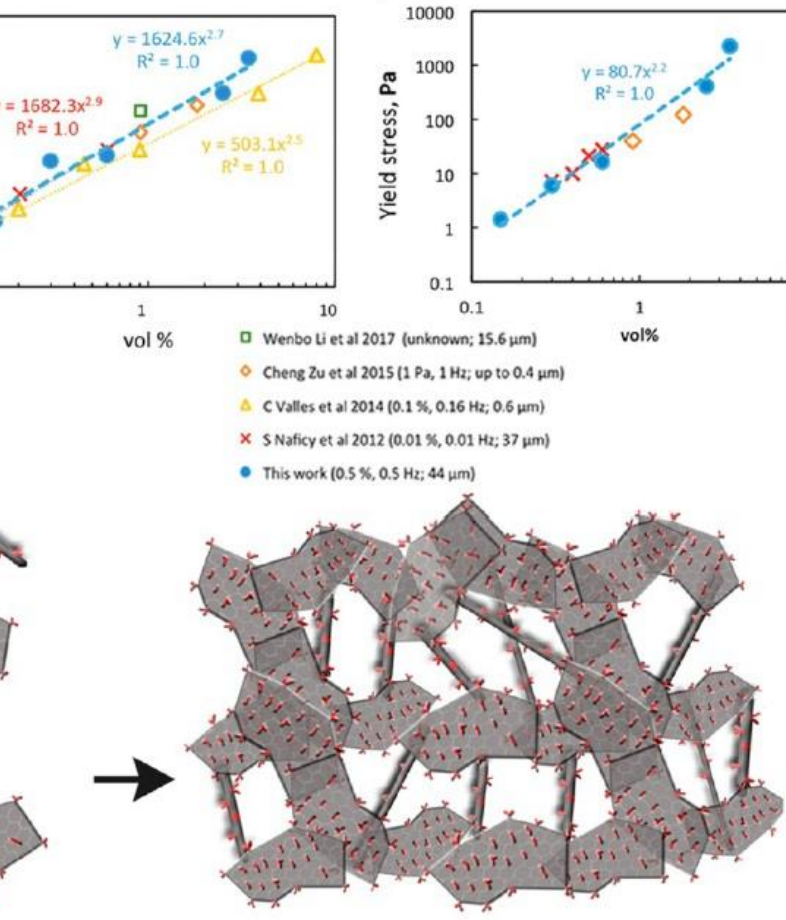

Figure 24. Viscoelastic properties for GO suspensions and pastes: fingerprints (a) and effect of GO concentration on $\mathrm{G}^{\prime}$ (storage modulus, b) and yield stress (c). The more concentrated systems are printable (labeled 3D-printable in "a"). Schematic showing the proposed assembly of GO flakes in water as concentration increases. (d) Some of the GO flakes roll up, forming graphene oxide scrolls; both assemble into a 3D liquid crystal structure with a strong elastic response "a". Reprinted with permission from [30]. Copyright (2017) American Chemical Society.

For the $\mathrm{Al}_{2} \mathrm{O}_{3}$ platelets pastes, the best printing behavior was found for a mixture of $\sim 28 \mathrm{vol} \%$ platelets with $1.1 \mathrm{vol} \% \mathrm{GO}$ (Figure 25, [30]). Also, during extrusion an orientation of platelets and the formation of the internal architecture of the printed objects took place. Cross-sections and lateral views of printed filaments (Figures 25c and d respectively, [30]) show how the platelets arrange on the outside edge forming a wall, while the inside has a mixture of domains (Figures 25c and d respectively, [30]). After a close-up observation, GO flakes appear to have a strong interaction with the platelets, spreading over and across the surfaces of multiple $\mathrm{Al}_{2} \mathrm{O}_{3}$ platelets, binding them together and forming bridges across them. After sintering, the structures made with GO had an average porosity of $60 \%$ with only $2 \%$ closed pores and showed good handling strength. 


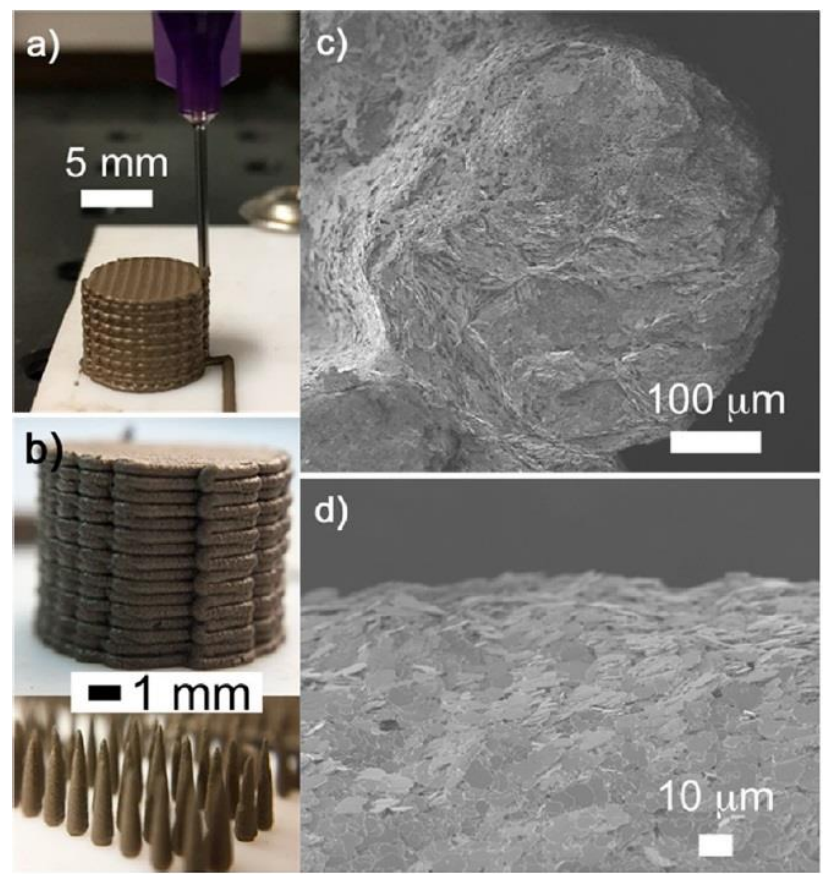

Figure 25. Printing alumina platelets using GO as the only additive: (a and b) 3D printed objects (cylinders and micro pillars) and mesoscale FESEM images (c and d). (c) Cross section of the printed filaments showing domains with random orientation in the middle and (d) external arrangement of the platelets on the surface of the filament due to the extrusion process. Reprinted with permission from [30]. Copyright (2017) American Chemical Society. 


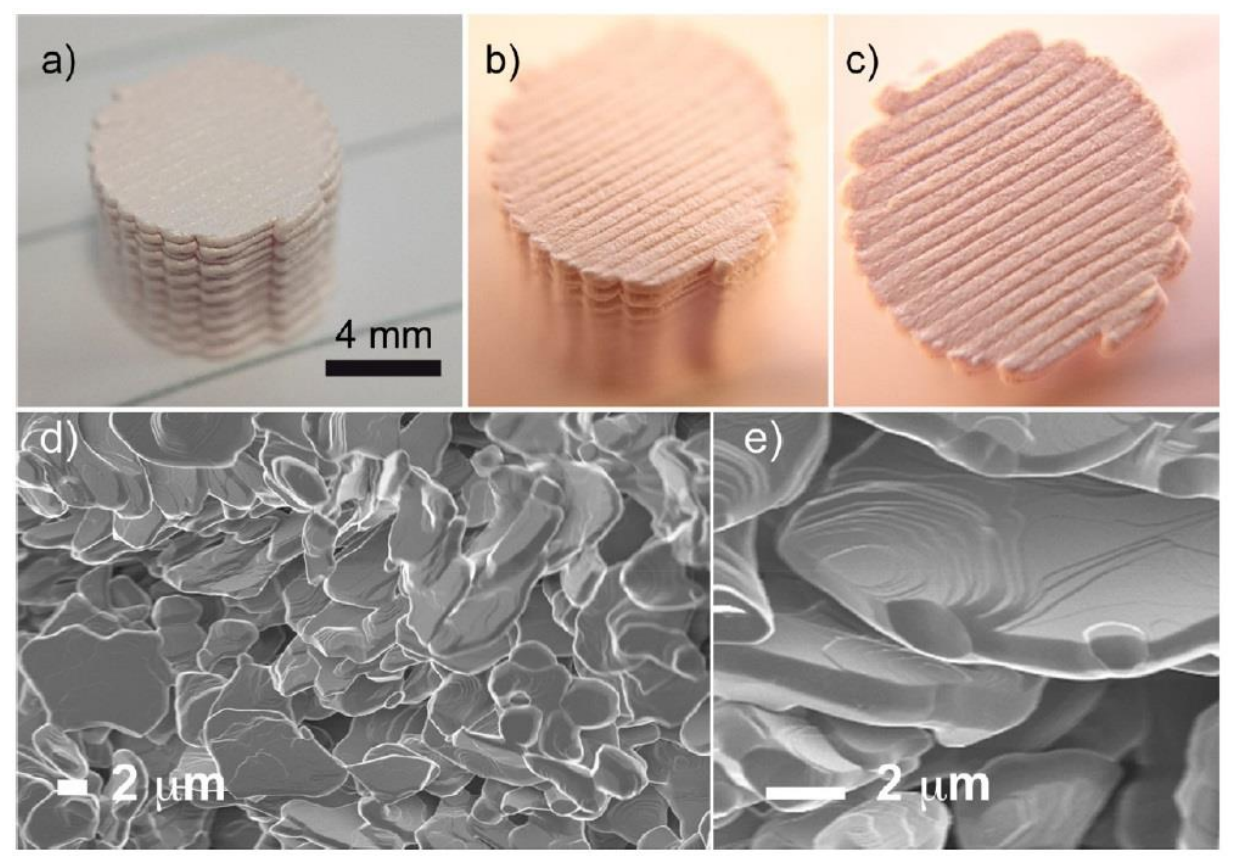

Figure 26. Structural characterization at multiple scale lengths of a $3 \mathrm{D}$ printed cylinder made with an $\mathrm{Al}_{2} \mathrm{O}_{3}$ platelets/GO paste after sintering at $1550{ }^{\circ} \mathrm{C}$. $(\mathrm{a}-\mathrm{c})$ Macroscopic images showing the external structure of the cylinder that preserves the morphological features of the printed filaments (side (a), angled (b), and top (c) views). The GO burn out results in a weight loss of $\sim 3 \mathrm{wt} \%$. The bulk volume is subjected to a homogeneous shrinkage of $\sim 4 \%$ after sintering. ( $\mathrm{d}$ and e) SEM images of the internal microstructure with open porosity of 60\% calculated using an Archimedes kit. GO also enhances the sintering between platelets (d). Reprinted with permission from [30]. Copyright (2017) American Chemical Society.

The SiC paste also showed suitable printing behavior. Dried 3D printed bars had strengths of $\sim 1 \mathrm{MPa}$, proving that $\mathrm{GO}$ is also acting as a binder of $\mathrm{SiC}$ surfaces. Sintered $\mathrm{SiC}$ bars $\left(2050^{\circ} \mathrm{C}\right.$ for $2 \mathrm{~h}$ ) have a final density of $3.21 \mathrm{~g} / \mathrm{cm}^{3}(96.4 \%$ of the theoretical) and bending strengths of $\sim 212 \mathrm{MPa}$.

In both cases, $\mathrm{XRD}$ analysis after sintering confirms that $\mathrm{Al}_{2} \mathrm{O}_{3}$ and $\mathrm{SiC}$ were the only crystalline phase, and no carbon bands were identified with Raman spectroscopy. Note that, GO can be either subsequently eliminated or retained during the postprocessing steps, thus potentially adding structural or functional properties to the final part.

Summarizing, this approach enables printing complex 3D ceramic structures using robocasting with similar properties to alternative formulations, thus demonstrating the potential of using $2 \mathrm{D}$ colloids in materials manufacturing.

\section{Summary}

In this review, it was shown that significant advances in additive technologies for 3D printing of graphene-based ceramic composites have been made in recent years. The state of the art of different additive techniques used for the manufacturing of both ceramic and graphene-based pieces was analyzed. In addition, various examples of 3D printing of graphene-based ceramic composites were discussed in detail.

First, a summary of existing additive technologies groups, techniques that are involved with them, and of the most popular feedstock nowadays was made, (see Table 1). After that, it was clear that not all AM technologies apply to the ceramic part manufacturing and even more for the graphene-based materials.

The introduction of Additive Manufacturing to the production of ceramics is related to the need to obtain complex structures that are impossible to realize using conventional methods since $3 \mathrm{D}$ printing can manufacture complex structures in a fast, simple and inexpensive way. With the aim of 
a better understanding, the AM technologies used in ceramic production were divided into 3 groups (powder-, slurry - and bulk solid-based) taking into account the type of feedstock used. The state of the art of AM technologies that are involved with these groups has been discussed in detail and illustrated with representative examples. Moreover, several historical facts about each technique were given.

The techniques (SLS, SLM, and BJ.) are involved in the group of powder-based technologies for the manufacture of 3D ceramic parts. SLS and SLM have a low surface finish, undesirable porosity, and high shrinkage of parts that limit their application in many fields. Besides, the thermal gradients and the high heating and cooling rates in the ceramic material produce cracks and distortions that are not desired in the final part. On the other hand, in BJ the formation of pores and the contraction of parts are related to the elimination of the binder used in the process. In BJ the mechanical properties of parts are affected by pore formation, despite this, this technique is a good method used in biomedical fields for the ceramic scaffold production.

The liquid-based group includes the SLA, DLP, TPP and IJP techniques. These methods proved to be more promising than the powder-based ones as they can achieve high resolution, good surface finish and required mechanical properties. Unfortunately, the high cost of the machines and the photopolymers that are necessary for the manufacture of parts limit their wide application in the industry. Furthermore, the working principle of TPP allows only the use of transparent polymers; i.e. the opaque polymers that were usually utilized in SLA and DLP are not applicable for TPP. On the other hand, IJP is limited only to the production of miniaturized parts due to the low ink volume used in each droplet.

In the third group are LOM, FDM and DIW techniques. In recent years, great development of the LOM technique has not been observed and its application has been restricted only for the manufacture of ceramic parts with simple geometry, and large sizes. On the contrary, FDM and DIW have found a great application in the manufacture of macro-pore structures for the biomedicine application as the production of scaffolds.

AM techniques have also been used for 3D printing of graphene-based materials thanks to the combination of its properties with the advantages of slurry-based methods and techniques that use a pseudoplastic feedstock. Additionally, the choice of such technologies is related to the fact that graphene oxide, the main precursor of graphene, can be easily dispersed in water and other solvents, which is not possible with graphene. Among the most used methods for printing graphene-based material, we can find SLA, IJP, FDM, and DIW techniques.

The SLA method has been utilized to manufacture polymer-based composites that are used in the production of scaffolds in biomedicine. On the other hand, IJP is one of the most used techniques in the printing of graphene-based materials despite the low resolution and limitations that it presents. It is possible to found polymer-based filaments with graphene fillers for FDM that are used in the production of parts for biomedicine or in electronics and other areas of application. The disadvantage of this method is its low precision and the quality of the surface.

DIW is the most studied technique and one of the most widely used for the manufacture of 3D parts from a graphene-based feedstock thanks to the combination of the great possibilities of DIW with the unique properties of graphene that has demonstrated remarkable printing capabilities with unique viscoelastic properties. For DIW, the rheology of the suspension is very important, so it is essential to establish the appropriate content of the components to obtain their homogeneous dispersion. After the part is printed, a subsequent process is necessary for the removal of the solvent, which leads to the appearance of pores in the structure. Similar structures are widely used in the production of biomaterial scaffolds and energy storage fields.

Finally, a detailed study with some examples of printed composites from graphene-based ceramic pastes by DIW is carried out. In this field, there is a tendency to reduce the number of additives that are used for obtaining a homogeneous dispersion and very often produce undesired effects. Some examples show that it is possible the use preceramic polymers for the reduction of additives and to perform the characteristics of printed composites. Of great importance is the work carried out to create ceramic pastes without any other additives than graphene oxide. Here it is 
appreciated how this material can be used as a dispersant, rheological modifier and binder at the same time.

This work has tried to show that the DIW method is very promising in the printing of complex graphene-based ceramic composites at reduced cost and in less time. We consider that this field should continue to develop so that soon the manufacture of graphene-based ceramic composites will take its place in the ceramic industry.

Author Contributions: Conceptualization, N.W.S.P., A.S.; data curation, N.P., A.Se.; formal analysis, N.W.S.P., N.P.; funding acquisition, P.P.; investigation, P.P., N.P.; methodology, A.S., N.W.S.P.; project administration, N.W.S.P., P.P.; resources, N.W.S.P., N.P.; software, P.P., A.Se.; supervision, N.W.S.P., A.S.; validation, A.Se., N.P.; visualization, P.P., A.S. ; writing - original draft, N.W.S.P., A.S.

All authors read and approved the final version of the manuscript.

Funding: We would like to thank the Russian Science Foundation for supporting this work under grant 19-7900355.

Conflicts of Interest: The authors declare no conflict of interest.

\section{References}

[1] Kingery, W.D.; Bowen, H.K.; Uhlmann, D.R. Introduction to Ceramics, second edition. Wiley, NewYork (1976), pp. 1-1056.

[2] C.B.; Norton, M.G. Ceramic Materials: Science and Engineering. Springer New York (2013), pp. 1-766.

[3] Smirnov, A.; Kurland, H.-D.; Grabow, J.; Müller, F.A.; Bartolomé, J.F. Microstructure, mechanical properties and low temperature degradation resistance of $2 \mathrm{Y}$-TZP ceramic materials derived from nanopowders prepared by laser vaporization. J. Eur. Ceram. Soc. 2015, 35, 2685-2691.

[4] Smirnov, A.; Beltrán, J.I.; Rodriguez-Suarez, T.; Pecharromán, C.; Muñoz, M.C.; Moya, J.S.; Bartolomé, J.F. Unprecedented simultaneous enhancement in flaw tolerance and fatigue resistance of zirconia-Ta composites. Sci. Rep. 2017, 7, 44922.

[5] Smirnov, A.; Bartolomé, J.F.; Kurland, H.-D.; Grabow, J.; Müller, F.A. Design of a new zirconia-alumina-Ta micro-nanocomposite with unique mechanical properties. J. Am. Ceram. Soc. 2016, 99, 3205-3209.

[6] Bartolomé, J.F.; Smirnov, A.; Kurland, H.-D.; Grabow, J.; Müller, F.A. New $\mathrm{ZrO}_{2} / \mathrm{Al}_{2} \mathrm{O}_{3}$ Nanocomposites Fabricated from Hybrid Nanoparticles Prepared by CO2 Laser Co-Vaporisation. Sci.Rep. 2016, 6, 20589.

[7] Microstructure and Mechanical Properties of $\mathrm{ZrO}_{2}$ Ceramics Toughened by 5-20 vol\% Ta Metallic Particles Fabricated by Pressureless Sintering. Ceram. Int. 2014, 40, 1829-1834.

[8] Gutierrez-Gonzalez, C.F.; Smirnov, A.; Bartolomé, J.F. Cyclic Fatigue Life- and Crack-Growth Behavior of Zirconia-Niobium Composites. J. Am. Ceram. Soc. 2013, 96, 1709-1712.

[9] Bengisu, M. Engineering Ceramics. Springer-Verlag Berlin Heidelberg (2001), pp. XXI, 620.

[10] Richerson, D.W.; Lee, W.E. Modern Ceramic Engineering: Properties, Processing, and Use in Design, fourth edition. CRC Press (2018), pp. 1-791.

[11] Fang, Z.Z. Sintering of Advanced Materials; fundamentals and processes. Woodhead Publishing (2010), pp. $1-483$.

[12] Pristinskiy, Y.; Solis Pinargote, N.W.; Smirnov, A. The effect of MgO addition on the microstructure and mechanical properties of alumina ceramic obtained by spark plasma sintering. In Materials today: proceedings (2019), 19 (5), 1990-1993.

[13] Chen, Z.; Li, Z.; Li, J.; Liu, C.; Lao, C.; Fu, Y.; Liu, C.; Li, Y.; Wang, P.; He, Y. 3D printing of ceramics: A review. J. Eur. Ceram. Soc. (2019), 39 (4), 661-687.

[14] Abdulhameed, O.; Al-Ahmari, A.; Ameen, W.; Mian, S.H. Additive manufacturing: Challenges, trends, and applications. Advances in Mechanical Engineering (2019), 11 (2), 1-27. 
[15] Gibson, I.; Rosen, D.; Stucker, B. Additive manufacturing technologies: 3D printing, rapid prototyping, and direct digital manufacturing, second edition. Springer New York (2015), pp. 1-498.

[16] International Organization for Standardization. ISO/ASTM 52900:2015 [ASTM F2792] Additive manufacturing - General principles - Terminology. Geneva: ISO; 2015.

[17] Shashi, G.M.; Laskar, M.A.R.; Biswas, H.; Saha, A.K. A Brief Review of Additive Manufacturing with Applications Proceedings of 14th Global Engineering and Technology Conference 29-30 December 2017. Dhaka, Bangladesh.

[18] Lewis, J.A.; Gratson, G.M. Direct writing in three dimensions. Mater. Today (2004), 7, 32-39.

[19] Martínez-Vázquez, F.J.; Perera, F.H.; Miranda, P.; Pajares, A.; Guiberteau, F. Improving the compressive strength of bioceramic robocast scaffolds by polymer infiltration. Acta Biomater. (2010), 6, 4361-4368.

[20] Lewis, J.A. Direct ink writing of 3D functional materials. Adv. Funct. Mater. (2006), 16 (17), $2193-2204$.

[21] Lewis, J.A.; Smay, J.E.; Stuecker, J.; Cesarano, J. Direct ink writing of three-dimensional ceramic structures. J. Am. Ceram. Soc. (2006), 89 (12), 3599-3609.

[22] Revelo, C.F.; Colorado, H.A. 3D printing of kaolinite clay ceramics using the Direct Ink Writing (DIW) technique. Ceram. Int. (2018), 44 (5), 5673-5682.

[23] Martínez-Vázquez, F.J.; Pajares, A.; Miranda P. A simple graphite-based support material for robocasting of ceramic parts. J. Eur. Ceram. Soc. (2018), 38, 2247-2250.

[24] Ordoñez, E.; Gallego, J. M.; Colorado, H.A. 3D printing via the direct ink writing technique of ceramic pastes from typical formulations used in traditional ceramics industry. Applied Clay Science (2019), 182, 105285.

[25] Ahn, B. Y.; Duoss, E. B.; Motala, M. J.; Guo, X.; Park, S. I.; Xiong, Y.; Yoon, J.; Nuzzo, R. G.; Rogers, J. A.; Lewis, J. A. Omnidirectional Printing of Flexible, Stretchable, and Spanning Silver Microelectrodes. Science (2009), 323 (5921), 1590-1593.

[26] Smay, J. E.; Gratson, G. M.; Shepherd, R. F.; Cesarano, J.; Lewis, J. A. Directed Colloidal Assembly of 3D Periodic Structures. Adv. Mater. (2002), 14 (18), 1279-1283.

[27] Heule, M.; Vuillemin, S.; Gauckler, L. J. Powder-Based Ceramic Meso- and Microscale Fabrication Processes. Adv. Mater. (2003), 15 (15), 1237-1245.

[28] Liu, D.-M. Influence of porosity and pore size on the compressive strength of porous hydroxyapatite ceramic. Ceram. Int. (1997), 23 (2), 135-139.

[29] Wang, J.; Liu, Y.; Fan, Z.; Wang, W.; Wang, B.; Guo Z. Ink-based 3D printing technologies for graphenebased materials a review. Adv Compos Hybrid Mater (2019), 2, 1-33.

[30] García-Tuñón, E.; Feilden, E.; Zheng, H.; D’Elia, E.; Leong, A.; Saiz, E. Graphene Oxide: An All-in-One Processing Additive for 3D Printing. ACS Appl. Mater. Interfaces (2017), 9, 38, 32977-32989.

[31] Lewis, J. A. Colloidal Processing of Ceramics. J. Am. Ceram. Soc. (2000), 83 (10), 2341-2359.

[32] Greil, P. Advanced Engineering Ceramics. Adv. Eng. Mater. (2002), 4 (5), 247-254.

[33] Xu, Z.; Gao, C. Aqueous Liquid Crystals of Graphene Oxide. ACS Nano (2011), 5 (4), 2908-2915.

[34] Liu, Y.; Xu, Z.; Gao, W.; Cheng, Z.; Gao, C. Graphene and Other 2D Colloids: Liquid Crystals and Macroscopic Fibers. Adv. Mater. (2017), 29, 1606794.

[35] Miranzo, P.; Belmonte, M.; Isabel Osendi, M. From bulk to cellular structures-A review on ceramic-graphene filler composites. Journal of the European Ceramic Society (2017), 37 (12), 3649-3672.

[36] Solis Pinargote, N.W.; Peretyagin, P.; Torrecillas, R.; Fernández, A.; Menéndez, J. L.; Mallada, C.; Díaz, L.A.; Moya, J. S. Electrically conductor black zirconia ceramic by SPS using graphene oxide. J Electroceram (2017), 38, 119-124.

[37] Smirnov, A; Peretyagin, P.; Bartolomé, J.F. Processing and mechanical properties of new hierarchical metalgraphene flakes reinforced ceramic matrix composites. J. Eur. Ceram. Soc. (2019), 39 (12), 3491-3497. 
[38] Gutierrez-Gonzalez, C.F.; Smirnov, A.; Centeno, A.; Fernández, A.; Alonso, B.; Rocha, V.G.; Torrecillas, R.; Zurutuza, A.; Bartolomé, J.F. Wear behavior of graphene/alumina nanocomposite. Ceram. Int. 2015, 41, 74347438 .

[39] Cascales, A.; Tabares, N.; Bartolomé, J.F.; Cerpa, A.; Smirnov, A.; Moreno, R.; Nieto, M.I. Processing and mechanical properties of mullite and mullite-alumina composites reinforced with carbon nanofibers. J. Eur. Ceram. Soc. 2015, 35, 3613-3621.

[40] André, J.C.; Le Mehauté, A.; De Witte, O. "Dispositif pour réalizer un modèle de pièce industrielle". Demande de brevet d'invention FR 2567668 filed July 16, 1984.

[41] Hull, C.W. "Apparatus for production of three-dimensional objects by stereolithography". U.S. Patent 4,575,330 filed August 8, 1984, and issued March 11, 1986.

[42] Ngo, T.D.; Kashani, A.; Imbalzano, G.; Nguyen, K.T.Q., Hui, D. Additive manufacturing (3D printing)-A review of materials, methods, applications and challenges. Composites Part B: Engineering (2018), 143, 172-196.

[43] Sachs, E.; Cima, M.; Cornie, J. Three-dimensional printing: rapid tooling and prototypes directly from a CAD model. CIRP Annals-Manufacturing Technology (1990), 39 (1), 201-204.

[44] Marcus, H.L.; Beaman, J.J.; Barlow, J.W.; Bourell, D.L. Solid freeform fabrication powder processing. American Ceramic Society Bulletin (1990), 69 (6), 1030-1031.

[45] Kruth, J. P. Material incress manufacturing by rapid prototyping techniques. CIRP Annals - Manufacturing Technology (1991), 40 (2), 603-614.

[46] Peretyagin, N.Y.; Pristinskii, Y.O.; Kuznetsova, E.V.; Peretyagin, P. Yu.; Seleznev, A. E.; Solis Pinargote, N. W.; Smirnov A. V. Microstructure and Properties of Boron-Carbide Composites Reinforced by Graphene. Russ. Engin. Res. (2020), 40, 94-96.

[47] Smirnov, A; Solís Pinargote, NW; Peretyagin, N; Pristinskiy, Y; Peretyagin, P; Bartolomé, J.F. Zirconia Reduced Graphene Oxide Nano-Hybrid Structure Fabricated by the Hydrothermal Reaction Method. Materials (Basel) (2020), 13(3), 687.

[48] Deckard, C.R. “Method and apparatus for producing parts by selective sintering”. U.S. Patent 4,863,538 filed October 17, 1986, and issued September 5, 1989.

[49] Lakshminarayan, U.; Marcus, H. Microstructural and Mechanical Properties of $\mathrm{Al}_{2} \mathrm{O}_{3} / \mathrm{P}_{2} \mathrm{O}_{5}$ and $\mathrm{Al}_{2} \mathrm{O}_{3} / \mathrm{B}_{2} \mathrm{O}_{3}$ Composties Fabricated by Selective Laser Sintering, 1991 International Solid Freeform Fabrication Symposium (1991).

[50] Lee, I. Densification of porous $\mathrm{Al}_{2} \mathrm{O}_{3}-\mathrm{Al}_{4} \mathrm{~B}_{2} \mathrm{O}_{9}$ ceramic composites fabricated by SLS process. Journal of materials science letters (1999), 18 (19), 1557-1561.

[51] Harlan, N.; Park, S.-M.; Bourell, D.L.; Beaman, J.J. Selective laser sintering of zirconia with micro-scale features. Proc. SFF Symp., Austin (1999), 297-302.

[52] Tang, H.-H. Direct laser fusing to form ceramic parts. Rapid Prototyping Journal (2002), 8 (5), $284-289$.

[53] Xiao, K.; Dalgarno, K.; Wood, D.; Goodridge, R.; Ohtsuki, C. Indirect selective laser sintering of apatitewollostonite glass-ceramic. Proceedings of the Institution of Mechanical Engineers, Part H: Journal of Engineering in Medicine (2008), 222 (7), 1107-1114.

[54] Liu, J.; Zhang, B.; Yan, C.; Shi, Y. The effect of processing parameters on characteristics of selective laser sintering dental glass-ceramic powder. Rapid Prototyping Journal (2010), 16 (2), 138-145.

[55] Clare, A.; Chalker, P.; Davies, S.; Sutcliffe, C.; Tsopanos, S. Selective laser sintering of barium titanatepolymer composite films. Journal of materials science (2008), 43 (9), 3197-3202.

[56] Tan, K.; Chua, C.; Leong, K.; Cheah, C.; Cheang, P.; Bakar, M.A.; Cha, S. Scaffold development using selective laser sintering of polyetheretherketone-hydroxyapatite biocomposite blends. Biomaterials (2003), 24 (18), 3115-3123.

[57] Gao, C.; Yang, B.; Hu, H.; Liu, J.; Shuai, C.; Peng, S. Enhanced sintering ability of biphasic calcium phosphate by polymers used for bone scaffold fabrication. Materials Science and Engineering: C (2013), 33 (7), 3802-3810. 
[58] Leu, M.C.; Pattnaik, S. and Hilmas, G.E. Investigation of laser sintering for freeform fabrication of zirconium diboride parts. Virtual and Physical Prototyping (2012), 7 (1), 2536.

[59] Lakshminarayan, U.; Ogrydiziak, S.; Marcus, H. Selective laser sintering of ceramic materials, 1990 International Solid Freeform Fabrication Symposium (1990).

[60] Shahzad, K.; Deckers, J.; Boury, S.; Neirinck, B.; Kruth, J.-P.; Vleugels, J. Preparation and indirect selective laser sintering of alumina/PA microspheres. Ceramics International (2012), 38 (2), 1241-1247.

[61] Sachs, E.M.; Haggerty, J.S.; Cima, M.J.; Williams P.A. “Three-dimensional printing techniques”. U.S. Patent 5,204,055 filed December 8, 1989, and issued April 20, 1993.

[62] Wu, B.M.; Borland, S.W.; Giordano, R.A.; Cima, L.G.; Sachs, E.M.; Cima, M.J. Solid free-form fabrication of drug delivery devices. Journal of Controlled Release (1996), 40 (1-2), 77-87.

[63] Sachs, E.; Wylonis, E.; Allen, S.; Cima, M.; Guo, H. Production of injection molding tooling with conformal cooling channels using the three-dimensional printing process. Polymer Engineering \& Science (2000), 40 (5), 1232-1247.

[64] Sachs, E.; Cima, M.; Williams, P.; Brancazio, D.; Cornie, J. Three dimensional printing: rapid tooling and prototypes directly from a CAD model. Journal of Engineering for Industry (1992), 114 (4), 481-488.

[65] Meiners, W.; Dr Wissenbach, K.; Dr Gasser, A. “Shaped body especially prototype or replacement part production". Germany Patent DE 19649865, filed December 2, 1996, and issued February 12, 1998.

[66] Simchi, A. Direct laser sintering of metal powders: Mechanism, kinetics and microstructural features. Materials Science and Engineering: A (2006), 428 (1-2), 148-158.

[67] Mercelis, P.; Kruth, J.-P.; Residual stresses in selective laser sintering and selective laser melting. Rapid prototyping journal (2006), 12 (5), 254-265.

[68] Shishkovsky, I.; Yadroitsev, I., Bertrand, P., Smurov, I. Alumina-zirconium ceramics synthesis by selective laser sintering/melting. Applied Surface Science (2007), 254 (4), 966-970.

[69] Deckers, J.; Meyers, S.; Kruth, J.; Vleugels, J. Direct selective laser sintering/melting of high density alumina powder layers at elevated temperatures. Physics Procedia (2014), 56, 117-124.

[70] Bertrand, P.; Bayle, F.; Combe, C.; Goeuriot, P.; Smurov, I. Ceramic components manufacturing by selective laser sintering. Applied Surface Science (2007), 254 (4), 989-992.

[71] Hao, L.; Dadbakhsh, S.; Seaman, O.; Felstead, M. Selective laser melting of a stainless steel and hydroxyapatite composite for load-bearing implant development. J Mater Process Tech (2009), 209 (17), 57935801.

[72] Abdulhameed, O.; Al-Ahmari, A.; Ameen, W.; Mian, S.H. Additive manufacturing-Challenges, trends, and applications. Advances in Mechanical Engineering (2019), 11 (2), 1-27.

[73] International Organization for Standardization. ISO 17296-2:2015 Additive manufacturing - General principles - Part 2: Overview of process categories and feedstock. Geneva: ISO; 2015.

[74] Kumar, S.; Bhushan, P.; Pandey, M.; Bhattacharya, S. Additive manufacturing as an emerging technology for fabrication of microelectromechanical systems (MEMS). Journal of Micromanufacturing (2019), 2 (2), 175-197.

[75] Kaur, M.; Srivastava A. Photopolymerization: a review. J Macromol Sci C Polym Rev (2002), 42, 481-512.

[76] Griffith, M.L.; Halloran, J.W. Ultraviolet curable ceramic suspensions for Stereolithography of ceramics. The 1994 international mechanical engineering congress and exposition (1994), 529-534.

[77] Griffith, M.L.; Halloran, J.W. Freeform fabrication of ceramics via stereolithography. J. Am. Ceram. Soc. (1996), 79 (10), 2601-2608.

[78] Allen Brady, G.; Halloran, J.W. Stereolithography of ceramic suspensions. Rapid Prototyping Journal (1997), 3 (2), 61-65. 
[79] Halloran, J.W.; Tomeckova, V.; Gentry, S.; Das, S.; Cilino, P.; Yuan, D.; Guo, R.; Rudraraju, A.; Shao, P.; Wu, T. Photopolymerization of powder suspensions for shaping ceramics. J. Eur. Ceram. Soc. (2011), 31 (14), $2613-$ 2619.

[80] Bae, C.-J.; Ramachandran, A.; Halloran, J.W. Quantifying particle segregation in sequential layers fabricated by additive manufacturing. J. Eur. Ceram. Soc. (2018), 38 (11), 4082-8.

[81] Chen, Z.; Li, D.; Zhou, W.; Wang, L. Curing characteristics of ceramic Stereolithography for an aqueousbased silica suspension. Proceedings of the Institution of Mechanical Engineers, Part B: Journal of Engineering Manufacture (2010), 224 (4), 641-651.

[82] Zhang, X.; Jiang, X.; and Sun C. Micro-stereolithography of polymeric and ceramic microstructures. Sensors Actuators A Phys (1999), 77, 149-156.

[83] Nakamoto, T.; Yamaguchi, K. Consideration on the producing of high aspect ratio micro parts using UV sensitive photopolymer. Micro Machine and Human Science. Proceedings of the Seventh International Symposium (1996), 53-58.

[84] Lu, Y.; Mapili, G.; Suhali G.; Chen, S.; Roy, K. A digital micro-mirror devicebased system for the microfabrication of complex, spatially patterned tissue engineering scaffolds. J Biomed Mater Res A (2006), 77, 396-405.

[85] Hornbeck, L.J. Digital light processing: a new MEMS based display technology. In: Technical digest of the sensor symposium, Kawasaki, Japan (1996), 297-304.

[86] Murphy, S.V.; Atala A. 3D bioprinting of tissues and organs. Nat Biotechnol (2014), 32, 773.

[87] Zhou, C.; Chen, Y. Calibrating large-area mask projection stereolithography for its accuracy and resolution improvements, Proceedings of Solid Freeform Fabrication Symposium, Austin (2009).

[88] Choi, J.-W.; Wicker, R.; Lee, S.-H.; Choi, K.-H.; Ha, C.-S.; Chung, I. Fabrication of 3D biocompatible/biodegradable micro-scaffolds using dynamic mask projection microstereolithography. J Mater Process Tech (2009), 209 (15-16), 5494-5503.

[89] Felzmann, R.; Gruber, S.; Mitteramskogler, G.; Tesavibul, P.; Boccaccini, A.R.; Liska, R.; Stampfl, J. Lithography-Based Additive Manufacturing of Cellular Ceramic Structures. Advanced Engineering Materials (2012), 14 (12), 1052-1058.

[90] Gmeiner, R.; Mitteramskogler, G.; Stampfl, J.; Boccaccini, A.R. Stereolithographic ceramic manufacturing of high strength bioactive glass. International Journal of Applied Ceramic Technology (2015), 12 (1), 38-45.

[91] Schwentenwein, M.; Schneider, P.; Homa, J. Lithography-based ceramic manufacturing: a novel technique for additive manufacturing of high-performance ceramics. Advances in Science and Technology, Trans Tech Publ (2014), 60-64.

[92] Scheithauer, U.; Schwarzer, E.; Moritz, T.; Michaelis, A. Additive Manufacturing of Ceramic Heat Exchanger: Opportunities and Limits of the Lithography-Based Ceramic Manufacturing (LCM). J Mater Eng Perform (2018), 27 (1), 14-20.

[93] Lantada, A.D.; de Blas Romero, A.; Schwentenwein, M.; Jellinek, C.; Homa, J. Lithography-based ceramic manufacture (LCM) of auxetic structures: present capabilities and challenges. Smart Materials and Structures (2016), 25 (5), 054015.

[94] Scheithauer, U.; Schwarzer, E.; Ganzer, G.; Kornig, A.; Becker, W.; Reichelt, E.; Jahn, M.; Har-tel, A.; Richter, H.; Moritz, T. Micro-Reactors Made by Lithography-Based Ceramic Manufacturing (LCM). Additive Manufacturing and Strategic Technologies in Advanced Ceramics: Ceramic Transactions (2015), 258, 31-41.

[95] Wu, E.-S.; Strickler, J.H.; Harrell, W.R.; Webb, W.W. Two-photon lithography for microelectronic application, Optical/Laser Microlithography V. International Society for Optics and Photonics (1992), 776-783.

[96] Maruo, S.; Nakamura, O.; Kawata, S. Three-dimensional microfabrication with twophoton-absorbed photopolymerization, Optics letters (1997), 22 (2), 132-134. 
[97] Deubel, M.; Von Freymann, G.; Wegener, M.; Pereira, S.; Busch, K.; Soukoulis, C.M. Direct laser writing of three-dimensional photonic-crystal templates for telecommunications. Nat Mater (2004), 3, 444.

[98] Sun, H.-B.; Kawata, S. Two-Photon Photopolymerization and 3D Lithographic Microfabrication. In: NMR 3D Analysis Photopolymerization. Advances in Polymer Science. Springer (2004), 170, 169-273.

[99] Fischer, J.; Wegener, M. Three-dimensional optical laser lithography beyond the diffraction limit. Laser Photonics Rev (2013), 7, 22-44.

[100] Lee, K.-S.; Kim, R.H.; Yang, D.-Y.; Park, S.H. Advances in 3D nano/microfabrication using two-photon initiated polymerization. Progress in Polymer Science (2008), 33 (6), 631-681.

[101] Pham, T.A.; Kim, D.P.; Lim, T.W.; Park, S.H.; Yang, D.Y.; Lee, K.S. Three-Dimensional SiCN Ceramic Microstructures via Nano-Stereolithography of Inorganic Polymer Photoresists. Adv Funct Mater (2006), 16 (9), 1235-1241.

[102] Singh, M.; Haverinen, H.M.; Dhagat, P.; Jabbour, G.E. Inkjet printing-process and its applications. Adv Mater (2010), 22 (6), 673-685.

[103] Le, H.P. Progress and trends in ink-jet printing technology. Journal of Imaging Science and Technology (1998), 42 (1), 49-62.

[104] Dong, H.; Carr, W.W.; Morris, J.F. An experimental study of drop-on-demand drop formation. Phys Fluids (2006), 18 (7), 072102.

[105] Lee, E.R. Microdrop generation. Boca Raton: CRC Press (2002), pp. 1-241.

[106] Kyser, E.L. Design of an impulse ink jet. J Appl Photogr Eng (1981), 7, 73-79.

[107] Kawase, T.; Shimoda, T.; Newsome, C.; Sirringhaus, H.; Friend, R.H. Inkjet printing of polymer thin film transistors. Thin Solid Films (2003), 438, 279-287.

[108] Kawahara, Y.; Hodges, S.; Cook, B.S.; Zhang, C.; Abowd, G.D. Instant inkjet circuits: lab-based inkjet printing to support rapid prototyping of UbiComp devices. Proceedings of the 2013 ACM international joint conference on Pervasive and ubiquitous computing (2013), 363-372.

[109] Nakamura, M.; Kobayashi, A.; Takagi, F.; Watanabe, A.; Hiruma, Y.; Ohuchi, K.; Iwasaki, Y.; Horie, M.; Morita, I.; Takatani, S. Biocompatible inkjet printing technique for designed seeding of individual living cells. Tissue engineering (2005), 11 (11-12), 1658-1666.

[110] Blazdell, P.; Evans, J.; Edirisinghe, M.; Shaw, P.; Binstead, M. The computer aided manufacture of ceramics using multilayer jet printing. Journal of materials science letters (1995), 14 (22), 1562-1565.

[111] Zhao, X.; Evans, J.; Edirisinghe, M.; Song, J. Formulation of a ceramic ink for a widearray drop-on-demand ink-jet printer. Ceramics International (2003), 29 (8), 887-892.

[112] Seerden, K.A.; Reis, N.; Evans, J.R.; Grant, P.S.; Halloran, J.W.; Derby, B. Ink-jet printing of wax-based alumina suspensions. Journal of the American Ceramic Society (2001), 84 (11), 2514-2520.

[113] Kunieda, M.; Nakagawa, T. Manufacturing of laminated deep drawing dies by laser beam cutting. Advanced Technology of Plasticity (1984), 1, 520-525.

[114] Obikawa, T.; Yoshino, M.; Shinozuka, J. Sheet steel lamination for rapid manufacturing. J. Mater. Process. Technol. (1999), 89-90, 171-176.

[115] White, D. “Ultrasonic object consolidation”. U.S. Patent 6,519,500 filed March 23, 2000, and issued February $11,2003$.

[116] Mekonnen, B.G.; Bright, G.; Walker, A. A Study on State of the Art Technology of Laminated Object Manufacturing (LOM). CAD/CAM, Robotics and Factories of the Future. Proceedings of the 28th International Conference on CARs \& FoF (2016), 207-216.

[117] Huang, S.H.; Liu, P.; Mokasdar, A.; Hou, L. Additive manufacturing and its societal impact: a literature review. Int J Adv Manuf Tech (2013), 67, 1191-1203. 
[118] Mathur, R. 3D printing in architecture. Int J Innovat Sci (2016), 3, 583-591.

[119] Mueller, B.; Kochan, D. Laminated object manufacturing for rapid tooling and pattern making in foundry industry. Comput Ind (1999), 39, 47-53.

[120] Griffin, C.; Daufenbach, J.; McMillin, S. Desktop manufacturing: LOM vs. pressing. Am. Ceram. Soc. Bull. (1994), 73 (8), 109-113.

[121] Griffin, C.; Daufenbach, J.; McMillin, S. Solid freeform fabrication of functional ceramic components using a laminated object manufacturing technique. Solid Freeform Fabrication (1994), 17-24.

[122] Klosterman, D.A.; Chartoff, R.P.; Osborne, N.R.; Graves, G.A.; Lightman, A.; Han, G.; Bezeredi, A.; Rodrigues, S. Development of a curved layer LOM process for monolithic ceramics and ceramic matrix composites. Rapid Prototyping Journal (1999), 5 (2), 61-71.

[123] Windsheimer, H.; Travitzky, N.; Hofenauer, A.; Greil, P. Laminated Object Manufacturing of PreceramicPaper-Derived Si-SiC Composites. Adv Mater (2007), 19 (24), 4515-4519.

[124] Travitzky, N.; Windsheimer, H.; Fey, T.; Greil, P. Preceramic Paper-Derived Ceramics. J. Am. Ceram. Soc. (2008), 91 (11), 3477-3492.

[125] Gomes, C.M.; Gutbrod, B.; Travitzky, N.; Fey, T.; Greil, P. Preceramic paper derived fibrillar ceramics. Ceram. Trans (2010), 210, 421-426.

[126] Weisensel, L.; Travitzky, N.; Sieber, H.; Greil, P. Laminated object manufacturing (LOM) of SiSiC composites. Advanced Engineering Materials (2004), 6 (11), 899-903.

[127] Griffin, E.; Mumm, D.; Marshall, D. Rapid prototyping of functional ceramic composites. American Ceramic Society Bulletin (1996), 75 (7), 65-68.

[128] Zhang, Y.; Han, J.; Zhang, X.; He, X.; Li, Z.; Du, S. Rapid prototyping and combustion synthesis of TiC/Ni functionally gradient materials. Materials Science and Engineering: A (2001), 299 (1-2), $218-224$.

[129] Gomes, C.; Travitzky, N.; Greil, P.; Acchar, W.; Birol, H.; Pedro Novaes de Oliveira, A.; Hotza, D. Laminated object manufacturing of LZSA glass-ceramics. Rapid Prototyping Journal (2011), 17 (6), 424-428.

[130] Crump, S.S. "Apparatus and method for creating three-dimensional objects". U.S. Patent 5,121,329 filed October 30, 1989, and issued June 09, 1992.

[131] Chua, C.K.; Leong, K.F.; Lim, C.S. Rapid prototyping: principles and applications. World Scientific (2003), pp. $1-448$.

[132] Rundle, G.A. Revolution in the Making. Affirm Press, South Melbourne, Australia, 2014; pp.1- 209

[133] Ahmad, A.; Darmoul, S.; Ameen, W.; Abidi, M.H.; Al-Ahmari, A.M. Rapid prototyping for assembly training and validation. IFAC Papersonline (2015), 48, 412-417.

[134] Wittbrodt, B.; Pearce, J.M. The effects of PLA color on material properties of 3-D printed components. Additive Manufacturing (2015), 8, 110-116.

[135] Wang, X.; Jiang, M.; Zhou, Z.; Gou, J.; Hui, D. 3D printing of polymer matrix composites: a review and prospective. Compos Part B (2017), 110, 442-458.

[136] Danforth, S. Fused deposition of ceramics: a new technique for the rapid fabrication of ceramic components. Mater Technol (1995), 10 (7-8), 144-146.

[137] Iyer, S.; McIntosh, J.; Bandyopadhyay, A.; Langrana, N.; Safari, A.; Danforth, S.; Clancy, R.; Gasdaska, C.; Whalen, P. Microstructural characterization and mechanical properties of Si3N4 formed by fused deposition of ceramics. International Journal of Applied Ceramic Technology (2008), 5 (2), 127-137.

[138] Allahverdi, M.; Danforth, S.; Jafari, M.; Safari, A. Processing of advanced electroceramic components by fused deposition technique. Journal of the European Ceramic Society (2001), 21 (10-11), 1485-1490.

[139] Yang, H.; Yang, S.; Chi, X.; Evans, J.R. Fine ceramic lattices prepared by extrusion freeforming. Journal of Biomedical Materials Research Part B: Applied Biomaterials (2006), 79 (1), 116-121. 
[140] Jafari, M.; Han, W.; Mohammadi, F.; Safari, A.; Danforth, S.; Langrana, N. A novel system for fused deposition of advanced multiple ceramics. Rapid Prototyping Journal (2000), 6 (3), 161-175.

[141] Hutmacher, D.W.; Schantz, T.; Zein, I.; Ng, K.W.; Teoh, S.H.; Tan, K.C. Mechanical properties and cell cultural response of polycaprolactone scaffolds designed and fabricated via fused deposition modeling. Journal of Biomedical Materials Research (2001), 55 (2), 203-216.

[142] Cao, T.; Ho, K.-H.; Teoh, S.-H. Scaffold design and in vitro study of osteochondral coculture in a threedimensional porous polycaprolactone scaffold fabricated by fused deposition modeling. Tissue engineering (2003), 9 (4), 103-112.

[143] Tsang, V.L.; Bhatia, S.N. Three-dimensional tissue fabrication. Advanced drug delivery reviews (2004), 56 (11), 1635-1647.

[144] Xu, N.; Ye, X.; Wei, D.; Zhong, J.; Chen, Y.; Xu, G.; He, D. 3D artificial bones for bone repair prepared by computed tomography-guided fused deposition modeling for bone repair. ACS applied materials \& interfaces (2014), 6 (17), 14952-14963.

[145] Sa, M.W.; Nguyen, B.N.B.; Moriarty, R.A.; Kamalitdinov, T.; Fisher, J.P.; Kim, J.Y. Fabrication and evaluation of 3D printed BCP scaffolds reinforced with $\mathrm{ZrO} 2$ for bone tissue applications. Biotechnology and bioengineering (2018), 115 (4), 989-999.

[146] Pilleux, M.E.; Safari, A.; Allahverdi, M.; Chen, Y.; Lu, Y.; Jafari, M.A. 3-D photonic bandgap structures in the microwave regime by fused deposition of multimaterials. Rapid Prototyping Journal (2002), 8 (1), 46-52.

[147] Chen, Y.; Bartzos, D.; Lu, Y.; Niver, E.; Pilleux, M.; Allahverdi, M.; Danforth, S.; Safari, A. Simulation, fabrication, and characterization of 3-D alumina photonic bandgap structures. Microwave and Optical Technology Letters (2001), 30 (5), 305-307.

[148] Cesarano, I.; Segalman, R. Robocasting provides moldless fabrication from slurry deposition. Ceramic Industry (1998), 148 (4), 94-100.

[149] Shen, A.; Caldwell, D.; Ma, A.W.K.; Dardona, S. Direct write fabrication of high-density parallel silver interconnects. Additive Manufacturing (2018), 22, 343-350.

[150] Hartmann, K.; Krishnan, R.; Merz, R.; Neplotnik, G.; Prinz, F.B.; Schultz, L.; Terk, M.; Weiss, L.E. Robotassisted shape deposition manufacturing. Proceedings of the 1994 IEEE International Conference on Robotics and Automation, San Diego, CA, USA (1994), 4, 2890-2895.

[151] Cesarano III, J.; Calvert, P.D. “Freeforming objects with low-binder slurry” U.S. Patent 6,027,326, filed October 28, 1997, and issued February 22, 2000.

[152] Cesarano, J. Robocasting: direct fabrication of ceramics from colloidal suspensions. Proc. Solid Free. Fabr. Symp., Austin, TX (1997), 25-36.

[153] Fu, K.; Wang, Y.; Yan, C.; Yao, Y.; Chen, Y.; Dai, J.; Lacey, S.; Wang, Y.; Wan, J.; Li, T.; Wang, Z.; Xu, Y.; Hu, L. Graphene oxide-based electrode inks for 3D-printed lithium-ion batteries. Adv Mater (2016), 28, 2587-2594.

[154] Farahani, R.D.; Dubé, M.; Therriault, D. Three-dimensional printing of multifunctional nanocomposites: manufacturing techniques and applications. Adv Mater (2016), 28, 5794-5821.

[155] Zhu, C.; Liu, T.; Qian, F.; Han, T.Y.-J.; Duoss, E.B.; Kuntz, J.D.; Spadaccini, C.M.; Worsley, M.A.1 Li, Y. Supercapacitors based on three-dimensional hierarchical graphene aerogels with periodic macropores. Nano Lett (2016), 16, 3448-3456.

[156] Zhang, F.; Wei, M.; Viswanathan, V.V.; Swart, B.; Shao, Y.; Wu, G.; Zhou, C. 3D printing technologies for electrochemical energy storage. Nano Energy (2017), 40, 418-431.

[157] Elsayed, H.; Colombo, P.; Bernardo, E. Direct ink writing of wollastonite-diopside glass-ceramic scaffolds from a silicone resin and engineered fillers. Journal of the European Ceramic Society (2017), 37 (13), 4187-4195.

[158] Feilden, E.; Blanca, E.G.-T.; Giuliani, F.; Saiz, E.; Vandeperre, L. Robocasting of structural ceramic parts with hydrogel inks. Journal of the European Ceramic Society (2016), 36 (10), 2525-2533. 
[159] Rao, R.B.; Krafcik, K.L.; Morales, A.M.; Lewis, J.A. Microfabricated deposition nozzles for direct-write assembly of three-dimensional periodic structures. Adv Mater (2005), 17 (3), 289-293.

[160] Schlordt, T.; Schwanke, S.; Keppner, F.; Fey, T.; Travitzky, N.; Greil, P. Robocasting of alumina hollow filament lattice structures. Journal of the European Ceramic Society (2013), 33 (15-16), 3243-3248.

[161] Smay, J.E.; Cesarano, J.; Lewis, J.A. Colloidal inks for directed assembly of 3-D periodic structures. Langmuir (2002), 18 (14), 5429-5437.

[162] Sun, K.; Wei, T.S.; Ahn, B.Y.; Seo, J.Y.; Dillon, S.J.; Lewis, J.A. 3D printing of interdigitated Li-Ion microbattery architectures. Adv Mater (2013), 25 (33), 4539-4543.

[163] Liu, C.; Cheng, X.; Li, B.; Chen, Z.; Mi, S.; Lao, C. Fabrication and Characterization of 3D-Printed HighlyPorous 3D LiFePO 4 Electrodes by Low Temperature Direct Writing Process. Materials (2017), 10 (8), 934.

[164] Miranda, P.; Saiz, E.; Gryn, K.; Tomsia, A.P. Sintering and robocasting of $\beta$-tricalcium phosphate scaffolds for orthopaedic applications. Acta biomaterialia (2006), 2 (4), 457-466.

[165] Eqtesadi, S.; Motealleh, A.; Miranda, P.; Lemos, A.; Rebelo, A.; Ferreira, J.M. A simple recipe for direct writing complex 45S5 Bioglass® 3D scaffolds. Materials Letters (2013), 93, 68-71.

[166] Simon, J.L.; Michna, S.; Lewis, J.A.; Rekow, E.D.; Thompson, V.P.; Smay, J.E.; Yampolsky, A.; Parsons, J.R.; Ricci, J.L. In vivo bone response to 3D periodic hydroxyapatite scaffolds assembled by direct ink writing. Journal of Biomedical Materials Research Part A (2007), 83 (3), 747-758.

[167] Dellinger, J.G. Development of model hydroxyapatite bone scaffolds with multiscale porosity for potential load bearing applications. Doctoral thesis, University of Illinois at Urbana-Champaign, Illinois, USA, 2005.

[168] Dellinger, J.G.; Eurell, J.A.C.; Jamison, R.D. Bone response to 3D periodic hydroxyapatite scaffolds with and without tailored microporosity to deliver bone morphogenetic protein 2. Journal of Biomedical Materials Research Part A (2006), 76 (2), 366-376.

[169] Miranda, P.; Pajares, A.; Saiz, E.; Tomsia, A.P.; Guiberteau, F. Mechanical properties of calcium phosphate scaffolds fabricated by robocasting. Journal of Biomedical Materials Research Part A (2008), 85 (1), $218-227$.

[170] Poole C.P.Jr.; Owens F.J. Introduction to Nanotechnology. A John Wiley \& Sons (2003), pp. 1-371.

[171] Grigoriev, S; Peretyagin, P.; Smirnov, A; Solis, W; Díaz, L.A.; Fernández, A. Effect of graphene addition on the mechanical and electrical properties of $\mathrm{Al}_{2} \mathrm{O}_{3}-\mathrm{SiCw}$ ceramics. J. Eur. Ceram. Soc. (2017), 37(6), 2473-2479

[172] Smirnov, A; Peretyagin, P.; Solis Pinargote, N.W.; Gerchman, I; Bartolomé, J.F. Wear behavior of graphenereinforced alumina-silicon carbide whisker nanocomposite. Nanomaterials (2019), 9 (2), 151

[173] Solis Pinargote, N. W.; Peretyagin, P.; Seleznev, A.; Torrecillas, R.; Moya, J. S. Black zirconia-graphene nanocomposite produced by spark plasma sintering. AIP Conference Proceedings, (2016), 1785 (1), 040074.

[174] Fokin, P. V.; Solis Pinargote, N. W.; Kuznetsova, E. V.; Peretyagin, P. Y.; Smirnov, A. Effect of Drying Methods of Alumina Powder and Graphene Oxide Mixture on the Mechanical and Electrical Properties of Sintered Composites Fabricated by Spark Plasma Sintering. Inorg. Mater. Appl. Res. (2018), 9, 930-936

[175] Markandan, K.; Chin, J. K.; Tan, M. T. T. Recent progress in graphene based ceramic composites: a review. Journal of Materials Research (2016), 32(01), 84-106.

[176] Nieto, A.; Bisht, A.; Lahiri, D.; Zhang, C.; Agarwal, A. Graphene reinforced metal and ceramic matrix composites: a review. International Materials Reviews (2016), 62(5), 241-302.

[177] Novoselov, K.S.; Fal'ko, V.I.; Colombo, L.; Gellert, P.R.; Schwab, M.G.; Kim, K. A roadmap for graphene. Nature (2012), 490, 192-200.

[178] Balandin, A.A.; Ghosh, S.; Bao, W.; Calizo, I.; Teweldebrhan, D.; Miao, F.; Lau, C.N. Superior thermal conductivity of single-layer graphene. Nano Lett (2008), 8 (3), 902-907.

[179] Balandin, A.A. Thermal properties of graphene and nanostructured carbon materials. Nat Mater (2011), 10, $569-581$. 
[180] Lee, C.; Wei, X.D.; Kysar, J.W.; Hone, J. Measurement of the elastic properties and intrinsic strength of monolayer graphene. Science (2008), 321(5887), 385-388.

[181] Zhu, Y.; Murali, S.; Cai, W.; Li, X.; Suk, J.W.; Potts, J.R.; Ruoff, R.S. Graphene and graphene oxide: synthesis, properties, and applications. Adv Mater (2010), 22 (35), 3906-3924.

[182] Novoselov, K.; Geim, A.K.; Morozov, S.; Jiang, D.; Katsnelson, M.; Grigorieva, I.; Dubonos, S.V.; Firsov, A.A. Two-dimensional gas of massless Dirac fermions in graphene. Nature (2005), 438(7065), 197-200.

[183] Nair, R.R.; Blake, P.; Grigorenko, A.N.; Novoselov, K.S.; Booth, T.J.; Stauber, T.; Peres, N.M.R.; Geim, A.K. Fine structure constant defines visual transparency of graphene. Science (2008), 320, 1308-1308.

[184] Jo, G.; Choe, M.; Lee, S.; Park, W.; Kahng, Y.H.; Lee, T. The application of graphene as electrodes in electrical and optical devices. Nanotechnology (2012), 23 (11),1-19.

[185] Bunch, J.S.; Verbridge, S.S.; Alden, J.S.; van der Zande, A.M.; Parpia, J.M.; Craighead, H.G.; Mc Euen, P.L. Impermeable atomic membranes from graphene sheets. Nano Lett (2008), 8, 2458-2462.

[186] Nayak, T.R.; Andersen, H.; Makam, V.S.; Khaw, C.; Bae, S.; Xu, X.; Ee, P.-L.R.; Ahn, J.-H.; Hong, B.H.; Pastorin, G.; Özyilmaz, B. Graphene for Controlled and Accelerated Osteogenic Differentiation of Human Mesenchymal Stem Cells. ACS Nano (2011), 5 (6), 4670-4678.

[187] Potts, J.R.; Dreyer, D.R.; Bielawski, C.W.; Ruoff, R.S. Graphene-based polymer nanocomposites. Polymer (2011), 52(1), 5-25.

[188] Papageorgiou, D.G.; Kinloch, I.A.; Young, R.J. Graphene/elastomer nanocomposites. Carbon (2015), 95, 460-484.

[189] Eda, G.; Chhowalla, M. Chemically derived graphene oxide: towards large-area thin-film electronics and optoelectronics. Adv Mater (2010), 22 (22), 2392-2415.

[190] Wang, J.; Xu, Y.; Chen, H.; Zhang, B. Ultraviolet dielectric hyperlens with layered graphene and boron nitride. Journal of Materials Chemistry (2012), 22 (31), 15863.

[191] Yoo, J.J.; Balakrishnan, K.; Huang, J.; Meunier, V.; Sumpter, B.G.; Srivastava, A.; Conway, M.; Reddy, A.L.M.; Yu, J.; Vajtai, R.; Ajayan, P.M. Ultrathin planar graphene supercapacitors. Nano Lett (2011), 11(4), 14231427.

[192] Patchkovskii, S.; John, S.T.; Yurchenko, S.N.; Zhechkov, L.; Heine, T.; Seifert, G. Graphene nanostructures as tunable storage media for molecular hydrogen. Proc Natl Acad Sci USA (2005), 102(30), 10439-10444.

[193] Schwierz, F. Graphene transistors. Nat Nanotechnol (2010), 5(7), 487-96.

[194] Bunch, J.S.; Van Der Zande, A.M.; Verbridge, S.S.; Frank, I.W.; Tanenbaum, D.M.; Parpia, J.M.; Craighead, H.G.; McEuen, P.L. Electromechanical resonators from graphene sheets. Science (2007), 315(5811), 490-493.

[195] Reina, A.; Jia, X.; Ho, J.; Nezich, D.; Son, H.; Bulovic, V.; Dresselhaus, M.S.; Kong, J. Large area, few-layer graphene films on arbitrary substrates by chemical vapor deposition. Nano Lett (2009), 9, 30-35.

[196] Hu, B.; Ago, H.; Ito, Y.; Kawahara, K.; Tsuji, M.; Magome, E.; Sumitani, K.; Mizuta, N.; Ikeda, K.; Mizuno, $\mathrm{S}$. Epitaxial growth of large-area single-layer graphene over $\mathrm{Cu}(111) /$ sapphire by atmospheric pressure CVD. Carbon (2012), 50, 57-65.

[197] Stankovich, S.; Dikin, D.A.; Piner, R.D.; Kohlhaas, K.A.; Kleinhammes, A.; Jia Y.; Wu, Y.; Nguyen, S.T.; Ruoff, R.S. Synthesis of graphene-based nanosheets via chemical reduction of exfoliated graphite oxide. Carbon (2007), 45, 1558-1565.

[198] Novoselov, K.S.; Geim, A.K.; Morozov, S.V.; Jiang, D.; Zhang, Y.; Dubonos, S.V.; Grigorieva, I.V.; Firsov, A.A. Electric field effect in atomically thin carbon films. Science (2004), 306, 666-669.

[199] Munz, M.; Giusca, C.E.; Myers-Ward, R.L., Gaskill, D.K.; Kazakova, O. Thickness-Dependent Hydrophobicity of Epitaxial Graphene. ACS Nano (2015), 9 (8), 8401-8411.

[200] Liu, J.; Tang, J.; Gooding, J.J. Strategies for chemical modification of graphene and applications of chemically modified graphene. Journal of Materials Chemistry (2012), 22(25), 12435. 
[201] Bagherzadeh, M.; Farahbakhsh, A. Surface Functionalization of Graphene. Graphene Materials (2015), 2565 .

[202] Sun, X.; Li, B.; Lu, M. A covalent modification for graphene by adamantane groups through two-step chlorination-Grignard reactions. J Solid State Chem (2017), 251, 194-197.

[203] Qi, X.; Pu, K.Y.; Li, H.; Zhou, X.; Wu, S.; Fan, Q.L.; Liu, B.; Boey, F.; Huang, W.; Zhang, H. Amphiphilic graphene composites. Angew Chem Int Ed (2010), 49, 9426-9429.

[204] Zaaba, N. I.; Foo, K.L.; Hashim, U.; Tan, S.J.; Liu, W.-W.; Voon, C. H. Synthesis of Graphene Oxide using Modified Hummers Method: Solvent Influence. Procedia Engineering (2017), 184, 469-477.

[205] Hummers, W.S.; Offeman, R.E. Preparation of graphitic oxide. J Am Chem Soc (1958), 80, 1339-1339.

[206] Singh, V.; Joung, D.; Zhai, L.; Das, S.; Khondaker, S.I.; Seal, S. Graphene based materials: past, present and future. Prog Mater Sci (2011), 56, 1178-1271.

[207] Stankovich, S.; Piner, R.D.; Chen, X.; Wu, N.; Nguyen, S.T.; Ruoff, R.S. Stable aqueous dispersions of graphitic nanoplatelets via the reduction of exfoliated graphite oxide in the presence of poly(sodium 4styrenesulfonate). J Mater Chem (2006), 16, 155-158.

[208] Becerril, H.A.; Mao, J.; Liu, Z.; Stoltenberg, R.M.; Bao, Z.; Chen, Y. Evaluation of solution-processed reduced graphene oxide films as transparent conductors. ACS Nano (2008), 2, 463-470.

[209] An, B.W.; Kim, K.; Kim, M.; Kim, S.Y.; Hur, S.H.; Park, J.U. Direct printing of reduced graphene oxide on planar or highly curved surfaces with high resolutions using electrohydrodynamics. Small (2015), 11, $2263-2268$.

[210] Zhang, J.-X.; Liang, Y.-X.; Wang, X.; Zhou, H.-J.; Li, S.-Y.; Zhang, J.; Feng, Y.; Lu, N.; Wang, Q., Guo, Z. Strengthened epoxy resin with hyperbranched polyamineester anchored graphene oxide via novel phase transfer approach. Adv Compos Hybrid Mater (2018), 1, 300-309.

[211] Yu, A.; Ramesh, P.; Itkis, M.E.; Bekyarova, E.; Haddon, R.C. Graphite nanoplatelet-epoxy composite thermal interface materials. J Phys Chem C (2007), 111, 7565-7569.

[212] Syurik, Y.V.; Ghislandi, M.G.; Tkalya, E.E.; Paterson, G.; McGrouther, D.; Ageev, O.A.; Loos, J. Graphene network organisation in conductive polymer composites. Macromol Chem Phys (2012), 213, 1251- 1258.

[213] Huang, X.; Yin, Z.; Wu, S.; Qi, X.; He, Q.; Zhang, Q.; Yan, Q.; Boey, F.; Zhang, H. Graphene-based materials: synthesis, characterization, properties, and applications. Small (2011), 7, 1876-1902.

[214] Wu, H.; Huang, X.; Qian, L. Recent progress on the metacompoistes with carbonaceous fillers. Eng Sci (2018), 2, 17-25.

[215] Zhou, X.; Huang, X.; Qi, X.; Wu, S.; Xue, C.; Boey, F.Y.C.; Yan, Q.; Chen, P.; Zhang, H. In situ synthesis of metal nanoparticles on single-layer graphene oxide and reduced graphene oxide surfaces. J Phys Chem C (2009), $113,10842-10846$.

[216] Yan, J.; Wei, T.; Qiao, W.; Shao, B.; Zhao, Q.; Zhang, L.; Fan, Z. Rapid microwave-assisted synthesis of graphene nanosheet/Co3 $\mathrm{O}_{4}$ composite for supercapacitors. Electrochim Acta (2010), 55, 6973-6978.

[217] Ahmad, J.; Majid, K. In-situ synthesis of visible-light responsive $\mathrm{Ag}_{2} \mathrm{O} /$ graphene oxide nanocomposites and effect of graphene oxide content on its photocatalytic activity. Adv Compos Hybrid Mater (2018), 1, 374-388.

[218] Guo, C.X.; Yang, H.B.; Sheng, Z.M.; Lu, Z.S.; Song, Q.L.; Li, C.M. Layered graphene/quantum dots for photovoltaic devices. Angew Chem Int Ed (2010), 49, 3014-3017.

[219] Acquah, S.F.A.; Leonhardt, B.E.; Nowotarski, M.S.; Magi, J.M.; Al-Hariri, L.A. Carbon Nanotubes and Graphene as Additives in 3D Printing. Carbon Nanotubes - Current Progress of their Polymer Composites, Mohamed Reda Berber and Inas Hazzaa Hafez, IntechOpen (2016).

[220] Compton, O.C.; Kim, S.; Pierre, C.; Torkelson, J.M.; Nguyen, S.T. Crumpled graphene nanosheets as highly effective barrier property enhancers. Adv. Mater. (2010), 22, 4759-4763.

[221] Kim, H.; Miura, Y.; Macosko, C.W. Graphene/polyurethane nanocomposites for improved gas barrier and electrical conductivity. Chem. Mater. (2010), 22, 3441-3450. 
[222] An, X.; Butler, T.W.; Washington, M.; Nayak, S.K.; Kar, S. Optical and sensing properties of 1pyrenecarboxylic acidfunctionalized graphene films laminated on polydimethylsiloxane membranes. ACS Nano (2011), 5, 1003-1011.

[223] Xu, Y.; Liu, Z.; Zhang, X.; Wang, Y.; Tian, J.; Huang, Y.; Ma, Y.; Zhang, X.; Chen, Y. A graphene hybrid material covalently functionalized with porphyrin: synthesis and optical limiting property. Adv. Mater. (2009), 21, 1275-1279.

[224] Ramanathan, T.; Abdala, A.A.; Stankovich, S.; Dikin, D.A.; Herrera-Alonso, M.; Piner, R.D.; Adamson, D.H.; Schniepp, H.C.; Chen, X.; Ruoff, R.S.; Nguyen, S.T.; Aksay, I.A.; Prud'Homme, R.K.; Brinson, L.C. Functionalized graphene sheets for polymer nanocomposites. Nat. Nanotechnology (2008), 3, 327-331.

[225] Chu, K.; Li, W.-S.; Jia, C.-C.; Tang, F.-L. Thermal conductivity of composites with hybrid carbon nanotubes and graphene nanoplatelets. Appl. Phys. Lett. (2012), 101, 211903.

[226] Yang, S.-Y.; Lin, W.-N.; Huang, Y.-L.; Tien, H.-W.; Wang, J.-Y.; Ma, C.-C.M., Li, S.-M.; Wang, Y.-S. Synergetic effects of graphene platelets and carbon nanotubes on the mechanical and thermal properties of epoxy composites. Carbon (2011), 49, 793-803.

[227] Stankovich, S.; Dikin, D.A.; Dommett, G.H.B.; Kohlhaas, K.M.; Zimney, E.J.; Stach, E.A.; Piner, R.D.; Nguyen, S.T.; Ruoff, R.S. Graphene-based composite materials. Nature (2006), 442, 282-286.

[228] Hicks, J.; Behnam, A.; Ural, A. A computational study of tunneling-percolation electrical transport in graphene-based nanocomposites. Appl. Phys. Lett. (2009), 95, 213103.

[229] Zhang, H.-B.; Zheng, W.-G.; Yan, Q.; Yang, Y.; Wang, J.-W.; Lu, Z.-H.; Ji, G.-Y.; Yu, Z.-Z. Electrically conductive polyethylene terephthalate/graphene nanocomposites prepared by melt compounding. Polymer (2010), 51, 1191-1196.

[230] Fang, M.; Wang, K.; Lu, H.; Yang, Y.; Nutt, S. Covalent polymer functionalization of graphene nanosheets and mechanical properties of composites. J. Mater. Chem. (2009), 19, 7098-105.

[231] Rafiee, M.A.; Rafiee, J.; Srivastava, I.; Wang, Z.; Song, H.; Yu, Z.-Z.; Koratkar, N. Fracture and fatigue in graphene nanocomposites. Small (2010), 6, 179-183.

[232] Gong, L.; Young, R.J.; Kinloch, I.A.; Riaz, I.; Jalil, R.; Novoselov, K.S. Optimizing the reinforcement of polymer-based nanocomposites by graphene. ACS Nano (2012), 6, 2086-2095.

[233] Lin, D.; Jin, S.; Zhang, F.; Wang, C.; Wang, Y.; Zhou, C.; Cheng, G.J. 3D stereolithography printing of graphene oxide reinforced complex architectures. Nanotechnology (2015), 26, 1-9.

[234] Lin, D. A laser sintered layer of metal matrix consisting of $0 \mathrm{D}, 1 \mathrm{D}$ and 2D nanomaterials and its mechanical behaviors. Doctoral thesis, Purdue University, Inidiana, USA, 2013.

[235] Lin, D.; Richard, L.C.; Cheng, G.J. Laser sintering of separated and uniformly distributed multiwall carbon nanotubes integrated iron nanocomposites. J. Appl. Phys. (2014), 115, 113513.

[236] Lin, D.; Richard, L.C.; Cheng, G.J. Single-layer graphene oxide reinforced metal matrix composites by laser sintering: microstructure and mechanical property enhancement. Acta Mater. (2014), 80, 183-193.

[237] Lin, D.; Ye, C.; Liao, Y.; Suslov, S.; Liu, R.; Cheng, G.J. Mechanism of fatigue performance enhancement in a laser sintered superhard nanoparticles reinforced nanocomposite followed by laser shock peening. J. Appl. Phys. (2013), 113, 133509.

[238] Verdejo, R.; Bernal, M.M.; Romasanta, L.J.; Lopez-Manchado, M.A. Graphene filled polymer nanocomposites. J. Mater. Chem. (2011), 21, 3301-3310.

[239] Guo, S.Z.; Gosselin, F.; Guerin, N.; Lanouette, A.M.; Heuzey, M.C.; Therriault, D. Solvent-cast threedimensional printing of multifunctional microsystems. Small (2013), 9 (24), 4118-4122.

[240] Guo, H.; Lv, R.; Bai, S. Recent advances on 3D printing graphene-based composites. Nano Materials Science (2019), 1 (2), 101-115. 
[241] Palaganas, N. B.; Mangadlao, J. D.; De Leon, A. C. C.; Palaganas, J. O.; Pangilinan, K. D.; Lee, Y. J.; Advincula, R. C. 3D Printing of Photocurable Cellulose Nanocrystal Composite for Fabrication of Complex Architectures via Stereolithography. ACS Appl. Mater. Interfaces (2017), 9 (39), 34314-34324.

[242] Tumbleston, J. R.; Shirvanyants, D.; Ermoshkin, N.; Janusziewicz, R.; Johnson, A. R.; Kelly, D.; Chen, K.; Pinschmidt, R.; Rolland, J. P.; Ermoshkin, A.; Samulski, E.T.; DeSimone, J.M. Continuous Liquid Interface Production of 3D Objects. Science (2015), 347, 1349-1352.

[243] Iftikhar, U. Nanoscribe Introduces Quantum X, A Two-Photon 3D Printer for Microoptics https://3dprintingindustry.com/news/nanoscribe-introduces-quantumx-a-two-photon-3d-printer-formicrooptics-157656/ (accessed March 08, 2020).

[244] Palaganas, J.O.; Palaganas, N.B.; Ramos L.J.I.; David C.P.C. 3D Printing of Covalent Functionalized Graphene Oxide Nanocomposite via Stereolithography. ACS Appl. Mater. Interfaces (2019), 11 (49), 46034-46043.

[245] Manapat, J.Z.; Mangadlao, J.D.; Tiu, B.D.B.; Tritchler, G.C.; Advincula, R.C. High-Strength Stereolithographic 3D Printed Nanocomposites-Graphene Oxide Metastability. ACS Appl. Mater. Interfaces (2017), 9 (11), 10085-10093.

[246] Feng, Z.; Li, Y.; Hao, L.; Yang, Y.; Tang, T.; Tang, D.; Xiong, W. Graphene-Reinforced Biodegradable Resin Composites for Stereolithographic 3D Printing of Bone Structure Scaffolds. Journal of Nanomaterials (2019), 2019, 1-13.

[247] Hensleigh, R.M.; Cui, H.; Oakdale, J.S.; Ye, J.C.; Campbell, P.G.; Duoss, E.B.; Spadaccini, C.M.; Zheng, X.; Worsley, M.A. Additive manufacturing of complex micro-architected graphene aerogels, Mater. Horizons (2018), 5 (6), 1035-1041.

[248] Ning, F.; Cong, W.; Qiu, J.; Wei, J.; Wang, S. Additive manufacturing of carbon fiber reinforced thermoplastic composites using fused deposition modeling. Compos. B Eng. (2015), 80, 369-378.

[249] Ren, Y.; Zhang, Y.; Fang, H.; Ding, T.; Li, J.; Bai, S.-L. Simultaneous enhancement on thermal and mechanical properties of polypropylene composites filled with graphite platelets and graphene sheets. Compos. Appl. Sci. Manuf. (2018), 112, 57-63.

[250] Bauer, J.; Schroer, A.; Schwaiger, R.; Kraft, O. Approaching theoretical strength in glassy carbon nanolattices. Nat. Mater. (2016), 15 (4), 438-443.

[251] Desai, J.A.; Biswas, C.; Kaul, A.B. Inkjet printing of liquid exfoliated, highly conducting graphene/poly(3,4 ethylenedioxythiophene):poly(styrenesulfonate) nanosheets for organic electronics. J Vac Sci Technol B Nanotechnol Microelectron: Mater Process Meas Phenom (2017), 35, 03 D112.

[252] He, Q.; Das, S.R.; Garland, N.T.; Jing, D.; Hondred, J.A.; Cargill, A.A.; Ding, S.; Karunakaran, C.; Claussen, J.C. Enabling inkjet printed graphene for ion selective electrodes with postprint thermal annealing. ACS Appl Mater Interfaces (2017), 9, 12719-12727.

[253] Torrisi, F.; Hasan, T.; Wu, W.; Sun, Z.; Lombardo, A.; Kulmala, T.S.; Hsieh, G.-W.; Jung, S.; Bonaccorso, F.; Paul, P.J.; Chu, D.; Ferrari, C. Inkjet-printed graphene electronics. ACS Nano (2012), 6, 2992-3006.

[254] Huang, L.; Huang, Y.; Liang, J.; Wan, X.; Chen, Y. Graphene based conducting inks for direct inkjet printing of flexible conductive patterns and their applications in electric circuits and chemical sensors. Nano Res (2011), $4,675-684$.

[255] Le, L.T.; Ervin, M.H.; Qiu, H.; Fuchs, B.E.; Lee, W.Y. Graphene supercapacitor electrodes fabricated by inkjet printing and thermal reduction of graphene oxide. Electrochem Commun (2011), 13, 355-358.

[256] Nikolaou, I.; Hallil, H.; Conédéra, V.; Plano, B.; Tamarin, O.; Lachaud, J.L.; Talaga, D.; Bonhommeau, S.; Dejous, C.; Rebiere, D. Electro-mechanical properties of inkjet-printed graphene oxide nanosheets. Phys Status Solidi A (2017), 214, 1600492.

[257] Saidina, D.S.; Eawwiboonthanakit, N.; Mariatti, M.; Fontana, S.; Herold, C. Recent Development of Graphene-Based Ink and Other Conductive Material-Based Inks for Flexible Electronics. Journal of Elec Materi (2019), 48, 3428-3450. 
[258] Li, J.; Sollami Delekta, S.; Zhang, P.; Yang, S.; Lohe, M.R.; Zhuang, X.; Feng, X.; Ostling, M. Scalable fabrication and integration of graphene microsupercapacitors through full inkjet printing. ACS Nano (2017), 11, 8249-8256.

[259] Li, J.; Ye, F.; Vaziri, S.; Muhammed, M.; Lemme, M.C.; Östling, M. Efficient inkjet printing of graphene. Adv Mater (2013), 25, 3985-3992.

[260] Dubowska-Sarapuk, L.; Kielbasinski, K.; Arazna, A.; Futera, K.; Skalski, A.; Janczak, D.; Sloma, M.; Jakubowska, M. Efficient Inkjet Printing of Graphene-Based Elements: Influence of Dispersing Agent on Ink Viscosity. Nanomaterials (2018), 8 (8), 602.

[261] Pei, L.; Li, Y.-F. Rapid and efficient intense pulsed light reduction of graphene oxide inks for flexible printed electronics. RSC Adv. (2017), 7, 51711-51720.

[262] Liu, Y.; Derby, B. Experimental study of the parameters for stable drop-on-demand inkjet performance. Physics of Fluids (2019), 31, 032004.

[263] Sinar, D.M. Synthesis and Drop-on-Demand Deposition of Graphene Derivative Inks for Flexible Thin Film Electronics. Doctoral thesis, The University of Western Ontario, Ontario, Canada, 2018.08.24. https://ir.lib.uwo.ca/etd/5636

[264] Guo, J.; Asli, A.E.N.; Williams, K.R.; Lai, P.L.; Wang, X.; Montazami, R.; Hashemi, N.N. Viability of Neural Cells on 3D Printed Graphene Bioelectronics. Biosensors (2019), 9 (4), 112.

[265] Asli, A.E.N.; Guo, J.; Lai, P.L.; Montazami, R.; Hashemi, N.N. High-Yield Production of Aqueous Graphene for Electrohydrodynamic Drop-on-Demand Printing of Biocompatible Conductive Patterns. Biosensors (2020), $10(1), 6$.

[266] Delekta, S.S. Inkjet Printing of Graphene-based Microsupercapacitors for Miniaturized Energy Storage Applications. Doctoral thesis, KTH Royal Institute of Technology, School of Electrical Engineering and Computer Science (EECS), Stockholm, Sweden, 2019.09.13

[267] Martinez-Flores, R.; Canto-Aguilar, E.J.; Rodriguez-Gattorno, G.; Oskam, G.; Meneses-Rodriguez, D.; RuizGomez, M.A. Inkjet-Printed Reduced Graphene Oxide (rGO) Films For Electrocatalytic Applications. Journal of the Electrochemical Society (2019), 165 (5), 3279-3285.

[268] Bassetto, V.C.; Xiao, J.; Oveisi, E.; Amstutz, V.; Liu, B.; Girault, H.H.; Lesch, A. Rapid inkjet printing of high catalytic activity $\mathrm{CO}_{3} \mathrm{O}_{4} / \mathrm{N}-\mathrm{rGO}$ layers for oxygen reduction reaction. Applied Catalysis A: General (2018), 563, 917.

[269] Li, L.; Secor, E. B.; Chen, K.-S.; Zhu, J.; Liu, X.; Gao, T. Z.; Seo, J.-W. T.; Zhao, Y.; Hersam, M. C. HighPerformance Solid-State Supercapacitors and Microsupercapacitors Derived from Printable Graphene Inks. Adv. Energy Mater. 2016, 6, 1600909.

[270] Li, J.; Mishukova, V.; Ostling, M. All-Solid-State Micro-Supercapacitors Based on Inkjet Printed Graphene Electrodes. Appl. Phys. Lett. 2016, 109, 123901.

[271] Karim, N.; Afroj, S.; Malandarki, A. Butterworth, S.; Beach, C.; Rigout, M.; Novoselov, K.S.; Casson, A.J.; Yeates, S.G. All inkjet-printed graphene-based conductive patterns for wearable e-textile applications. J. Mater. Chem. C. (2017), 5, 11640-11648.

[272] de Leon, A.C.; Chen, Q.; Palaganas, N.B.; Palaganas, J.O.; Manapat, J.; Advincula, R.C. High performance polymer nanocomposites for additive manufacturing applications. React Funct Polym (2016), 103, 141-155.

[273] Parandoush, P.; Lin, D. A review on additive manufacturing of polymer-fiber composites. Compos. Struct. (2017), 182, 36-53.

[274] Plymill, A.; Minneci, R.; Greeley, D.; Gritton, J. Graphene and Carbon Nanotube PLA Composite Feedstock Development for Fused Deposition Modeling. Chancellor's Honors Program Projects. University of Tennessee Honors Thesis Projects (2016), 5, 1-17.

[275] Fraser, D.; Patoary, N.H.; Moore, A.L.; Weiss, L.; Radadia, A.D. Temperature-dependent electrical resistance of conductive polylactic acid filament for fused deposition modeling. The International Journal of Advanced Manufacturing Technology (2018), 99, 1215-1224. 
[276] Tambrallimath, V.; Keshavamurthy, R.; Saravanbavan, D.; Kumar, G.S.P.; Kumar, M.H. Synthesis and characterization of graphene filled PC-ABS filament for FDM applications. AIP Conference Proceedings (2019), $2057,020039$.

[277] Wei, X.; Li, D.; Jiang, W.; Gu, Z.; Wang, X.; Zhang, Z.; Sun, Z. 3D printable graphene composite. Sci. Rep. (2015), 5, 11181.

[278] Chen, Q.; Mangadlao, J.D.; Wallat, J.; De Leon, A.; Pokorski, J.K.; Advincula, R.C.; 3D printing biocompatible polyurethane/poly(lactic acid)/graphene oxide nanocomposites: anisotropic properties. ACS Appl Mater Interfaces (2017), 9, 4015-4023.

[279] Vernardou, D.; Vasilopoulos, K.C.; Kenanakis, G. 3D printed graphene-based electrodes with high electrochemical performance. Appl Phys A (2017), 123, 623

[280] Foster, C.W.; Down, M.P.; Zhang, Y.; Ji, X.; Rowley-Neale, S.J.; Smith, G.C.; Kelly, P.J.; Banks, C.E. 3D printed graphene based energy storage devices. Sci Rep (2017), 7, 42233.

[281] Zhang, D.; Chi, B.; Li, B.; Gao, Z.; Du, Y.; Guo, J.; Wei, J. Fabrication of highly conductive graphene flexible circuits by 3D printing. Synth Met (2016), 217, 79-86.

[282] Foo, C.Y.; Lim, H.N.; Mahdi, M.A.; Wahid, M.H.; Huang, N.M. Three-dimensional printed electrode and its novel applications in electronic devices. Sci. Rep. (2018), 8 (1), 7399.

[283] Huang, C.-T.; Kumar Shrestha, L.; Ariga, K.; Hsu, S.-H. A graphene-polyurethane composite hydrogel as a potential bioink for 3D bioprinting and differentiation of neural stem cells. J Mater Chem B (2017), 5, 88548864 .

[284] Sun, G.; An, J.; Chua, C.K.; Pang, H.; Zhang, J.; Chen, P. Layerby- layer printing of laminated graphenebased interdigitated microelectrodes for flexible planar micro-supercapacitors. Electrochem Commun (2015), 51, 33-36.

[285] Zhong, J.; Zhou, G.-X.; He, P.-G.; Yang, Z.-H.; Jia, D.-C. 3D printing strong and conductive geo-polymer nanocomposite structures modified by graphene oxide. Carbon (2017), 117, 421-426.

[286] Naficy, S.; Jalili, R.; Aboutalebi, S.H.; Gorkin, Iii R.A.; Konstantinov, K.; Innis, P.C.; Spinks, G.M.; Poulin, P.; Wallace, G.G. Graphene oxide dispersions: tuning rheology to enable fabrication. Mater Horiz (2014), 1, 326331.

[287] Yao, Y.; Fu, K.K.; Yan, C.; Dai, J.; Chen, Y.;Wang, Y.; Zhang, B.; Hitz, E.; Hu, L. Three-dimensional printable high-temperature and high-rate heaters. ACS Nano (2016), 10 (5), 272-5279

[288] Kim, J.H.; Chang, W.S.; Kim, D.; Yang, J.R.; Han, J.T.; Lee, G.W.; Kim, J.T.; Seol, S.K. 3D printing of reduced graphene oxide nanowires. Adv. Mater. (2015), 27 (1), 157-161.

[289] Liu, Y.; Zhang, B.; Xu, Q.; Hou, Y.; Seyedin, S.; Qin, S.; Wallace, G.G.; Beirne, S.; Razal, J.M.; Chen, J. Development of graphene oxide/polyaniline inks for high performance flexible microsupercapacitors via extrusion printing. Adv Funct Mater (2018), 28, 1706592.

[290] Jakus, A.E.; Secor, E.B.; Rutz, A.L.; Jordan, S.W.; Hersam, M.C.; Shah, R.N. Three dimensional printing of high-content graphene scaffolds for electronic and biomedical applications. ACS Nano (2015), 9 (4), 4636-4648.

[291] Roman-Manso, B.; Figueiredo, F.M.; Achiaga, B.; Barea, R.; Perez-Coll, D.; Morelos-Gomez, A.; Terrones, M.; Osendi, M.I.; Belmonte M.; Miranzo, P. Electrically functional 3D-architectured graphene-SiC composites. Carbon (2016), 100, 318-328.

[292] Tubio, C.R.; Rama, A.; Gomez, M.; del Rio, F.; Guitian, F.; Gil, A. 3D-printed graphene- $\mathrm{Al}_{2} \mathrm{O}_{3}$ composites with complex mesoscale architecture. Ceramics International (2018), 44 (5), 5760-5767.

[293] Moyano, J.J.; Gomez-Gomez, A.; Perez-Coll, D.; Belmonte, M.; Miranzo, P.; Osendi, M.I. Filament printing of graphene-based inks into self-supported 3D architectures. Carbon (2019), 151, 94-102.

[294] de la Osa, G.; Perez-Coll, D.; Miranzo, P.; Osendi, M.I.; Belmonte, M. Printing of graphene nanoplatelets into highly electrically conductive three-dimensional porous macrostructures. Chem. Mater. (2016), 28, 63216328. 
[295] Shen, C.; Calderon, J.E.; Barrios, E.; Soliman, M.; Khater, A.; Jeyaranjan, A.; Tetard, L.; Gordon, A.; Seal, S.; Zhai, L. Anisotropic electrical conductivity in polymer derived ceramics induced by graphene aerogels. J. Mater.Chem.C. (2017), 5, 11708-11716.

[296] Bernardo, E.; Fiocco, L.; Parcianello, G.; Storti, E.; Colombo, P. Advanced Ceramics from Preceramic Polymers Modified at the Nano-Scale-A Review. Materials (2014), 7 (3), 1927-1956.

[297] Pierin, G.; Grotta, C.; Colombo, P.; Mattevi, C. Direct Ink Writing of micrometric SiOC ceramic structures using a preceramic polymer. Journal of the European Ceramic Society (2016), 36 (7), 1589-1594.

[298] Manso, B.R.; Moyano, J.J.; Perez-Coll, D.; Belmonte, M.; Miranzo, P.; Osendi, M.I. Polymer-derived ceramicgraphene oxide architected composite with high electrical conductivity and enhanced thermal resistance. Journal of the European Ceramic Society (2018), 38 (5), 2265-2271.

[299] Moyano, J.J.; Mosa, J.; Aparicio, M.; Pérez-Coll, D.; Belmonte, M.; Miranzo, P.; Osendi, M.I. Strong and light cellular silicon carbonitride-Reduced graphene oxide material with enhanced electrical conductivity and capacitive response. Additive Manufacturing (2019), 30, 100849.

[300] You, X.; Yang, J.; Huang, K.; Wang, M.; Zhang, X.; Dong, S. Multifunctional silicon carbide matrix composites optimized by three-dimensional graphene scaffolds. Carbon (2019), 155, 215-222.

[301] Rossi, S.; Puglisi, A.; Benaglia, M. Additive Manufacturing Technologies: 3D Printing in Organic Synthesis. ChemCatChem (2018), 10, 1512. 